Año LII urtea

N. ${ }^{\circ}$ 94. zk.

2020

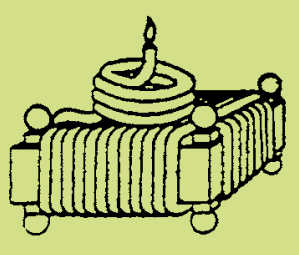

\section{CUADERNOS de Etnología y Etnografía de Navarra}

SEPARATA

\title{
Etxe izen zizelkatuak. Ageriko idazkunak etxeetan eta hilobietan
}




\section{Sumario / Aurkibidea}

\section{Cuadernos de Etnología y Etnografía de Navarra}

Año LII urtea - N. ${ }^{\circ}$ 94. zk. - 2020

\section{ARTÍCULOS/ARTIKULUAK}

Etxe izen zizelkatuak. Ageriko idazkunak etxeetan eta hilobietan

Koldo Colomo Castro

Recardera, oficio de mujer

Ricardo Gurbindo Gil

Aralar mugarriturik (1523-1857)

Jose Luis Erdozia Mauleon

El lecayo, una soka-dantza del siglo XVI

Ricardo Urrizola Hualde

El recuerdo público de una muerte política: historiografía periodística y etnografía de la ritualidad pública (José Luis Cano Pérez, 1949-1977)

Kepa Fernández de Larrinoa, Karlos Irujo Asurmendi, Santiago Martínez Magdalena, Txuri Ollo Gorriti, Cristina Saura Blanco

El Camino de Santiago en Navarra en 1971 a la luz de un informe para su mejora elaborado por la Dirección de Turismo, Bibliotecas y Cultura Popular Fernando Vega López

Reformulación del discurso significativo sociocultural en el entramado fortificado de la Línea P (Valle de Roncal-Navarra) 


\section{Sumario / Aurkibidea}

NOTICIAS/BERRIAK

Joxe Ulibarrena y su pasión por la Etnografía

Elur Ulibarrena Herce

Normas para la presentación de originales / Idazlanak aurkezteko arauak / 


\section{Etxe izen zizelkatuak Ageriko idazkunak etxeetan eta hilobietan}

Nombres de casa en piedra: escrituras expuestas en casas y tumbas

House names in stone: public writings on houses and tombs

Koldo COLOMO CASTRO

Investigador

koldocolomo@yahoo.com

DOI: https://doi.org/10.35462/CEEN94.1 


\section{LABURPENA}

Etxe izenak etxeetako aurrealdean eta hilarrietako ageriko idazkunetan ager daitezke XVI. mendetik. Lan honetan, Euskal Herriko ekialdeko 386 tradizioko etxe izen bildu ditugu. Horrez gain, idazkunen ezaugarriak, kronologia eta funtzioak aztertu ditugu.

Gako hitzak: etxe izenak; hilarria; atalburua; ageriko idazkunak.

\section{RESUMEN}

Los oicónimos pueden aparecen cincelados en las fachadas de las casas y en las lápidas desde el siglo XVI. En este trabajo hemos recogido 386 nombres de casas tradicionales del área oriental de Euskal Herria. Además, hemos analizado las características de las escrituras expuestas, su cronología y sus funciones.

Palabras clave: oicónimos; estela; dintel; escrituras expuestas.

\section{ABSTRACT}

House names can be found chiselled on the facades of houses and on tombstones as early as the 16th century. In this work, 386 traditional house names from the eastern part of the Basque Country are collected. In addition, the characteristics of the texts, the chronology, distribution and functions of the public writings are analysed.

Keywords: houses names; tombstones; lintels; public writting.

10 Cuadernos de Etnología y Etnografía de Navarra (CEEN), 94, 2020, 9-62 ISSN: 0590-1871 ISSN-e: 2530-5840 ISSN-L: 0590-1871 
1. Motibazioa. 2. Helburuak eta metodologia. 3. Etxe izenei buruZ Zer dakiGUN. 3.1. Etxe izenei buruzko ikerlanak. 3.2. Etxe izenaren definizioa. 3.3. Etxe izenen osaketa. 3.4. Nafarroa Garaiko etxe izenen mapa baterantz. 4. AGERIKO IDAZKUNEN TESTUINGURUARI BURUZKO HAINBAT ARGIBIDE. 4.1. Ageriko idazkunak. 4.2. Etxeak. 4.3. Hilobiak. 4.4 Etxearen eta hilobiaren arteko lotura. 4.5. Etxe eta hilobietako ageriko idazkunen hizkuntzak. 4.6. Etxeko jabeen izenak eta etxe izenak. 5. ETXE IZEN ZIZELKATUAK. 5.1. Zeharkako informazioa ematen duten ageriko idazkunak. 5.2. Etxe izenak. 6. ONDORIOAK 7. ETXE IZENEN ZERRENDA. 7.1. Transkripziorako jarraibideak. 7.2. Etxe izenen zerrenda testuinguruaren eta euskarri motaren arabera antolaturik. 7.3. Etxe izenen zerrenda herrialdeka antolaturik. 8. ERREFERENTZIAK.

\section{MOTIBAZIOA}

Azken urteotan etxe izenen ondasunekiko interesa areagotu egin da Euskal Herrian. Nafarroa Garaian, adibidez, zenbait ibarretan etxe izenak jaso, normalizatu eta argitaratu egin dira, herritarren, adituen eta administrazioen arteko elkarlanean. Nik neuk ere Izarbeibarko eta Mañeruibarko etxe izenak ikertzeko proiektuan parte hartzeko aukera izan nuen 2014. urtean, hain zuzen ere, etxe izenen hegoaldeko mugan bertan.

Oraingoan, baina, etxe izenen gaiari ikuspegi materialetik heldu nahi diot, ikuspegi linguistiko eta antropologiko batetik jorratzeko. Izan ere, ondasun materialaren eta ez materialaren arteko muga txanpon bereko bi aldeak baino ez dira, eta ikergai honetan biak elkarren ondoan daude. Izan ere, dobeletan, atalburuetan, karteletan, hilarri diskodunetan eta tabularretan, gurutzeetan eta jarlekuetan dauden etxe izenak aztergai izanen ditugu hurrengo lerroetan. Ikusiko dugunez, euskarri hauek dokumentazio iturri aparta eskaintzen digute etxe izenak eta garaiko mundu-ikuskera hobeki ezagutu dezagun.

Dokumentazio mota hau ikerlan gutxitan hartu da kontuan. Beharbada, Buces Cabello (2011) izan da etxeetako atalburuak modu sistematikoan landu duen bakarrenetako bat. Ikusiko dugunez, euskarri hauek ez dute presentzia orekatua eremu guztietan, eta ez dute informazio bera ematen, eta hori izan daiteke oztopo bat ikertzeko unean.

Euskarrien lege babesari dagokionez, idazkun anitz galtzeko arriskuan daude. Nafarroa Garaian hilarriak eta etxe aitzineko atalburuak babesturik daude legez, baina 
azken kasu honetan soilik heraldika aurkezten dutenak edo legez babesturik dagoen eraikin batean daudenak ${ }^{1}$. Euskal Herriko iparraldean hilarriak ere babesturik daude, baina ez, ordea, etxeetako atalburuak (Duvert, 2017, 79. or.). Horregatik, nago premiazkoa dela pieza hauek dokumentatzea, iparraldean zein hegoaldean.

Esker bereziak eman nahi dizkiot Xamarri, Mikel Belaskori eta Eneka Maiz Ulaiarri artikulu hau idazteko emandako iradokizun oparoengatik.

\section{HELBURUAK ETA METODOLOGIA}

Lan honen helburu nagusiak ondoko hauek dira:

- Ageriko idazkunak dokumentazio iturri gisa aurkeztea, interesgarritasun linguistiko eta antropologikoa erakutsiz.

- Ageriko idazkunetan agertzen diren etxe izenak jasotzeko metodologia proposamen bat egitea.

- Ageriko idazkunetako etxe izenen testuinguru geografiko, kronologiko, funtzionala, linguistiko eta kulturala aztertzea.

- Ageriko idazkunetako etxe izenen zerrenda biltzea eta eskaintzea.

Ikerlan honen esparru geografikoa Euskal Herriko ekialdea da, alegia, Nafarroa Garaia, Nafarroa Beherea, Lapurdi eta Zuberoa. Zerrendan salbuespen pare bat onartu dugu, hain zuzen ere, Ternuako hilarri bat (Ipar Amerikan), segur aski, Lapurdiko etxe bati loturik dagoena, eta Bearnoko Eskiula herriko inskripzio bat. Kronologiari dagokionez, idazkun guztiak 1512tik 1924ra doan denbora-bitartean kokatuak daude.

Etxe izen zerrendak osatzeko Catálogo monumental de Navarra (García Gainza, 1989) lana erabili dugu, nagusiki Nafarroa Garaia aztertzeko, eta La tombe basque (Colas, 1923) liburua, Iparraldeko probintzien azterketarako ezinbestekoa izan dena. Gainontzeko iturriak kontsultagarri daude bibliografia orokorrean. Horrez gain, Aezkoan (2018), Larraunen (2020) eta beste zenbait tokitan eginiko landalanak oso lagungarriak izan dira ageriko idazkunak hobeki ezagutu eta interpretatzeko.

Amaieran, etxe izenak bi zerrendatan aurkeztuta daude kontsultagai. Lehenengoa antolaturik dago toki geografikoaren eta euskarri motaren arabera, hurrenkera alfabetikoari jarraiturik. Etxe izen bakoitzarekin euskarri mota, herria, erreferentzia 
bibliografikoa eta testua erraztasunez aurki daitezke. Bigarren zerrendan, etxe izenak eskualdeka eta herrika antolaturik daude. Azkenik, transkripzioa egiteko erabili diren irizpideak ongi zehazturik daude jarraibideetan.

\section{ETXE IZENEI BURUZ ZER DAKIGUN}

Jarraian, etxe izenen garapen historiografikoa, definizioa, osaketa eta distribuzio mapak aztertuko ditugu, etxe izenen testuingurua hobeki ezagutzeko asmoz.

\subsection{Etxe izenei buruzko ikerlanak}

Etxe izenen inguruko interes zientifikoa XX. mendeko bigarren hamarkadan hasi zen. Bonifacio Etxegarai Korta (1926), euskal zuzenbideko historialaria, izan zen gai honi buruz idatzi zuen lehenatariko bat. Izan ere, Luis Eleizaldek (1923) egindako toki izenen zerrenda baliatu zuen Etxegaraik, eta oikonimoak aztertu eta gaika antolaturik aurkeztu zituen argitalpen batean. Haren iritziz, etxe izenen zabalpen geografikoaren arrazoia populazio sakabanaketan eta jaraunspen bakarreko sisteman zegoen. Urte berean, 1923an, Luis Colasek La Tombe basque argitaratua zuen. Baionako Lizeoko irakasle normandiarrak sakontasunez aztertu zituen Euskal Herriko iparralde osoko hilarriak, dekorazioak eta idatziak jasoz. Idazkunetan etxe izen anitz zeuden eta zenbaitetan izena etxearekin lotzen saiatu zen ikerlaria. Nafarroan Garaian, 1926 urtean, Aurizberriko etxe izenak aztertu zituen Jose Miguel Barandiaranek (1926), herriari buruzko lan etnografikoan.

1940ko hamarkadan, Caro Barojak (2000 [1949]) etxe izenei kapitulu bat eskaini zien Los Vascos liburuan. Bidasoa aldean egindako ikerlanen emaitzak erabili zituen etxe izenen atzizkien banaketa geografikoaz hitz egiteko. Tantaka bada ere, hurrengo hamarkadetan beste lan interesgarri batzuk argita eman ziren, besteak beste, Jose Miguel Barandiaranek Saran egindakoa eta Jose Mari Satrustegik (1965) Luzaiden.

Hirurogeiko hamarkadatik aitzina, toponimia lanetan etxe izen anitz jaso ziren (Esparza, 1964, 1965; Jimeno Jurío, 1986-1991; Leizaola, 1985; Urtasun, 1971, besteak beste), bai eta euskara, historia eta etnografia ikerlanetan ere. Azpimagarria da hamarkadan horretan Carrasco Perezek idatzitako XIV. mendeko Nafarroa osoko suen ikerketa. Horrez gain, Hernandorenak (1978) Goizuetako etxe izenak jaso zituen oso modu aitzindarian, ikuspegi diakroniko batetik jorratuak.

1996tik aitzina ikuspegi linguistiko hutsetik egin dira hainbat ikerlan, hain zuzen ere, Andres Iñigok (1996, 2000, 2005, 2008), Patxi Salaberrik (1995, 2006, 2009) eta Jean-Baptiste Orpustanek (2000) idatzitakoak. Urte horietan ere, Nafarroa Garaian arlo linguistikoa, dokumentala edota etnografikoa uztartzen dituzten lanak argitaratu ziren, besteak beste, Erroibarren eta Esteribarrean (Ibarra, 2002, 2003), Itzagaondoan eta Untzitin (Itulain, 2002, 2005, 2019), Etxalarren (Apezetxea \& Salaberri, 2009), Goizuetan (Perurena, Salaberri \& Zubiri, 2011) eta Orbaizetan (Buces, 2011). Iturri dokumental soilean oinarritzen direnak ere ez dira falta, Maiora Mendiak Orban eta 
Izarbeibarren aztertzen dituen bezalakoak (Maiora, 2013, 2014); edota helburu genealogiko batekin landurik daudenak, hain zuzen ere, Antzinako aldizkarian argitaratu diren hainbat artikulu (Aldaba, 2014; Dibon, 2011; Garciandia, 2013; Sagüés, 2012, 2013, 2015, 2016, 2017, 2018, 2019, 2020). Bestalde, Euskal Herriko Iparraldean nabarmentzekoak dira Saran eta Barkoxen egindako lanak (Dibon, 2011; Elosegi, 2005) biak bilakaera sozialean eta deituretan zentratuak. Ikuspegi berezi batetik landuta direnak ere badaude, esaterako, herri arkitekturari buruz (Xamar, 2016) eta mitoei eta elezaharrei buruz (Lopez-Mugartza, 2008). Azkenik, etxe izenak aski erroturik dauden hainbat eremutan telefono gidak argitaratu dira: Euskal Herriko iparraldean (Annuaire, 1988), Imotzen (1997), Baztanen (Doike Eskuara Taldea, 2005) eta Arantzan (Arantzako Euskara Batzordea, 2016).

Azken urteotan, Nafarroa Garaiko zenbait ibarretan etxe izenei buruzko ikerlanak metodologia transbertsal batekin garatu dira. Izan ere, hizkuntzalarien, boluntarioen eta instituzioen elkarlanaren bitartez zenbait lan gauzatu dira etxe izenak dokumentatu eta normalizatu erabilera administratiboa eta soziala bermatzeko. Orain arte lau proiektu egin dira Nafarroa Garaian, Izarben eta Mañerun (2014), Erronkarin (2018), Aezkoan (2018) eta Artzibarren (2019). Lan hauetan erabili den metodologia ezagutzeko Mikel Belaskok (2014) eta Lopez-Mugartzak (2018a, 2018b) idatzitako artikuluak irakur daitezke. Bestalde, oikonimiari buruzko ikerlanen emaitzak erabilera kartografiko ofizial batera igaro dira zenbait kasutan eta egun kontsultagai daude IDENAren atarian. Atal hau amaitu baino lehen ez dugu aipatu gabe utzi nahi udal plan orokorrak, etxe izenak ezagutzeko informazio iturri berria izaten hasi direlako. Adibidez, Ultzamakoa plan eredugarria da, etxe izenak eta etxeko fatxadetan agerian dauden idazkunak jasotzen baititu, idatziz zein argazkiz (Braga et al., 2014).

Agerikoa da, beraz, etxe izenen ikerketan ikuspegi eta metodologia anitzak erabili direla.

\subsection{Etxe izenaren definizioa}

Caro Barojak (1974, 69. or.) etxe izenaren definizioa eman zuen Berako ikerlanean «bere izena dute, urteen buruan alda daitekeena, baina arruntena hainbat mendetan zehar mantentzea dela, iraunkorra, eraiki berri den etxeari eman zitzaionetik gaur egunera arte».

Definizioaz ari garelarik Salaberrik $(2006,872$. or.) desberdintzen ditu etxe izen tradizionalak eta etxe izen berriak, azken hauek, esaterako, Artaxoan eta Uxuen tarteka agertzen dira «Hemen etxeek izena badute zenbaitetan (Casa la Martina, adibidez, Uxuen), baina ez da tradiziokoa, berria da, aurreko mendean berean bizitu den norbaitena, oraingo jendearen gurasoena edo aitona-amonena».

Etxea oinarrizko erakundea izan da euskal kulturan, eta etxekoei identitatea eman zaie izenaren bidez. Etxe izenaren baitan eraikina, etxeko lurrak, ondasuna, hobia eta auzo kontuetan bozka emateko eskubidea dago. Eraikina desagertuta ere, orubeari etxe izenarekin izendatzen jarraitzen zaio Aezkoan, etxakuntze izena erabiliz (Ibáñez, 2017). 
Etxe izenak XI-XV. mendeetan azaltzen hasten dira dokumentazioan, administrazioaren garapenari loturik. Zergak taxuz biltzeko, beharrezkoa zen etxe guztien identifikazio zehatza egitea. Zerrenda horietan gizarte maila desberdinetako etxe izenak agertzen dira: etxe nobleak, libreak edo infantzoiak eta maizterrenak (Xamar, 2016, 26. or.). Dokumentazioarekin jarraikiz, 1366ko su-en ikerketan Carrasco Pérezek (1973) herriz herriko biztanleen zerrendak argitaratu zituen, Nafarroa Garaikoak zein Beherekoak. Zerrenda hauetan, nabarmenki ikusten da Nafarroa Beherean pertsonak etxe izenarekin ezagutzen zirela, eta Nafarroa Garaian, berriz, patronimikoekin, salbuespenak salbuespen. Mikel Belaskoren iritziz, errealitate honen ondorioz baliteke etxe izena abizen-sortzailea bihurtzea Aro Modernoan, abizen mota hauek ohikoak baitira Euskal Herriko iparraldean nahiz Nafarroako iparraldeko hainbat tokitan.

Nafarroako Foruaren arabera etxea auzotartasun-harremanetan eskubide eta betebeharren subjektua da, eta pertsona juridikoa ez izan arren, etxeko jaun-anderei dagokie etxe izena iraunaraztea eta defendatzea.

\subsection{Etxe izenen osaketa}

Ustez toponimikoak izan ziren lehenengo etxe izenak, izen mota horiek zabaldurik baitaude Euskal Herriko lurralde osoan. Caro Barojak (1949, 129. or.) proposatu zuen bezala, Araba, Nafarroa Garaia eta Euskal Herriko Iparraldea oso aberatsak dira izen pertsonaletan, hots, etxeko jabeari erreferentzia egiten diotenak (patronimikoa, izena, deitura, izengoitia, lanbidea edo jentilizioa). Euskal Herriko mendebaldea, ordea, aberatsa da izen deskriptiboetan, alegia, etxearen nolakotasunari edo kokapenari erreferentzia egiten diotenak (Barandiaran \& Manterola, 2011, 159. or.). Nolakotasunarekin jarraikiz, Xamarrek azpimarratzen du, berezitasun gisa, Bizkaiko herri batzuetan etxe izenaren aurretik auzoaren izena paratzen dela (Xamar, 2016, 32. or.). Tokia zehaztu eta herriko etxe izen berdinak bereizteko baliabide eraginkorra izan da.

Etxe izenen atzizkiari dagokionez, -ena zabalduena da. Atzizki honetatik, gainera, zenbait aldaera sortu dira, -ena, -enea, -enia eta -enekoa. Geografikoki ere, oso zabaldurik dago - $k o$ atzizkia, eta beste atzizki bat duten etxe izenekin maiz agertzen da. Beste atzizki bat da -baita, XVII. mendetik aitzina Euskal Herriko iparraldean eta Bidasoan erabilia. Laugarren atzizkia da -egi, -tegi, -degi eta, oro har, izenarekin, abizenarekin, izengoitiarekin eta lanbidearekin lotzen da. Azkenik, atzizkirik gabe erabil daitezke etxe izenak; horixe da ohikoena Nafarroa Garaiko Zaraitzu eta Erronkariko ibarreetan, Bidankoz salbuespen bakarra izanik (Belasko, 2014, 12. or.).

\subsection{Nafarroa Garaiko etxe izenen mapa baterantz}

Argi da, beraz, Nafarroa Garaia osoan etxe izenek ez dutela indar eta iraunkortasun bera izan. Indarrari dagokionez, Kantauri aldean (Bizkaia, Gipuzkoa eta Iparralde) etxeak abizena sortu du. Nafarroa Garaiko iparraldean gauza bera gertatu da, hain zuzen ere, Larraun, Basaburua, Ultzama, Aezkoa eta Zaraitzu ibarretan eta, ohikoa 
ez bada ere, Sakanan, Iruñerrian eta ekialdeko ibarretan (Belasko, 2017). Nafarroa Garaiko gainontzeko eremuetan etxearen izena osatu da jabearen izena, deitura, izengoitia edo lanbidearen bidez.

Bonifacio Etxegarai abokatuak (1926), etxe izenen zabalpenaren muga aztertu zuenenean, argiki ikusi zuen oikonimoak ez zeudela soilik euskal eremuan eta, herentzia sistema kontuan harturik, muga-lerroa zehaztu zuen Euskal Herriko maparen gainean, Cadagua ibatik ekialderantz. Berriki Patxi Salaberrik (2006), Andrés Iñigok eta Patxi Rekaldek (2018) Nafarroa Garaiko etxe izenen muga zehaztu dute hainbat eremutan. Muga honen arabera, Ameskoa, Goñerri, Etxauribar, Galar, Zizurko zendeak, Mañeruibar, Izarbeibar, Orbaibar, Ibargoiti, Urraulbeiti eta Urralgoiti ibarrak, Zaraitzu eta Erronkaribar etxe izen tradizionaleko eremuan sartzen dira.

Muga hori zehazten jarraitzeko ohar batzuk eman nahi ditugu lerro hauetan. Deierriko etxe apeoetan ${ }^{2}$ ez dira etxe izenak aurkitzen. Hala ere, zenbait herritako agiri$\tan$ (Eraul, Hiriberri eta Aritzala) -rena forma agertzen da oikonimo batzuetan. Haien iraupenaz, berriz, ez dakigu deus, baina lagungarria izan liteke, dokumentazioarekin behin alderatuz gero, Deierriko udalek jasoak dituzten etxe izenen zerrendak kontsultatzea. Gesalazen antzeko egoera bat ematen da. Apeoetan ${ }^{3}$ etxe izenak azaldu ez arren; Isidoro Ursuak (2001) 300 baino gehiago jaso ditu hainbat agiritatik, guztiak 1641etik 1830 artekoak.

Ekialderaxeago jotzen badugu, Mañeruibarko iparraldeko herrietan iraupen luzeko etxe izen batzuk agertu dira. Etxarrenen, Girgilaon eta Argiñarizen (XX. mendean hustue eta birpopulatu zena) -rena etxe izen atzizkidunak aurkitzen ditugu, eta XX. mendera arteko iraupena \% 41,6 (1725etik), \% 26,9 (1816tik) eta \% 25,8 (1824tik) $\mathrm{da}$, hurrenez hurren (Belasko \& Colomo, 2014). Artazun, etxe izenak badaude ere, iraupen luzeko kasu bakar bat baino ez dugu aurkitu (Burruña). Izarbeibarren, berriz, etxe izenak ohikoak dira eta 1850 urtetik hona etxe izenen \% 45 inguruk iraun du (Belasko, 2017, prentsan), Obanos barne (Pérez de Laborda). Alta, mugatik kanpo utzi dugu Gares herria, bertan iraupen luzeko etxe izenak agertzen ez direlako. Izan ere, aurretik aldagai anitz ditu ez izateko: herri harresitua da, etxeak elkar-gainka eraikita daude -Ziraukin bezala-, gune komertziala da eta 1789 urtetik ubidea du (Colomo, 2014, 2020a). Bi ibarretako errealitatea laburbilduz, Mañeru eta Izarbe ibarretan etxe izenen presentzia nabarmenagoa izan da ipar-ekialdean mendebaldean baino (Belasko, 2014, 20. or.).

Nafarroako ekialdera jauzi eginez, Nabazkozera goaz. Asinek (1995) Nabaskozeko etxe izenak jaso zituen, guztiak atzizkigabekoak, eta gure kalkuluen arabera XVIII. mendetik etxe izenen iraupena \% 38 da. Erromantzatuan, ordea, ez dirudi izan direnik eta, hala ere, Biotzarin etxe izen zizelkatu bat aurkitu dugu Cruchaga y Purroyren lanean

2 Deierri: 1678ko apeoa, RE _ ESTADISTICA, leg. 14, n. ${ }^{\circ}$ 33; 1726ko apeoa, RE _ ESTADISTICA, leg. 15, n. 30.

3 Gesalatz: 1668ko apeoa, RE _ ESTADISTICA, leg. 14, n. ${ }^{\circ}$ 24; 1726ko apeoa, RE _ ESTADISTICA, leg. 15, n. 22. 
(1970, 224. or.). Ikerlari honek XX. mendean jasotako Biotzariko etxe izen zerrenda eta apeoak ${ }^{4}$ kontsultatu ondoren, esan daiteke etxe izenen iraupena \% 23 dela. Badakigu muga lerroak ekialderago jarraitzen duela, Jazetaniako Ansó eta Sigüés herriak barnean hartuz (Lopez-Mugartza, 2012; Belasko, 2016). Hortaz, formari eta iraupenari dagokionez, Nabazkozeko eta Jazetaniako etxe izenek Erronkarikoen antza dutela esan daiteke.

Ondorio gisa, etxe izenen hegoaldeko muga oraindik lausoa da eta zenbait eremutan ikertu gabea. Alta, argi dago ez datorrela bat jaraunsle bakarreko eremuarekin (ikus mapa, Caro Baroja, 1972, II*** 142. or.), akaso jabetasun motak eta etxearen jabetasun kudeaketak (bezino, etxemaizterra) eragin haundiagoa izan dutelako. Horrez gain, agerikoa da etxe izenen muga ez datorrela bat euskarak Nafarroa Garaian historikoki izan duen zabalpenarekin. Hala ere, aitortu behar da mugak antza duela 1778 urtean euskarak zuen zabalpenarekin (Irigarai, 1974), are gehiago, Zirauki, Artaxoa edo Lerga herri gotortuak izateagatik baztertzen baditugu (Salaberri, 871-872. or.). Euskarak etxe izenen erabileran eta iraupenean izan duen eraginaz ikertu dago oraindik.

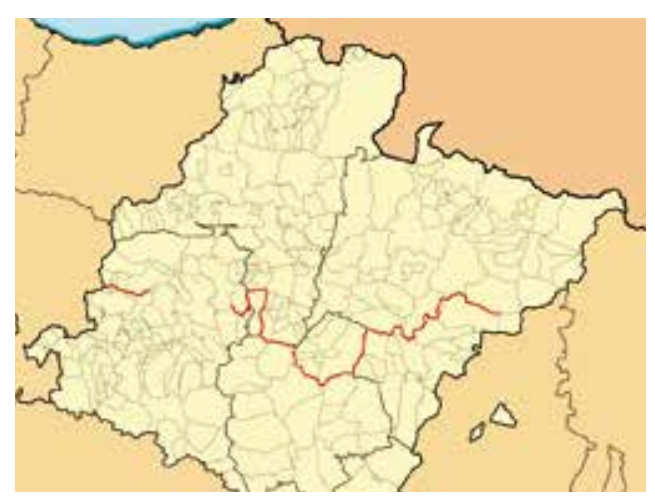

1. irudia. Etxe izenen muga Nafarroa Garaian. Salaberri (2006), Iñigo \& Rekalde (2018), Colomo (2020).

\section{AGERIKO IDAZKUNEN TESTUINGURUARI BURUZKO HAINBAT ARGIBIDE}

Datozen lerroetan hainbat kontzeptu argitu nahi ditugu, etxe izenen testuingurua, euskarriak eta erabilitako formula epigrafikoak hobeki uler daitezen.

\subsection{Ageriko idazkunak}

Esposto popolare edo ageriko idazkuna ${ }^{5}$ terminoa Armando Petrucci italiarrak sortu zuen hirurogeita hamarreko hamarkadan. Petruccik (2013a, 2013b) eta Quinto Antonellik (2006) espazio publikoan agertzen diren idazkiak eta irudiak aztertu dituzte jendartearen analisi sozial eta kulturala egiteko. Petruccik, gehienbat, boteregunetik zabaltzen diren ageriko idazkunak ikertu ditu eta Antonellik, berriz, mendeko klasekoen artekoan, anitzetan idazkun jasoen antzera egiten direnak. Castellotek eta Fernández Lópezek (2017, 128. or.) ageriko idazkunen ezaugarri nabarmenak azpimarratu dituzte

4 Erromantzatua: $1677 \mathrm{ko}$ apeoa, RE _ ESTADISTICA, leg. 23, n. ${ }^{\circ} 22 ; 1727 \mathrm{ko}$ apeoa, RE _ ESTADISTICA, leg. 24, n. ${ }^{\circ} 29$.

5 Jatorrizko terminoa italieraz datorkigu «exposto popolare» edo «scrittura popolare». Frantsesez «écriture exposées» erabiltzen da, ingelesez «public writting» eta gaztelaniaz «escrituras expuestas». Euskaraz ez dugu mailegu bat topatu eta «ageriko idazkunak» terminoa proposatzen dugu artikulu honetan. 
«hainbat dira idazketa horiek definitzen dituzten irizpideak, baina garrantzitsuenak hiru izango lirateke: irakurgarritasuna, ikusgarritasuna eta publizitatea». Oro har, ageriko idazkunak XVI. mendetik aitzina eremu publikoan arrunt bilakatzen dira. Haien testuingurua etxekoa, lanekoa, auzokoa edo erlijiozkoa izan daiteke eta idazkera batbatekoa edo planifikatua. Ageriko idazkunen bidez jabeak aditzera ematen du jabetza, memoria, sinesmena edota estatus soziala, besteak beste. Idazkun hauei esker beste garai bateko bizimoduaren eta pentsamenduen berri ezagutzen ahal dugu.

\subsection{Etxeak}

Erdi Arotik arrunta da ateko dobela nagusian leinuaren armarria paratzea, Nafarroa Garaiko jauregi gotiko anitzetan gertatzen den moduan. Ohitura horrek hurrengo mendeetan jarraipena izanen du, baina modu orokortuan, alegia, jendartearen maila sozial gehiagorengana helduz. Horregatik, XVI. mendean dobeletan eta XVII. mendetik aitzina etxeko aurrealdeetan, sarritan aurkitzen ditugu irudi heraldikoak, sasi heraldikoak eta idazkunak.

Euskal Herriko iparraldean atalburuen sormen ahalmenak gailurra jo zuen XVII. eta XVIII. mendeetan, berariazko dekorazio estiloa garatua. Euskarri hauek aski zabaldurik daude, eta gehienetan etxearen eraikitze data eta jabeen izen-abizenak erlijioirudigintzarekin eta apaingarri geometrikoekin nahasten dira. Azken finean, ageriko idazkunak, etxeko aitzinaldean jarrita, baliagarriak dira familiaren prestigio soziala eta etxearen maila ekonomikoa lau haizeetara zabaltzeko.

\subsection{Hilobiak}

Hilarrien tipologia anitza da eta garai, lurralde eta estatus sozialaren arabera erabili da mota bat edo bestea. Erdi Aroan ehorzketak hilerrian egiten ziren. XIII. mendetik aitzina Elizako goi-kargudun eta nobleak ehorzten ziren tenpluaren barruan, hil kaperetan eraikiz edota aldarearen inguruan, eremu sakratutik gertu egoteko eta, aldi berean, maila soziala agerian uzteko. Nafarroa Garaiko Erdi Aroko hilerrien artean forma diskoduna da euskarririk erabiliena, batez ere, XII. eta XV. mendeen bitartean. Harrigarria bada ere, Erdi Aroan zehar Euskal Herriko iparraldean ez dira diskodunak aurkitu, eta ezagutzen ditugun guztiak Aro Modernokoak dira. Erdi Aroko diskodunetako dekorazioari dagokionez, orokorrean gurutzeak eta geometriak ikus daitezke, eta, noizbehinka, hildakoak zuen ogibidea edo bere leinuarekin loturiko beste irudi heraldiko edo sasi heraldikoren bat ere aurki daiteke. Epigrafia eskasa da oso eta dagoenean, prestigio handiko hildakoekin lotzen $\mathrm{da}^{6}$.

6 Irantzuko monasterioan Erdi Aroko bi diskodun epigrafiatuak aurkitzen ditugu, haietako bat monasterioko priorearekin loturik. Horrez gain, gotiko berantiarrean sar daitezke, nire ustez, zenbait diskodun epigrafiatuak: Lizoaingoa eta Aietxukoa. Ziurrenik, berantiarra ere bada Nafarroako museoan dagoen beste pieza epigrafiatu bat. Horrez gain, atal honetan ez ditugu sartu hizkiak dituzten anagramak, hain zuzen ere krismoia eta XV. eta XVI. mendeko IHSak. Dena dela, azken kasu hauetan ez dago lotzerik prestigio duten pertsonekin, nonbait. 
XVI. mendetik aitzina Nafarroa Garaiko ehorzketa gehienak tenplu barruan egin ziren. Salbuespenak gutxi dira eta, oro har, Nafarroa Garaiko iparraldeko herri txikietan aurki daitezke, indarrean jarraitzen duten kanpoko hilerrietan. Eliz barneko ehorzketak nabearen lur azpian egiten ziren, sepulturen nahiz jarlekuen bitartez. Jarlekuen hurrenkera estatus sozialaren arabera antolatzen zen; etxe garrantzitsuenak ebanjelioaren aldean edo aldaretik gertu hobiratuta zeuden. Jarleku hauek harrizkoak nahiz egurrezkoak ziren eta euren azaletan, epigrafia, hildakoaren armarria, hildakoaren ogibidea eta, beranduago, zenbaki soil bat zizelkatzen zen. Euskal Herriko iparraldean, baina, eliz kanpoko hilerri guztiek indarrean jarraitu zuten, soilik apaizak eta seroraren bat ehortzita daude tenpluaren barruan. Nobleak ere eliz atarian hilobiratzen ziren euren sepulturetan eta gainontzekoak eliz inguruko hilerrira zihoazen. Euskal Herriko Iparraldeko hilerrietan, XVIII. mende hasiera arte diskodunak izan dira erabilienak (Lapurdiko hegoaldeko tabularren salbuespenare$\mathrm{kin}^{7}$ ) eta handik aitzina gurutzeak eta tabularrak nagusitu ziren (Lauburu, 2004, 22. or.).

Azkenean, bertzelako funtzionalitatea duen beste hilarri mota bat aipatu behar da, hilerritik kanpo kokatzen dena: oroitzapenezko hilarria edo bideko hilarria da. Forma anitzetakoa izan daiteke -diskoduna, tabularra edo gurutzea-, berrerabilia kasu batzuetan, eta, XVII. mendetik aitzina, Pirinioetako bi aldeetan agertzen da, bereziki hegoaldean. Bat-bateko heriotza bat gertatu den tokian paratzen da, beti bide ondoan, gertaera tamalgarria (istripua, hilketa edo heriotza naturala) gogorarazteko eta arimaren aldeko otoitza eskatzeko.

\subsection{Etxearen eta hilobiaren arteko lotura}

Etxea eta hilobia harremanetan daude. Etxean, XX. mendera arte, bataiatu gabe zeuden jaioberri hilak etxeko teilatuaren hegalpean lurperatzeko ohitura mantendu da, gorpua bi teilaren artean babesturik. Gainera, etxeko baratzea hildakoarekiko gurtzarekin lotu egin da tradizionalki. Etxe bakoitzak bere jarlekua zuen elizan, eta bertan ehorzten ziren etxeko guztiak. Etxea eta hilobia enborreko ondasunak dira Bizkaiko Foruan, eta elkarrekin saltzen ziren, hainbatetan. Etxearen eta hilobiaren artean bide fisiko bat dago, hilbidea edo elizbidea izenekoa, eta auzokoek pasabidea errespetatu beharra dute, hilotzen segizioarentzat bidea libre utziz (Lauburu, 2004, 20. or.). Etxe batera emakume jabe berria ezkontzen zelarik, emakume jabe zaharrarekin etxeko jarlekura joaten zen etxearen jabetza hartu, arbasoekin elkartu eta familian sartzeko (Barandiaran, 1980, 596. or.).

Landa eremuko herrietan, oro har, etxea eta hilobia loturik mantendu dira mendeetan zehar. Horregatik, landa eremuetan eliz barneko hilobien distribuzioa herriko etxeek auzoan dutenarekin bat dator. Hala ere, ez zen gauza bera gertatzen aldaketa

7 Hilarri tabularren kasu berezia aipatu behar da. Jatorriz arrotza, Lapurdiko hegoaldean zabaldu zen XVII. mendean maila altuko familien artean. Dekorazio motiboak euskal tradiziotik jasota daude, eta anitzetan zizelkatzen dira, baina, gehienetan, alde batetik soilik (Duvert, 2006). 
sozioekonomiko nabarmenak zituzten herrietan. Bertan, jarlekuen salerosketak arruntak ziren eta aberastutako etxeetakoek, aukera zegoelarik, aldaretik ahalik eta jarleku hurbilenak erosten saiatzen ziren (Madariaga, 2004, 445. or.). Ehorzteko modu honek XIX. mendera arte iraun zuen, kanpoko hilerriak eraiki arte. Orduz geroztik, eta Vaticanoko II. Kontzilioa izan arte, etxeko emakumeek jarlekua modu sinbolikoan erabiltzen jarraitu dute, otoitza eta eskaintzak egiteko, alegia.

\subsection{Etxe eta hilobietako ageriko idazkunen hizkuntzak}

Etxe izenen eremu osoan euskara izan da ahozko hizkuntza nagusia XIX. mendera arte. Hala ere, Euskal Herriko iparraldean ageriko idazkunak zenbait hizkuntzatan idatzita daude -euskara, gaztelania, okzitaniera, frantsesa eta latina-, XVIII. mendetik aitzina frantsesa nagusia izanik (Moutché, 2010, 152. or.). Nafarroa Garaian, aldiz, gaztelaniaz daude idazkun guztiak, salbuespen bakan batzuk kenduta ${ }^{8}$.

Euskal Herriko iparraldean ematen den hizkuntza aniztasunak azalpen historiko bat dauka. XVI. mendean, Nafarroa Behereko administrazioko notarioei eta erregeofizialei euskara jakiteko derrigortasuna ezarri zitzaien (Monteano, 2017, 145. or.). Era berean, protestantismoaren testuinguruan, Albreteko Joana erreginak liturgian euskararen eta okzitanieraren erabilera bultzatu zuen (Adot, 2014, 29. or.) eta eliz literaturari esker euskara idatziaren estandarizazioa gizarteratu zen, Lapurtera oinarritzat harturik. Izan ere, Lapurdi, itsas aldeko eskualdea izanik, bizimoduz eta biztanlez aurreratuta zegoen (Zuazo, 2005, 39. or.). Hortaz, euskarak prestigioa eta estandarizazio maila erdietsi zuen Euskal Herriko iparraldean, eta sozialki pribilegiatua izan zen XVII. mendearen bigarren erdialdera arte. Nafarroa Garaian, ordea, nafar erromantzearen erabilera goiz zabaldu zen administrazioan, eta botereak bultzaturiko mendekotasunak ageriko idazkunen hizkuntzan eragin zuzena izan zuen.

\subsection{Etxeko jabeen izenak eta etxe izenak}

Trentoko kontzilioak hainbat erabaki hartu zituen bataiatuen identifikazioaren inguruan, eta ondorioz abizenak ofizialtasun prozesu batean sartu ziren XVII. mendetik aitzina. Ordura arte abizenen erabilera oso malgua zen, bederen, jendarteko maila altukoak ez zirenen artean. Izendatzeko modua alda zitekeen solaskidearen arabera, modu ezberdinak erabiliz pertsona bera deitzeko. Kontuan hartu behar da orduko izenen errepertorioa hertsia eta mugatua zela eta pertsonak ongi identifikatzeko beste baliabide batzuk erabili behar zirela (hipokoristikoak, izengoitiak...). Nafarroa

8 Nafarroa Garaian euskaraz idatzita dauden ageriko idazkunak salbuespenezkoak dira. Iturmendin XVIII. mendeko armarri bat eta Kalbarioko zenbait gurutze epigrafiatuak baino ez dago (Arbizu, 1996), Gipuzkoa aldetik etorritako harginen lana? eta Luzaiden XIX mendeko hiru hilarri ditugu (Frankowski, 1920, 125. or.). Azken kasu hau ulergarriagoa da. Izan ere, Luzaide Nafarroa Beherean kokaturik zegoen geografiko eta kulturalki eta Iparraldeko ageriko idazkunetan euskararen presentzia \% 17koa da, XVIII. mendean (Moutche, 2010, 152. or.). 
Garaiko ipar erdialdean, lurretik hartzen zen baliabide hori, alegia, egungo nafar abizenen artean etxe izenak eta herri izenak dira nafar deitura arruntenak (Zabalza, 2010).

Aro Modernoan, Nafarroa Beherean eta Nafarroa Garaiko ipar erdialdean, gizonak, beste etxe batera ezkontzen zenean, etxe berriaren izena hartzen zuen. Egoera honetaz kexu agertzen zen Pierre de Lancre 1609, urtean (Lancre, 2004). Magistratu ospetsuaren hitzetan, euskaldunek «normalean baztertzen dituzte beren izena eta beren familien deiturak, are emazteek beren senarren deiturak ere, bere etxeetako izena hartzeko». Horrez gain, haren ustez, «aldakortasun eta arinkeria hori deabruaren izaerarekin bat zetozela». Euskaldunen beste ohitura bat ere gaitzetsi zuen Lancrek, estamentudun jendartearen ikuspegitik, hain zuzen ere, edozein etxetako jabeek jaun eta andre formulak erabiltzea «gizon eta emakume herritar pobreenek ere halako etxetako jaun eta andreak deitzeko eskatzen dute, bakoitzak bere herrian duten etxeak direlarik, zerritoki bat baizik ez delarik» (Xamar, 2016, 55. or.).

\section{ETXE IZEN ZIZELKATUAK}

Bi motatako informazio aurki ditzakegu ageriko idazkunetan. Lehenengoa etxe izenaren inguruko informazio zuzena ematen duena da eta bigarrena, berriz, zeharkako informazioa. Azken hau ere oikonimia lanetarako biziki interesgarria da.

\subsection{Zeharkako informazioa ematen duten ageriko idazkunak}

Ageriko idazkunetan etxeko jabearen edo jabeen izen-abizena agertzen da, maiz. Batzuetan, abizena bat dator etxe izenarekin, bai etxeak jabeari eman diolako, bai jabeak etxeari, eta horri esker etxe izenaren jatorriari buruzko informazioa eskura dezakegu.

Aezkoan, 2017an, etxeetako idazkun guztiak jaso nituen landa-lan batean. Idatzirik zeudenen artean, XVII eta XIX. mendeetako 28 kasutan jabe baten abizen bat etxe izenarekin bat dator (Colomo, 2020b, 106. or.). Adibide gisa dugu, besteak beste, Portalena (Hiriberri) «ESTA PRESENTE / PYEDRA Y PORTAL / HYZO HACER / IOANES PORTAL / ECO ABBA 18 DE / IVNYO DEL AÑO 1652», Xintorena (Hiriberri) «JOAnES GINTO / HIZO AZER / AñO 1658 IESUS NARIA / JOSEF IOCH / x Y ANA», Gartziarena (Orbaizeta) «JOANES GARCYA 1659./.r. /Brc», Erlandrerena (Abaurregaina) «MIGUEL / DE ERLANDE / HIZO LA CASA / EL AÑO 1756 FRANZISC / DEREMO/NDEGII / ERLANDE/ 1756», Botoarena (Aribe) «IZO HAER / JU/A/N/ MAR/T/IN / D/E/LI/Z/O/N/D/O y BOTOA». Dobelan, berriz, «AÑO de / 1797» edo Konderena (Orbaizeta) «REDIFI/CO ES/TA CASA / GREGO/RIO ECH/ EVERRIA / MARIA / CONDE / ANO / 1807».

Aezkoako etxe izenak iraupen luzekoak dira orokorki, eta multzo bat Erdi Arotik datorkigu (Hainbat, 2018b). Horrez gain, ibar horretako etxeek abizena sortzen dute, Zaraitzun, Euskal Herriko iparraldean eta Nafarroa atlantikoan gertatzen den gisa. Ondoko kasuetan hala gertatu dela dirudi. 
1. taula

\begin{tabular}{|l|c|c|}
\hline \multicolumn{1}{|c|}{ Etxe izena eta herria Aezkoa } & Atalburuaren datazioa & Etxe izena dokumentatua \\
\hline Arretsekoa (Hiriberri) & 1860 & $1366,1786,1852$ \\
\hline Ertegikoa (Aria) & XVIII & 1366,1733 \\
\hline Gartziarena (Orbaizeta) & 1659 & 1366,1680 \\
\hline Iturburukoa (Abaurregaina) & 1796 & 1366 \\
\hline Larrañetakoa (Orbaizeta) & 1745 & 1427,1662 \\
\hline
\end{tabular}

Bucesek (2011) Orbaizetako (Aezkoa, Nafarroa Garaia) atalburuetako idatziak jaso zituen bere ikerlanean, eta dokumentazio idatzian gehitu zituen etxe izenaren eta etxearen historiaren informazioa.

Ildo beretik jarraikiz, Aezkoako hilarri zaharretan zenbait jaberen izen-abizenak agertzen dira idatzirik, hain zuzen ere, Garaioako eta Aribeko pieza banatan. Garaioan «EST/A SE/PVLTV/RA ES / IOANES AI/NCI(O)A I MARIA / (MAR)TIN SV MVGER» eta Ariben «IOAN FR/CO (?) IACUE» (Colomo, 2020, 103. or.; Ibáñez, 2020, 161, 175. or.). Bi abizenak etxe izenak dira: Garaioan, Aincioa (Hainbat, 2018b, 137. or.), 1796 urtean, eta Ariben, Xakuerena, 1726 urtean (Hainbat, 2018b, 103. or.).

Aurrerago ikusiko dugun bezala, Aezkoako atalburuetan etxe izen zuzenak ere idatzirik daude zenbait atalburu eta hilarritan. Atalburuen artean ditugu Mariato (Hiriberri), Alcaizarena (Hiriberri), Elizalde (Abaurregaina), eta agian, Iturburu (Abaurregaina). Azken horretan izena laburturik egon liteke «CAYTrU» (casa Yturburu?), baina, argia ez denez, etxe izenen zerrendan ez sartzea erabaki dugu.

\subsection{Etxe izenak}

Atal honetan, oro har, etxeetako fatxadetatik eta hilarrietatik jaso ditugun etxe izenak aurkeztuko ditugu. Etxe izenak zuzenean adierazita daude atalburu edo hilarrian. Beste euskarri tradizional batzuetan ere etxe izenen bilaketa egin dugu, baina ez dugu inolako idazkunik topatu. Dirudienez, dokumentazioaz aparte, etxe izenak etxean eta hobian baino ez ziren idazten.

Gaur egun arte heldu zaizkigun adibideekin ez da erraza esatea zenbateko maiztasunarekin agertzen ziren etxe izenak. Hala ere, Luis Colasek (1923) Iparralderako eman zituen datuen arabera, etxeetako eta hilarrietako ageriko idazkunak, denak batera zenbaturik, \% 15 ingurukoa da.

Gure kalkuluen arabera, herri bakoitzean hiruzpalau idazkun kontserbatu dira, batez beste. Salbuespenak ere badaude, Lapurdiko Sara eta Senperen hamalauna idazkun jaso ditugu, hilarrietan batez ere, eta Nafarroa Garaian, Arizkunen (11), Beran (10), Etxalarren (45) eta Zigan (42) etxe izen multzo handienak ditugu, berriz ere hilarrietan daude gehienak. Zigako kasua berezia da eta herriko etxe izen guztiak atalburu bakarbatean idatzita daude. Dena dela, pentsa daiteke izen anitz galdu direla, hilerrian, elizako zoluan 
edota etxeko fatxadetan margoturik edo zizelkaturik zeudenak. Duvert ere iritzi berekoa da Iparraldeko etxeen kasuan anitz galdu baitira, berak ikusia ere (Duvert, 2017, 79. or.).

Ondoko taulan daude lan honetan jaso ditugun inskripzio guztiak, euskarriaren eta herrialdearen arabera antolaturik eta haien ehunekoak emanez:

2. taula. Lan honetan bildutako idazkun kopuruak eta ehunekoak euskarriaren eta herrialdearen arabera antolatuak

\begin{tabular}{|l|r|r|r|r|r|r|r|}
\hline Inskripzioak & Lapurdi & $\begin{array}{c}\text { Nafarroa } \\
\text { Beherea }\end{array}$ & $\begin{array}{c}\text { Nafarroa } \\
\text { Garaia }\end{array}$ & Zuberoa & Ternua & Guztiz & $\%$ \\
\hline Dobela & 0 & 0 & 10 & 0 & 0 & 10 & 2,59 \\
\hline Atalburua & 7 & 14 & 60 & 1 & 0 & 82 & 21,24 \\
\hline Kartela & 5 & 15 & 21 & 0 & 0 & 41 & 10,62 \\
\hline Leihoburua & 0 & 0 & 2 & 0 & 0 & 2 & 0,52 \\
\hline Armarria & 0 & 1 & 2 & 0 & 0 & 3 & 0,78 \\
\hline & 12 & 30 & 95 & 1 & 0 & 138 & 35,75 \\
\hline Jarlekua & 47 & 5 & 20 & 2 & 0 & 74 & 19,17 \\
\hline Diskoduna & 16 & 51 & 51 & 13 & 0 & 131 & 33,94 \\
\hline Gurutzea & 1 & 12 & 2 & 1 & 0 & 16 & 4,15 \\
\hline Tabularra & 19 & 0 & 0 & 0 & 1 & 20 & 5,18 \\
\hline Tabularra 2 & 0 & 0 & 6 & 0 & 0 & 6 & 1,55 \\
\hline Mausoleoa & 0 & 0 & 1 & 0 & 0 & 1 & 0,26 \\
\hline & 83 & 68 & 80 & 16 & 1 & 248 & 64,25 \\
\hline Osotara & 95 & 98 & 175 & 17 & 1 & 386 & 100 \\
\hline \% & 24,61 & 25,39 & 45,34 & 4,40 & 0,26 & & \\
\hline
\end{tabular}

Etxe izenen zerrenda amaierako atalean aurkezten da. Jarraian, ageriko idazkunen azterketa formalari ekinen diot, idazkunen ezaugarriak hobeki ulertzeko.

\subsubsection{Etxe izen kopuruak}

Euskal Herriko ekialdeko 386 etxe izen zizelkatuak jaso ditugu; horietatik \% 64,2 hilarrietan daude, batez ere, diskodunetan eta jarlekuetan. Etxeetako fatxadetan \% 35,7 aurkitzen dugu, bereziki atalburuetan eta karteletan. Eskualdeka banaturik, jasotako etxe izenen \% 45,3 Nafarroa Garaian daude, berrogeita bost herritan banaturik; Nafarroa Beherean, \% 25,4, berrogeita hamar herritan; Lapurdin, \% 24,6, hogeita bat herritan banaturik eta Zuberoan, berriz, \% 4,4, hamar herritan. Euskal Herritik kanpo, Eskiulan dugu idazkun bat (Zuberoako datuetan sartuta) eta, itsasoz gaindi, etxe izen bat topatu dugu Ternuan (Ipar Amerikan), ziurrenik, Lapurdiko etxeren bati loturik.

\subsubsection{Euskarriak}

Ageriko idazkunen euskarriak harrizkoak dira gehienbat, baina zenbaitetan egurrezkoak ere badaude, besteak beste, Berako Yrazoquiberria (1731) etxeko habe batean zizelkaturik dagoena. Etxeko fatxadetan atalburuak eta kartelak dira euskarri arruntenak, espazio 
aldetik egokiak baitira idazkunak paratzeko. Aldiz, arraroagoa da etxe izenak leihoburu, armarri edota dobeletan aurkitzea; azken hauek soilik Nafarroa Garaian aurkitu ditugu. Hilarrietan etxe izenak euskarri mota guztietan zizelkatzen dira, baina espazio aldetik jarlekuak eta hilarri tabularrak egokienak dira idazkunetarako.

Etxe izen guztiak etxeko fatxadetan eta hilarrietan topatzen ditugu. Salbuespenak dira Senpereko errekaren presa batean dagoen Camiet etxearen kartela «HAV DAPRESA-EGINA-MAR:/TIN DE-HIRIART-HELBARV:/N-CAMIET-BALDERNA APEZCEN-VRTHEAN-1705», eta Eltzaburuko eskoletan dagoen XX. mendeko plaka oroigarria «EN MEMORIA DE JOSE YABEN (DE LA CASA DE MICHELCORENA) / Y D MARTIN ERVITI (DE LA CASA MARTIÑENA) / BENEMÉRITOS HIJOS DE ELZABURU A CUYAS EXPENSAS SE SOSTUVO LA ESCUELA PÚBLICA / DE EL AÑO 1795 HASTA EL AÑo 1924». Amaitzeko, baina ildo beretik jarraikiz, Burlatako Hilarión Eslavaren mausoleoan nafar Diputazioak idatzi zuen oroigarria aipatzea merezi du «LA EXC(elentísi)MA-/DIPUTACION-/ DE- NAVARRA / AL INSIGNE MAES-/TRO-COMPOSITOR-Y- MUSICÓLOGO-D-/ MIGVEL / HILARION / ESLAVA / ELIZONDO / HIJO-ESCLARECIDO- DE-ESTE-LVGAR- DE-/ BURLADA/ A Casa Benitorena 21 octubre 1807/ W Madrid 23 Julio 1878». Kasu hauetan pertsonaiaren izen abizenekin batera etxearen izena paratu da, nolabait ere, tradizioari jarraitu eta herrian identifikazioa errazteko.

\subsubsection{Ageriko idazkunen informazioa}

Ageriko idazkunak garaian garaiko mundu-ikuskeraren adierazleak dira. Eraikinetan agertzen diren ageriko idazkunen informazio nagusia jabeen identitateari loturik dago: leinuaren armarria, abizena, etxearen izena, eraikitze data, ogibidea eta fedea. Anitzean, gurutzeak eta erlijio irudiak agertzen dira epigrafiaren ondoan, etxea eta etxekoak babestu eta, aldi berean, elizaren dogmak eta sinismenak lau haizeetara zabaltzeko. Hilarrietan, ordea, idazkunek jabetza, identitatea eta oroimena adierazi ohi dute gehienbat, eta, batzuetan, irakurtzen duenari arimaren aldeko otoitza ere eskatzen diote. Mendez mende eta belaunaldiz belaunaldi errepikatzen den ohitura bati jarraikiz, topografia sozial eta erlijioso komun bat osatzen dute idazkun guztiek.

\subsubsection{Etxe izenen atzizkiak}

Lapurdin, Nafarroa Beherean eta Nafarroa Garaian -ena, -enia, -tegi eta -koa; bi atzizki elkarrekin, -ena + -koa, Nafarroa Beherean eta Nafarroa Garaian eta -baita Nafarroa Garaian, Urdazubin. Zuberoan, berriz, ez da etxe izen atzizkidunik agertu.

Eraikuntza motari dagokionez, Lapurdin eta bi Nafarroetan borda hitza erabiltzen da landako eraikinei deitzeko (Socuen bordacua, Voriena borda, Quiquerenborda, borda de Maritorena...); Nafarroa Beherean sala jauregientzat (sala de Echepare) eta maison Euskal Herriko iparralde osoan (la maison de Gastambide, la maison de Domec...) erabiltzen da; Nafarroa Behereko hegoaldean eta Nafarroa Garaian casa (casa de Apalasia, casa de Elizalde, casa del zurdo, casa de Apezabaita, casa Garacoechea, esta casa es Maticonea...). Iturenen (Nafarroa Garaia), salbuespenez, euskarazko echea hitza agertzen da «HEDIFICARO HIZIEROM LA CAS/SA LLAMADA ALBERROBARREN / ECHEA EN EL ANNO DE 1612». 
Etxe izenari dagokionez, bakarra da orokorki, baina bestelako kasuak aurkitu ditugu. Bi kasutan etxeak izen konposatua du, bi deiturekin osaturik, beharbada: Haricelet-Lafaiect «IHS-MA/ MARTIN / DVRUTI-LE / S(sieur)R D(e) HARICELET-LAFAIE/CT -1641» (Ainhoa, Lapurdi) eta Chenperene-Etcheberri «MARTIN DE HABANS M(aitr)E CHIRVRGIEN. ET / IEANETTE DE MONDVTEGVY. SIEVR ET / DAME DE CHENPERENE-ETCHEBERRIA / F(ait). L' AN. 1707» (Senpere, Lapurdi). Beste batean, etxe izenaren aurretik auzoa paratu dela dirudi «IHALARRE / HAROZARE/NECO IARLE/CHVA» (Sara, 1723). Beste bi kasutan, jabea etxera joana da eta hobeki identifikatzeko jatorrizko etxe izena ere jakinarazten da: «[...] BERNARD ETCHEBER/RY ITCEINECO SEMIE GA/STIGARRECO NAGUSI GASTEA» (Banka, 1832) eta «[...] manais/ souh/ourou-suiar/inchahar/ etco Jauna/ marie/ orsafr/in aldu/deco etchotoco alaba (Banka, 1784).

Etxe izena ez bada ongi ezagutzen duda azalduz idatz daiteke, Zibitzen (Nafarroa Beherea) dugun bezala «ECHE. HUNEC. / DUKE. ICENA. M/ERCABIDE [...]» (Xamar, 2016, 52. or.). Zigan (Nafarroa Garaia), herriko etxe izen guztiak agertzen dira atalburu batean. Kasu honetaz gehiago solastuko gara funtzionalitatearen atalean.

Hilarrien artean, bi etxek partekatzen dute jarleku bera, Kanbon eta Azkainen (Lapurdi) «SEPVLTVRE DE- LA- MAISON DE BASSVSENA ET CELLE DE- LARREBVRVA» (Kanbo, 1724); «CETHAB/ERENECO / THONB/ATIC-HV/NARAIN/OCOAC-A/SCAIN-ER/ROTACO/AKDIRA» (Azkain). Horrez gain, Larresoron (Lapurdi) etxearen izena aldaketa prozesu batean sarturik dago «LA / MAISON- DE M/OROCVRENIA / AVTREMENTE S(ai)/NTPERENIA 1714». Azken kasu honetan, baliteke orduko jabeak, Pierre de Saint Pe maisu zirujauak, etxeari ekarpen garrantzitsu bat egin izana eta, ondorioz, herriko jendea etxea haren deiturarekin ezagutzen hastea.

\subsubsection{Formula idatziak}

Idazkunetako formulen estruktura eta edukiak errepikatzen dira euskarri guztietan, malgutasuez jokatuz eta formula batzuk edo besteak erabiliz, euskarriaren arabera. Atalburuetan nahiz hilarrietan eraikitze data eta lehenengo jabeen izen-deiturak agertzen dira gehienetan. Hilarrietan, berriz, hildakoen izen abizenekin eta etxe izenarekin batera formula erlijiosoak idazten dira, Jesus eta Maria ohiko bitartekariak edota arimaren aldeko otoi eskaria eginez, azken formula hau hil eremukoa esklusiboa izanik.

Oro har, Iparraldeko idazkunak Nafarroa Garaikoak baino hotshandikoagoak edo harroagoak direla esan daiteke. Horrela, etxeko jabeak hainbat modutan eta hizkuntzatan aipatzen dira, betiere errespetuzko formulapean. Adibidez, Lapurdiko idazkunetan nagusiki sieur eta dame terminoak agertzen dira, bai eta maître eta maîtresse, eta kasuren batean maîtres jeunes ere. Azken formula hau erabiltzen zen jabe zaharrak eta gazteak elkarrekin bizi zirenean. Nafarroa Beherean aniztasun handiago dago hizkuntza eta formulen aldetik. Horrela, frantsesez sieur eta dame, heritiére eta monsieur ditugu; gaztelaniaz sennor eta senora; euskaraz jaun eta andrea (etcheco jauna eta anderea) eta nagusi gaztea; eta, kasu bakar batean, done gaskoieraz. Azkenik, Nafarroa Garaian dueños edo amo - «AMO DE CASA JULIANA» (Biotzari)- edo tokiko herritarra dela jakinarazteko vecino edo natural. Larrasoañan (Nafarroa Garaia), adibidez, herritartasun bikoizko jabea dugu, aldi berean bi etxeren jabe baitzen, Larrasoañan eta 
Iruñean «CONDERENA / ESTA CASA ES DE PEDRO DE GARAICOECHEA NATURAL / Y VECINO DE ESTA VILLA Y DE PAMPLONA. AÑO DE 1784».

Etxeko fatxadetan, formula erlijiosoak aurkitzen ditugu, babesa lortu eta orduko doktrinak zabaltzeko xedearekin eginak: Laus deo, Jesus-Maria-Joseph, IHS, MA. Hilarrietan ete etxeetan errepikatzen dira formula batzuk IHS, MA, baina beste batzuk, berriz, berariazkoak dira, hain zuzen ere, Memento mori (Landibarre eta Jutsin, Nafarroa Beherea ) eta Inri (Zohazti eta Ostankoan, Nafarroa Beherea).

Hilarriek izen ezberdinak hartzen dituzte, hilarri motaren, tokiaren eta hizkuntzaren arabera. Diskodunari euskaraz esaten zaio ilharria, ileherri eta hobia, eta XVIII-XIX. mendeetan, sepultura ere deitzen zaio Etxalarren (Nafarroa Garaia). Jarlekuari edo sepulturari, berriz, sepultura gaztelaniaz, sepulture, thonba edo monument frantsesez, eta jarlekua edo hilerria euskaraz deitzen zaio. Lapurdin, hilarri tabularretan sepulture hitza idatzita dago.

Epitafioen artean Hic iacet formula idazten da Nafarroa Beherean, latinez, frantsesez ici gist Lapurdin eta Zuberoan, eta ici est Nafarroa Beherean. Euskaraz ere badugu hemen da, heben daca, daca (Nafarroa Beherea) edo hau da... jarlekua / thomba Lapurdin.

Genero ikuspegiari dagokionez, hemen katalogatutako atalburuen artean emakumea bakarrik oso kasu gutxitan agertzen da, gehienetan emakumea gizonarekin batera agertzen da, edo gizona bakarrik. Emakume bi kasu baino ez ditugu (guztizkoaren \% 2,2), biak Nafarroa Garaian: Mariato (Hiriberri Aezkoa), etxe izena lekukoa, eta Etxezuria (Ziga) «ETXEZURIA EDIFICADA / POR MARIA FRANCISCA / GARBALENA DE MAÑERU / EL AÑO DE 1851». Izan ere, ohikoena da gizonaren izen-abizenak agertzea (guztizkoaren $\%$ 36), edota gizonaren eta emakumearen izen-abizenak (guztizkoaren \% 36,3); azken datu hori Nafarroa Beherean'. Anitz ere badira soilik etxe izena erakusten dutenak, jabeen izenik gabe (guztizkoaren \% 23), batez ere, XVIII. mende amaieran eta XX. mendean. Hilarrietara joz, jarlekuetan senar-emazteak edo gizonak bakarrak agertzen dira kasu gehienetan. Diskodunei dagokionez, berriz, emakumeak nagusitzen dira (guztizkoaren \% 58), gehienak egonik banakako ehorzketetan. Hilarri tabularretan, berriz, gehienak banakako ehorzketak dira eta kopuru parekoak ditugu genero aldetik, gizonak pixka bat gailendu arren. Gurutzeetan, maiz agertzen da etxearen izena (\% 33,3) eta emakume soilaren presentziak ehuneko berbera du (\% 33,3).

Nafarroa Beherean, idazkunak etxekoen maila ekonomikoa eta soziala jakinaraz dezake, noble maison edo infancon hitzak erabiliz, Nafarroa Beherean. Batzuetan, ogibidea ere aipatzen da, anitzetan jarlekuetan; presbitero edo apeza, maître martinetier, maître chirurgien, maître charpentier, medecin du roy, notaire...

9 Genero ikuspegiarekin jarraikiz, baina oraingoan gure ikergaitik kanpo, uste dugu interesgarria dela nabarmentzea etxe izena modu ez zuzenean ematen den atalburu batean bi emakumeren izen abizenak azaltzen direla Irulegin (Nafarroa Beherea) «MARIA DE BIDEAGAIN JOANA DE BIDEGAIN 1761». Ez da kasu bakarra. Eskertzen diot informazioa Xamarri. 
Etxekoa edo etxeko jabea dela aipatzeko semia edo semea formula dago (Arcubico semia, Mendiondoco semec, «BERNARD ETCHEBER/RY ITCEINECO SEMIE GA/STIGARRECO NAGUSI GASTEA» eta alaba (Etchotoco alaba) edo gaztelaniaz hijo de. Batzuetan, data emateko orduan, jazoera historikoak aipatzen dira "se quemó el año 1746», eta, bestetan, arlo juridikoari lotutako kontuak «LAQVELE- MAISON-NE-SE POVRRA VANDRE / NY-ENG-AIGER».

Izengoitien presentzia oso apala da zerrendan. Datua ez da harritzekoa, etxe izena sortzen duten izengoitiak \% 8 baino ez dira (Iñigo, 2008, 303. or.). Arrietan (Nafarroa Garaia) casa del zurdo dugu Ezkerra etxeko ageriko idazkunean (zurdo gaztelaniazko izenaren itzulpena). Euskal Herriko iparraldean, izengoitia aipatzerakoan, dit formula ikus dezakegu, eta formula zenbaitetan, etxe izena izengoitia da «AG(v)ER / GILEN/ DIT COPEN 1806» Ozazen (Nafarroa Beherea), Copen etxean.

Idazkunak zizelkatzen zituzten harginak ezezagunak ditugu, orokorrean. Gehienek ere ez zekiten idazten, eta idazkunak egiteko kopiak edo txantiloiak erabiltzen zituzten, hain zuzen ere, eskribauek prestatzen zizkiotenak. Hori dela eta, ageriko idazkunetan administrazioaren dokumentazio idatziaren eragin nabarmena antzematen da, idazteko erabiltzen den hizkuntza barne. Hala ere, harginek iruditeri tradizionala ederki menperatzen zuten, betiere tradizioari ekarpena eginez. Hargin batzuen izenak gugana heldu dira, etxeetako jabeen izen-abizenekin batera atalburuetan idaztirik daudelako: Jose de Zela(i)eta (Eraso, 1755), Pedro de Belar(ra), hargin maisua (Eratsun, 1751) eta Juan de Suescun (Oltza, 1753) ${ }^{10}$. Hargin guztiak ingurukoak dira.

Zenbaitetan etxea bera da mintzo zaiguna, bereziki Nafarroa Garaian soy de, me llamo, me izo eta mi amo formulapean. Kasu aparta eta umoretsu samarra Nafarroa Garaiko Ziako Loperenan dugu, aipatzea merezi duena: «ME PAREZE QUE ESTOY BUENA / SY ACASSO NO LO SABEN / MI AMO JUAN DE YRIBARREN / YO ME LLAMO LOPERENA / AÑO 1754».

\subsubsection{Kronologia}

Kronologiari dagokionez, etxe izendunen data goiztiarrenak Lapurdin ditugu XVI. mendean diskodun batean (Makea, 1534) eta zenbait jarlekutan (Senpere, 1566 eta Azkaine, 1592) ${ }^{11}$.

Lapurdin, etxe izenak agertzen dira jarlekuetan, XVII-XVIII. mendeetan nagusiki, eta, oro har, maila sozial altuko pertsonaiei loturik, besteak beste, zurgin maisuak, errege

10 García Gainzaren lanean beste hargin batzuen izenak agertzen dira Nafarroa Garaiko gainontzeko etxeetako atalburuetan, gutxi badira ere. Guztiak XVIII. mendekoak dira. Hona hemen izenak: Pedro de Oria (Untzu, 1783), Francisco de Goldarazena, maisua (Arruitz, 1774) eta Pedro Jose de Madoz (Madotz, 1774). Iparraldean, berriz, askoz ere gehiago dira bere izena paratu duten harginak, XVII. mende amaierako kasu bat salbu, gainontzeko guztiak XVIII eta XIX. mendeetakoak dira (Motché, 2010, 178. or.).

11 Colasek 1512n urteko jarleku etxe izenduna aurkezten digu Bidarten. Hala ere, epigrafiari erreparatuz, akats bat dago transkripzioan eta 1612 urteko pieza bat delakoan nago. 
kontseilaria eta sendagilea, errege notarioak eta nobleak. Diskodunetan oso oparoa da etxe izenaren presentzia Nafarroa Beherean, XVII. mendean. Azken adibideak, XIX. mendean Nafarroa Garaian eta Nafarroa Beherean topatzen ditugu. Euskarri tabularrari dagokionez, Lapurdiko hegoaldean hainbat etxe izen agertzen dira XVII. mendean, eta XVIII, XIX. eta XX. mendeetan, aldiz, Nafar iparraldean. Gurutzeetan, oro har, XVIII. mendetik aitzina agertzen dira etxe izenak.

Etxeko aitzinaldean, baina, XVII. mendetik aitzina agertzen dira etxe izenak, alegia, hilarrietan baino mende bat beranduago. Eskualde guztietan badaude ere, Nafarroa Behereko eta Nafarroa Garaiko etxeko aitzinaldeetakoak nabarmentzen dira, XVII. eta XIX. mende bitartean. Adibide goiztiarrenak ditugu Nafarroa Garaiko Iturenen (1612) eta Lapurdiko Kanbon (1618). Arruntena da atalburuetan eta karteletan agertzea, euskarri horietan dagoen espazioa egokiagoa baita idazteko. Nafarroa Garaian dobeletan ere idazteko ohitura dago, bai eta kasu bakan batzuetan leihoburuan eta armarrietan ere.

Lan honetan jasotako hondarretako idazkun tradizionalak toki eta data ezberdinetakoak dira. Lapurdin katalogatu dugun azken adibidea 1806koa da, Etxetxahar etxean (Urruña), baina, pieza etxe izendun berantiarragoak daude. Adibidez, Azkainen, 1855ean, koleraren biktimen oroimenez berrogeita bederatzi diskodun eta bi gurutze paratu zirela Sokorriko Ama Birjinaren baselizan, eta pieza batzuetan etxe izenak epigrafiaturik daude (Aguirre, 2013).

XX. mendea, aldiz, ez dugu taxuz jorratu eta ondoren datuak ez dira esanguratsuak, baina adibide batzuk ditugu lan honetan, 1909. urtean (Mendihy, Armendaritze, Nafarroa Beherea) eta lan honetatik kanpo ${ }^{12}$ ere, bederen 1920 arte. Hilarrietako etxe izenei dagokienez, 1860 urtera arte jaso dut Euskal Herriko iparraldean, eta 1930 arte Nafarroa Garaian, azken hau Arizkunen (Nafarroa Garaia), Bydegaina.

XX. mendeko hilarriak ere ez ditugu sakonki aztertu baina datu esanguratsu batzuk hemendik eta handik jaso ditugu. Pieza bana ezagutzen ditugu Aezkoako Garraldako hilerrian (Bizcai) eta Abaurregaineko hilarrien museoan (Casa Remondegui). Horrez gain, badakigu 1964tik hona Aurizko kanposantuetako hilarrietan etxe izenen presentziak garrantzia galdu duela eta, denborak aitzina egin ahala, familien deiturekin ordezkatzen joan direla (Irigaray Gil, 2019, 275. or.) ${ }^{13}$. Iparraldeko hilerrietan ere XX. mendean zehar etxe izen tradizionalaren erabileraren gainbehera eman zela dirudi. Agerikoa denez, izen neobaskoek ez du legitimotasunik hilarrietan agertzeko, hain zuzen ere, izen tradizionalak betetzen zituen funtzio identitarioak eta sozialak ordezkatzen ez dituztelako. Hala ere, Nafarroako Garaiko iparraldeko zenbait kanposantutan 1970 urtetik aitzina ahaleginak egin ziren etxe izen tradizionalen erabilera bultzatzeko hilarrietan, bereziki, diskodunetan. Horrela ikusten ahal da, besteak beste, Garralda, Auritz, Hiriberri edota

12 Elgorriagan Indartea (1908) eta Legasan Oteizenea (1900) eta Elizaldea (1912).

13 Mikel Belaskok postaz aipatzen dit etxe izenak agertzen direla Bidankozeko kanposantuan, hain zuzen ere, -rena atzizkia erabiltzen den Erronkariko herri bakarrean. Hala ere, tradizioko hilarri eta atalburuetan Erronkarin eta ingurukoetan ez dugu etxe izenik topatzen (López Selles, Saralegui \& Cruchaga y Purroy, 1983). 
Orbaizetako hilerrietan, hasieran, Jose Rotak eta, gero, Pello Iraizozek zizelkatuak, Euskal Herriko iparraldeko hilarrien plastikari imitatuz (Otero et al., 2007). Gure ikerketa esparrutik at antzeko joera antzematen da Gipuzkoan, Apozaga eta Orendaingo hilerrietan, oikonimoak agertzen baitira 1970ko hamarkadako hilarri diskodunetan (Aguirre Sorondo, 2004, 875. or) eta Bizkaian, Bermeoko Mañuas auzoan.

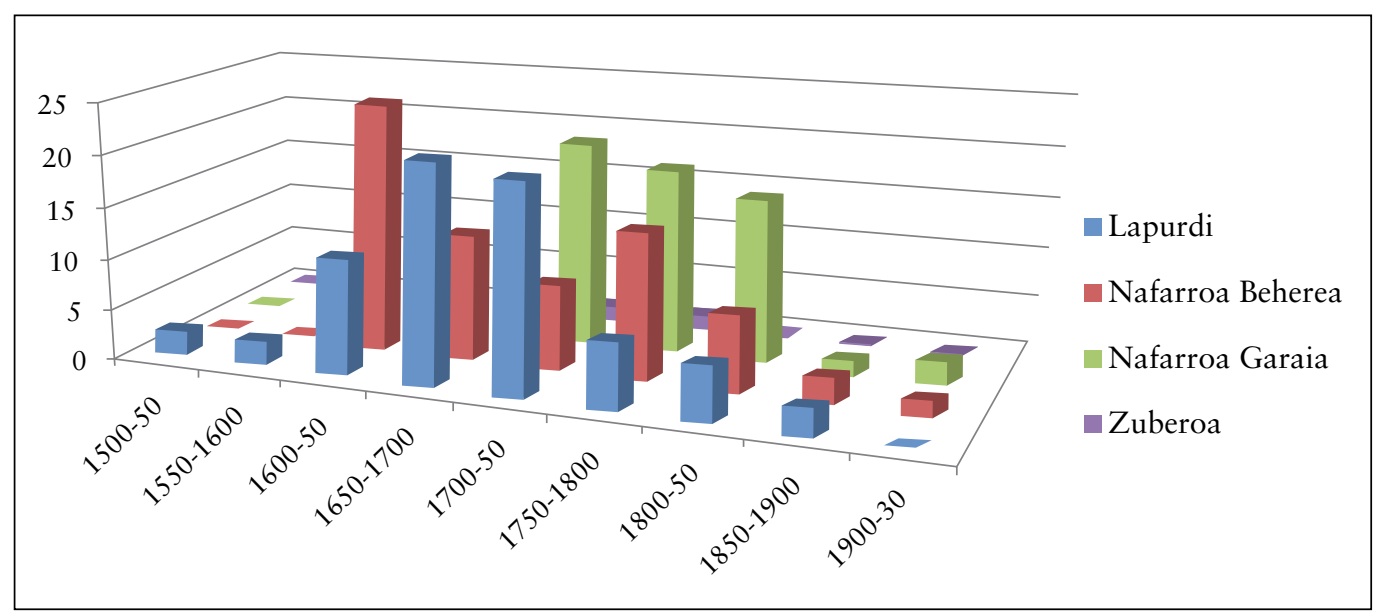

1. grafikoa. Etxe izen datatuen kopuruak lau herrialdetan eta kronologiaren arabera.

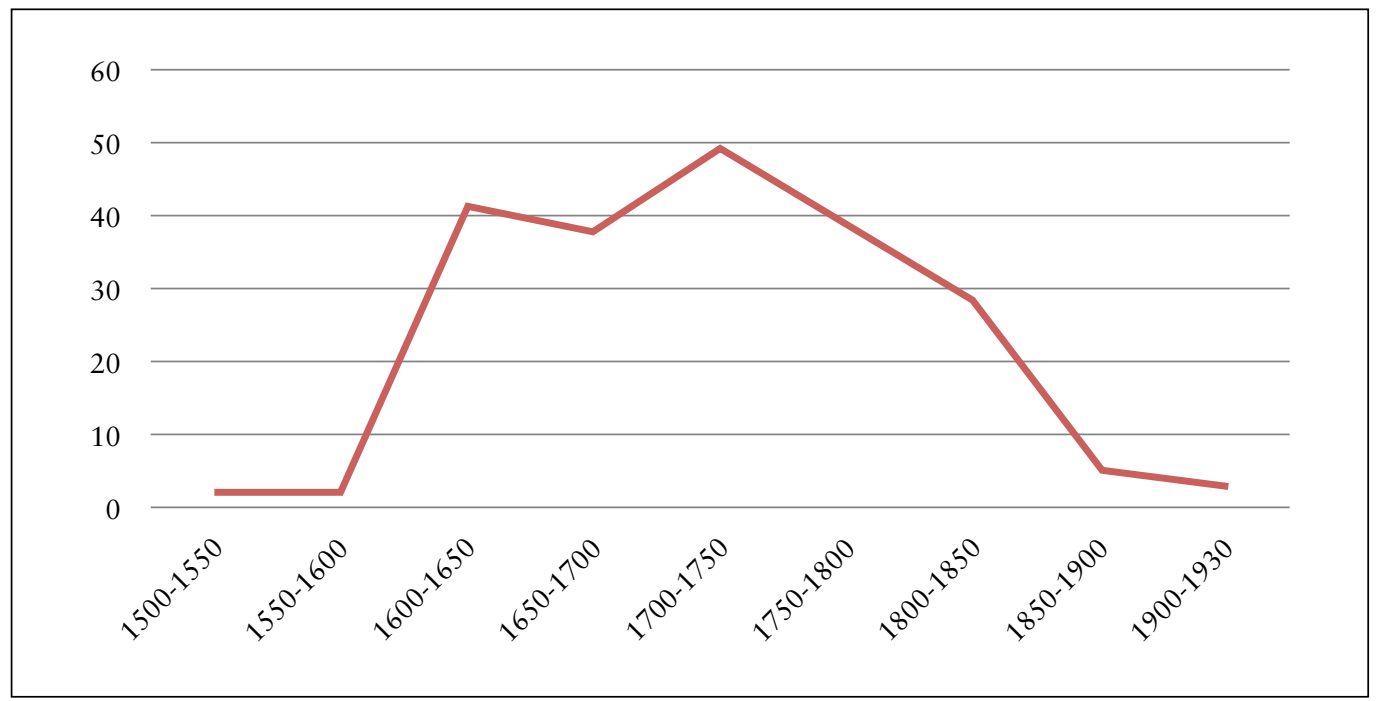

2. grafikoa. Etxe izen datatuen kopuruak kronologiaren arabera.

\subsubsection{Ageriko etxe izen tradizionalen funtzio sozialak}

Etxe izena identifikaziorako bide ohikoena izan da euskaldunen artean. Haren bidez definitu daiteke, sozialki, pertsonak nor diren. Mixel Duverten hitzetan (2017, 5-6. or.) etxearen izena da «egungo pasaportea... biztanleen nortasunaren gordetzailea». Izan ere, etxe izenak pentsatuak zeuden denbora zeharkatzeko eta, aldi berean, arbasoekiko 
lotura eta etxeko ondarearen batasuna adierazteko. Gainera, hainbat tokitan etxekoak identifikatzeko etxe izena bide bakarra izan da XX. mendera arte, abizenaren gainetik (Irigarai 1955, 495. or.).

Trentoko kontzilioak (1545-1563) aldaketak ekarri zituen pertsonak izendatzeko moduan eta, haren ondorioz, abizenaren erabilera finkatzeko oinarriak paratu zituen. Hala ere, euskal eremuan izen deiturarekin batera etxe izena idazten jarraitu zuten etxeko jabeek, ziurrenik, Lancre bezalako erlijio gizonen iritziaren aurka. Beharbada, beste latitude batzuetako ageriko idazkunekin alderatuz, etxe izena eta emakumeen presentzia goiztiarra bi ezaugarri esanguratsuenak izan daitezke gurean.

Ageriko etxe izen tradizionalen funtzio sozialak lau dira, nagusiki: publizitatea, prestigioa, jabetasuna eta antolamendu sozialaren hizkuntza paisaia.

- Publizitatea

Ageriko idazkunen funtzionalitate nagusia publizitatea da. Horregatik, etxe izenak modu publikoan, irakurgarrian eta ikusgarrian zizelkatu dira. Gainera, harrian zizelkaturik daude denboran zehar iraun dezaten.

- Prestigioa

XVI. mendearen bigarren erdialdetik aitzina ageriko idazkunen erabilera orokortzen hasi zen. Ordura arte, idazkunak botereguneekin eta eliteen produkzioarekin estuki loturik egon ziren, alegia, prestigio handiko eremuei atxikirik. Zabalpen honetan lagungarriak izan ziren, besteak beste, inprimategiaren asmaketa, jendartearen alfabetizazioren lehenengo pausoak edota kaligrafia metodoen argitalpenak, Juan de Icíar Vizcainok idatzi zuen bezalakoa.

- Jabetasunaren adierazpena

Hil eremutik datozkigun lehenengo etxe izen zizelkatuek hilobiaren jabetasuna aldarrikatzeaz gain, hildakoen mundua etxearekin lotu zuten modu epigrafikoan. Idazkunari esker, beraz, etxeko jarlekuaren kokapena jakin daiteke modu publikoan eta, aldi berean, jabetasuna, eskaintzak egiteko tokia eta etxearen garaiko posizio soziala agerikok dira.

- Antolamendu sozialaren hizkuntza paisaia

Herriaren antolamenduaren oinarrizko unitatea da etxe izena, hots, auzotartasunharremanetan eskubide eta betebeharren subjetua. Etxe izen guztiek osatzen dute komunitatea eta haien presentzia publikoak, hilerrian nahiz etxeko fatxadetan, komunitatearen egitura adierazten dira hizkuntza paisaia edo Thopos baten bidez.

Zigako ostatuko atalburua ezohiko adibide dugu. Bertan, 1741. urteko herriko argazki soziala dago, etxe izen guztiak zizelkaturik agertzen baitira. Baztango ostatuak etxe handiak eta zabalak dira, auzokide guztien elkarlanari esker eraikiak ziren batzarreak egiteko (Pérez de Villarreal, 1986, 360-361. or.). Horregatik, atalburuan eraikitzaile guztien izenak agertzen dira, aken finean, batzarrean boza eta udal pribilegioez gozatzeko eskubidea zituztenak. 


\subsubsection{Etxe izenen tradizioaren aldaketa eta jarraipena XX. mendean}

Etxe izen neobaskoen hastapena XX. mende hasiera dago. XIX. mendearen bigarren erdialdetik modan jarri zen oporraldiak Lapurdin igarotzea, hain zuzen ere, Napoleon III.-k eta Montijoko Eugeniak bisita egin ondoren. Hara joaten zen burgesiaren nahiak asetzeko, neobasque estiloa asmatu zuten arkitektoek Lapurdiko etxeetako kanpo ezaugarrietan oinarriturik. Horretarako, O'Shea-k 1887. urtean argitaratutako etxearen inguruko lana lagungarria suertatu zen.

Etxe neobasko estiloarekin batera lehenengo etxe izen berriak zabaldu ziren, burgesiaren estetika eta baloreei atxikirik (Toki Eder, Haitzurra, Harotzaldea-Getaria, 1900eta Etche Berdea -Getaria, 1905-). Mendearen lehenengo hamarkadetan zehar, etxe erosle guztiak atzerritarrak izan ziren eta bertako kulturan integratzeko euskara erabili zuten etxeak izendatzeko (Irrintzina-Ziburu, 1929-, Asmutegia-Donibane Lohitzune, 1929-, Pare Gabea -Donibane Lohitzune, 1923-, Arri Gorri -Baiona, 1926-) (Bidart, 1997). 1950tik aitzina, ordea, bertakoak hasi ziren erosten Lapurdiko txalet berriak. Erdi-mailako klasekoak ziren eta hiria eta landa gunearen artean egiten zuten bizimodua. Euskara transmititzeari uko egin zioten baina txaletaren izenaren bitartez euskarari keinu egin nahi zioten (Gure Doya, Gure Egoitza, Iguski Alde, Bichta Eder, Goizeko Izarra, Zoriontsu, Nic nahia, Gostukoa, Gure Lanetik, Gure Xokoa, Goxoki, Agur, Argi Eder, Gure Etxola, Gure Izarra, Aire Ona...) (Bidart, 1997). Ordutik aitzina, etxe izen modernoa zabaltzen doa, kutsu kultural eta politikoarekin, hasieran neobasko estiloko arkitekturarekin loturik, baina, azkenean, edozein etxebizitzatara zabaldu zen.

Laburbilduz, etxe izen neobaskoak beste behar batzuei erantzuten dizkio eta, horregatik, ez ditu betetzen etxe izen tradizionalak dituen identifikazio eta antolamendu sozialaren funtzioak, zentzu estetiko batera mugatzen delako. Hori dela eta, izen neobaskoa ez da kanposantuetako hilarrietan agertzen.

\subsubsection{Etxe izenen distribuzioaren mapak}

Ageriko idazkunetako etxe izenen geografia mapa batera eraman dugu haren zabalpena modu ikusgarrian izateko. Kontuan hartu behar da mapak egin direla ikuspegi kronologikoa kontuan hartu gabe. Etxe izenen presentziaren intentsitate diakronikoa kontsultatu nahi bada, lurralde nahiz euskarriaren arabera, 3. 4. eta 5. grafiketara jo daiteke.

Euskal Herriko iparraldean, etxe izenen presentzia ageriko idazkunetan orokorra dela esan daiteke, Lapurdin eta Nafarroa Beherean haren presentzia trinkoagoa izanik. Lapurdiko ipar mendebaldeko muturrean hutsuneak antzematen dira, alegia, BaionaAngelu-Biarritz-Bokale udalerrietan, eta Zuberoan, Lexantzüko jarlekua salbuetsita. Guztiak iparraldean metaturik daude, eta hegoaldeko erdialde osoa hutsik dago. Etxe izenak Bearnora ere zabaltzen dira, bederen, euskal kulturako Eskiula herrira helduz.

Pirinioetako hegoaldean, Nafarroa Garaian, ageriko idazkunetan etxe izenak ipar erdialdean daude, Iruñeko merindadearen ekialdean (Urdazubi, Zugarramurdi, Baztan, Malerreka, Bortziriak, Leitza, Larraun, Ultzama, Atetz, Imotz, Txulapain, Ezkabarte, Orkoien, Zizur eta Zabaltza), eta Zangozako merindadearen ipar eta hego mendebaldean (Elortzibar, Esteribar, Erroibar, Lizoain-Arriasgoiti, Artzibar, Luzaide, Aezkoa 
eta Zaraitzu). Iruñerrian (Zabaltza, Orkoien, Zizurko zendea eta Elortzibar), hegoaldeko etxe izenen mugatik gertu. Adibide guztiak iraupen luzeko etxe izenen eremuan daude Biotzari salbuespen bakarra izanik. Ongi azaldu gabe geratzen da, baina, zergatik ez den etxe izen zizelkatu gehiago agertzen Nafarroa Garaiko ekialdean, etxe izenen eremu barruan. Egoera azaltzeko hipotesi ekonomikoak, sozialak eta dekoratiboak ditugu, geroan tokian tokikoak aztertu beharrekoak.

Lapurdin eta Nafarroa Behereko etxeetako adibideak hegoaldeko erdialdean kokatzen dira, Zuberoan kasu bakarra egonda. Nafarroa Garaian, aldiz, zabalpena handiagoa da geografikoki eta gehienak ipar aldean bildu arren, Iruñerriraino ere heltzen dira mendebaldetik, Belateko bideari jarraikiz. Hilarriei dagokienez, hauek zabalpen zabalagoa eta homogeneoagoa izan dute Euskal Herriko iparraldean, kanposantu zaharrak bere horretan mantendu baitira gaur egun arte.

3. taula. Mapetako ikurren legenda

\begin{tabular}{|c|}
\hline . Etxea \\
\hline O- Hilarri diskoduna. \\
\hline X- Jarlekua. \\
\hline D- Hilarri tabularra. \\
\hline +- Gurutzea. \\
\hline M- Mausoleoa. \\
\hline
\end{tabular}

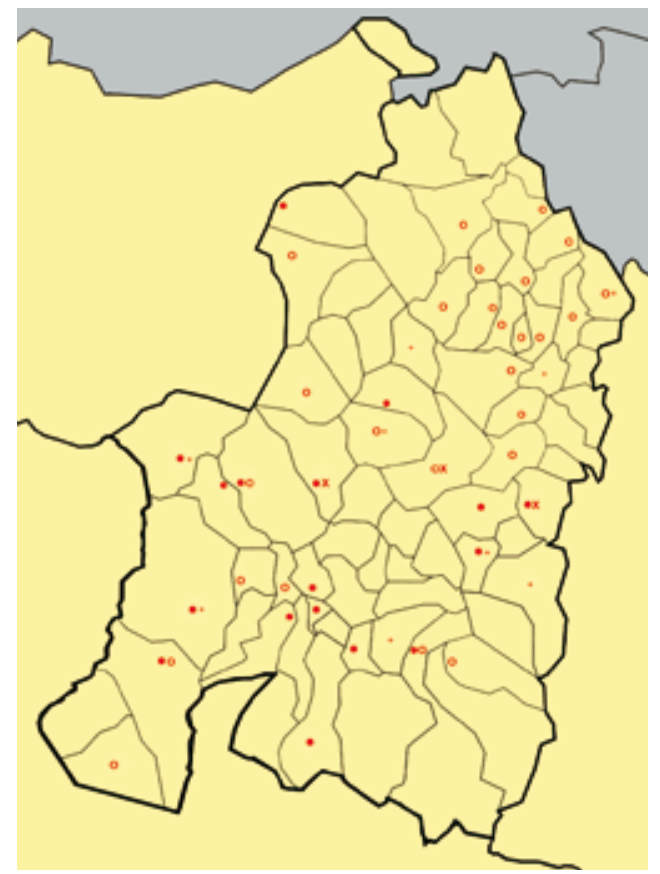

3. irudia. Nafarroa Beherea.

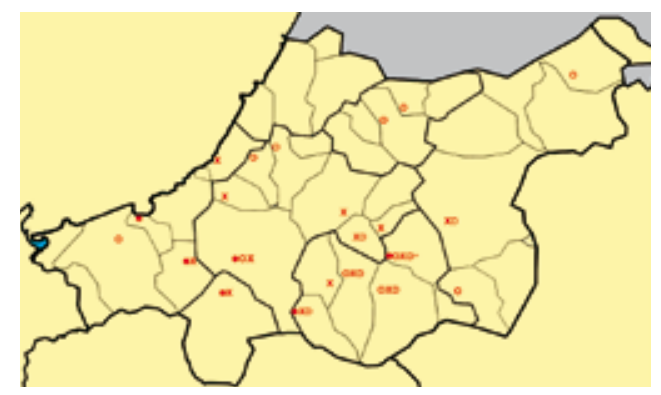

2. irudia. Lapurdi.

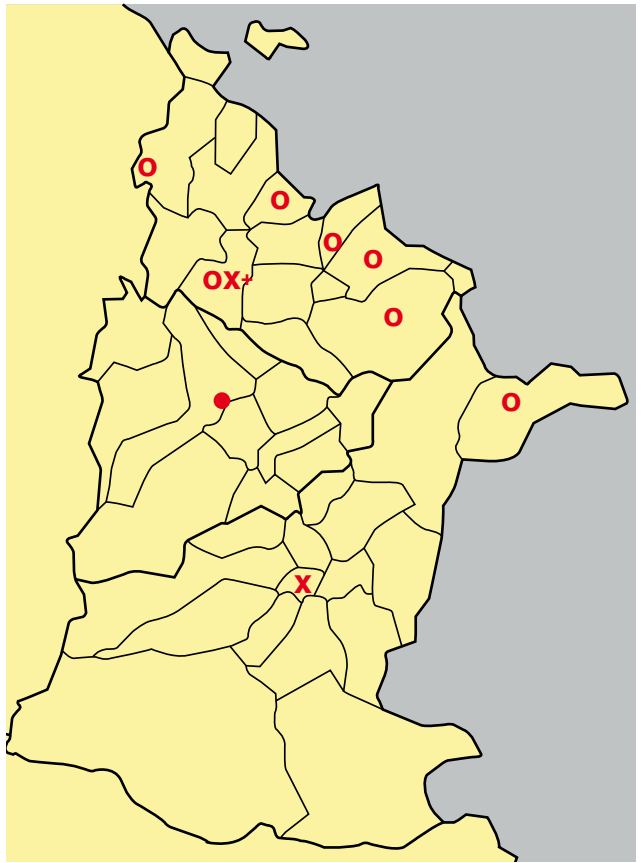

4. irudia. Zuberoa eta Eskiula. 


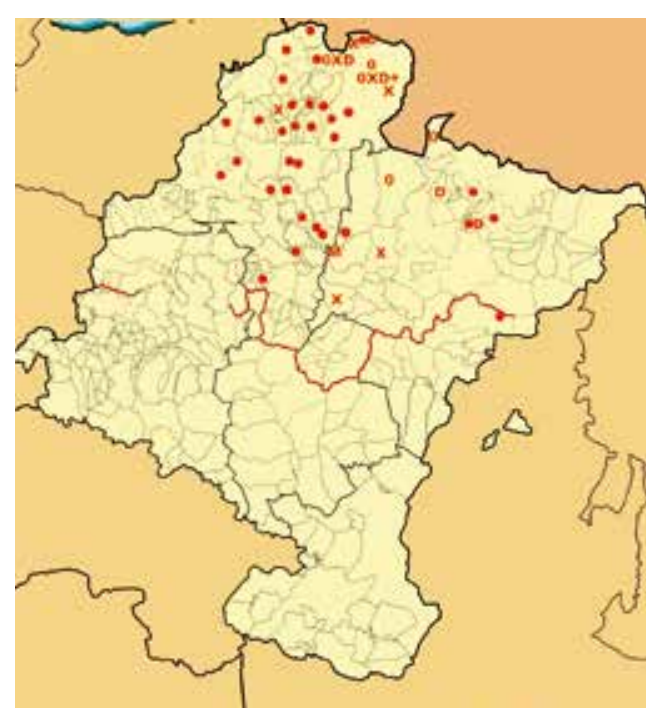

5. irudia. Nafarroa Garaia.

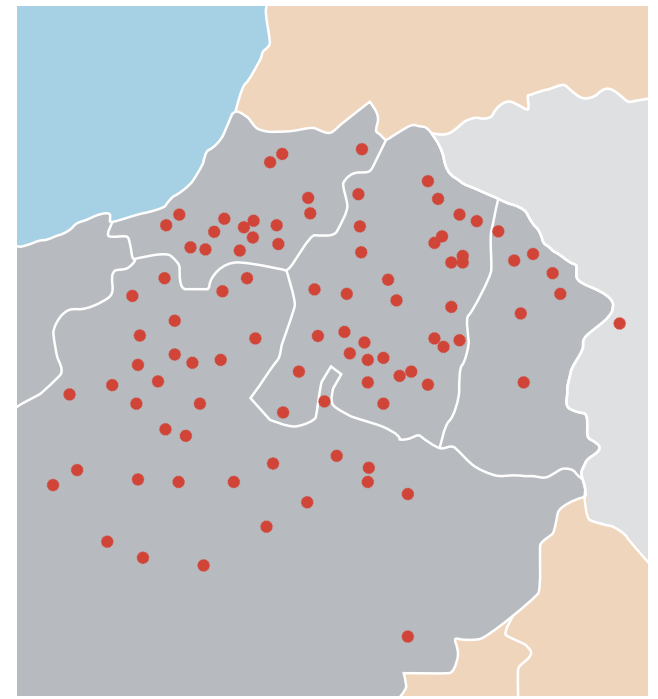

6. irudia. Distribuzio orokorra Euskal Herriko ekialdean.

\section{ONDORIOAK}

Euskal kulturan etxekoak deitu eta identifikatzeko etxe izena izan da jatorrizko bidea. Izendatzeko modu honek bizirik darrai egun, eta XX. mendeko lehenengo hamarkadetara arte hainbat tokitan baliabide bakar gisa erabili izan da. Etxe izenak presentzia publikoa izan du, eta badu landa eremu herrietako etxeko fatxadetan eta hilobietan. Biak, historikoki, berariazko esparru izan dira etxe izena modu publikoan idazteko eta biak loturik daude hildakoen eta bizidunen arteko komunitate baten kontzeptupean.

Artikulu honetan Euskal Herriko ekialdetik 386 etxe izen jaso ditut (Lapurdi, Nafarroa Garaia, Nafarroa Beherea eta Zuberoa), guztiak XVI. mendetik XX. mende hasiera artekoak. Idazkunen \% 64,4 hilarrietan dago eta \% 35,5 etxeko fatxadetan, ia guztiak harrian landurik. Izenak euskaraz badira ere, idazkun guztiak gaztelaniaz daude.

Banaketa geografikoari dagokionez, etxe izen zizelkatuen manifestazio historikoak Piriniotako bi isurialdeetan zentraltasuna hartu zuen, hain zuzen ere, Lapurdiko hegoaldean, Nafarroa Beherea osoan, Nafarroa Garaiko iparraldean eta Zuberoako iparraldean. Nafarroa Garaiari dagokionez, etxe izen guztiak etxe izenen mugaren barruan agertzen dira, Biotzari herriaren salbuespenarekin. Kopuruei begira etxe izen anitz agertzen dira Baztan-Bera-Etxalarren eta Sara-Senperen eremuetan, hain zuzen ere, elizan eta hilerriko hilarri anitz kontserbatu direlako.

Etxe izena eta ageriko idazkunetako etxe izenen funtzionalitateak desberdindu behar dira. Etxe izenaren funtzionalitatea, berez, identitarioa da. Hala ere, ageriko idazkunen funtzionalitatea publizitarioa da nagusiki, jabetza, prestigio eta antolamendu soziala erakusteko xedearekin. Azken ezaugarri honek hizkuntza paisaia edo thopos sozial eta kultural bat osatzen du. 
Lehenbiziko etxe izen zizelkatuak XVI. mendean agertzen dira, Lapurdin, oparaldi demografiko eta ekonomiko baten testuinguruan. Hil eremuan daude, diskodunetan eta jarlekuetan, prestigio eta jabetza funtzioak betez. Garai horretan, ageriko idazkunak hedatzen dira Europa mailan (Petrucci, 2013), eta gurean maila sozial altua dutenen artean tokia oihartzuna zuten. Beste lekuetan ez bezala, Euskal Herrian etxe izen tradizionala zizelkatzen da jabearen izenaren eta erlijio formulen ondoan, etxekoen izaera kolektiboa azpimarratuz.

XVII. mende hasieratik ageriko idazkunen erabilera gizartearen multzo sozial zabalago batera heltzen da, eta orduan etxe izenak hil euskarri gehiagoetara eta bereziki etxeko fatxadetara heldu ziren. XVII. mendeko hedapen hau gertatzen da Iparraldeko herri artearen pizkundearen testuinguruan (Duvert, 2017, 79. or.), hilarrietan nahiz atalburutan, non iruditeri berria zabaltzen eta idazkunak ugaritzen baitira.

Etxe izenen presentziak goia jo zuen 1650-1750 urteen bitartean, eta handik aitzina gainbehera arin eta luze batean sartzen da, erabilera publikoa mantenduz XX. mendeko lehenengo hamarkadetara arte. Ikertzeko dago, beraz, XX. mendeko etxe izenen bilakaeraren nolakotasuna, etxeko fatxadetan nahiz kanposantuetan. Argi dago, beraz, izen neobaskoek ez dutela asetzen izen tradizioanalak dituen funtzio sozialak, eta arlo identitarioa eta estetikora baino ez dira mugatzen -nahiak, desioak, gustuak, ideiak...-. Hori dela eta, hilarrietan ez ditugu izen neobaskoak aurkituko.

Egun, arlo sozialean, akademikoan eta administratiboan etxe izenen biziberritze bat ematen ari da. Jendartean, identitate bilaketa ematen ari den bitartean, instituzietatik etxe izen neotradizionalen erabilera bultzatzen ari dira. Proposatutako etxe izen hauek tradizioari jarraitzen diote, edukieraz (toponimia, lanbidea, antroponimoa...) nahiz formaz (-r-ena atzizkia). Dudarik gabe, honek guztiak hizkuntza paisaian eragin bat izaten du.

Ikerlan honetan erabili ditudan iturriak oparoak bezain mugatzaileak izan dira ageriko idazkunen manifestazioa ezagutzeko. Hemendik aitzina ikerketa lan gehiago egitea beharrezkoa izanen da, landa-lana batez ere. Ederki dakigu, geografikoki ere, ageriko idazkunen presentzia ez dela soilik Euskal Herriko ekialdera mugatzen; iparmedebaldean etxe izen zizelkatuak tradizionalak, arruntak baitira $\left(\right.$ Gipuzkoan $^{14}$,

14 Mutrikun (Gipuzkoa) Aranzamendi etxe izena idatzia zegoen bideko gurutze batean, Deba eta Mutriku artean «Tomas Alcorta de 32 años. Murio 3 de abril de 1865. Hijo de Aranzamendi. Q.E.P.D.». (Echegaray, 1925, 194. or.). Peña Santiagok (1999, 246. or.) Gipuzkoako jarlekuetan zenbait etxe izen ematen ditu: Chulonea (Usurbil), -de Aguerre (Akizu), eta Martilena (Arrona), azken hau egurrezkoa. Larrañaga Guridik Bergaran aldeko zenbait baserritako etxe izen zizelkatuak jaso ditu: Gomezcorta "GOMEZCORTA / REEDIFICADO POR SU DUEÑO / JOSE MARIA DE LARRAÑAGA / AÑO DE 1843» (https://sites.google.com/site/ bergarakobaserriak/home/elosua/gomezkorta); Alzvaran «ESTA CASA SOLAR INFANZONA DE ALZUARAN / CABO DE ARMERIA SE REDIFICO POR SV DVEÑO Y / POSEHEDOR D. PEDRO FRANCISCO DE GARITANO ALZVARAN / AÑO DE 1875» (https://sites.google.com/site/bergarakobaserriak/home/angiozar-auzoa/partegoitiapartaitti/alzuaran---altzuaran). 
Bizkaian $\left.{ }^{15}\right)$. Beraz, oraindik badugu zer ikasia eta espero dugu hemen zabaldutako bidea lagungarria izatea geroko ikerketarako.

\section{ETXE IZENEN ZERRENDA}

\subsection{Transkripziorako jarraibideak}

- Harginak idatzi zuen bezala utzi dugu hizki larriz eta hizki xehez idatzita dagoena, bai eta akatsak eta errepikapenak ere.

_ « Ageriko idazkunen testua kakotsen artean idatzi dugu.

- Testuetako hitzak ulergarriagoak egiteko, bereizi egin ditugu. Jatorrizkoak erreferentzia bibliografikoan kontsulta daitezke.

- / lerro aldaketa barra etzan batekin irudikatu dugu.

- // bi barra jarri ditugu testuak piezaren beste aldetik jarraitzen duenean. Zenbait kasutan, atalburuen, dobelen eta kartelen testuak bigarren pieza batean jarraitzea gerta liteke.

- U hizkia V grafiarekin idatzi dagoen kasuetan bere horretan utzi dugu.

_ * + Testu barruan gurutzeak edo izartxoak agertzen direnean ageriko idazkunean dauden apaingarrien berri ematen dugu (gurutzeak edo beste irudi begetal nahiz geometrikoak).

- . : Puntu, bi puntu edota gidoia testuan idatzita daude jatorrizko idazkunean halakoak agertzen direnean.

- Transkripzioan hitz elkarketak ez daude ongi islaturik eta horretarako jatorrizko idazkunetara jo behar da. Adibidez, DE preposizioan, anitzetan, gertatzen da E hizkia D hizkiaren barruan dagoela, baina transkripzioan ez dugu hori islatu.

- S(ieu)R ; SEP(vltv)RA; M(aitr)E; (hil)HER(ri)A ... Irakurleak uler dezan laburdurak osatu egin ditugu, hitza osatzeko falta diren hizkiak parentesi artean eta letra txikian idatziz.

15 Arratian «Errotabarriko sepulturia» dago (Barandiaran, 1980, III, 595. or.). Bizkaiko Berrizko baserriak liburuan ere idazkunetan dauden hainbat etxe izen jaso dira (Martínez, Gorostiza \& Gorrotxategi, 2013). Horrez gain, Bermeoko Mañuas auzoko hilerrian etxe izena duten diskodunak paratu dira azken urteotan. 
- (?); ( ). Hitza edo hitzaren zati bat galdu da higaduragatik. Kasu batzuetan parentesi artean proposamena jasotzen da, idazkunean ez dagoena.

- ... Testuaren zati bat galdu da.

\subsection{Etxe izenen zerrenda testuinguruaren eta euskarri motaren arabera antolaturik}

\subsubsection{Armarria}

- Nafarroa Beherea

Ibarrola: Palacio de Vhalde (Colas, 1923, 792. ird.) «LAS ARMAS / DEL PALACIO / DE VHALDE / DE IBARROLA».

- Nafarroa Garaia

Donamaria: Suriotena (García Gainza, 1989, V*, 555. or.) «JUAN DE ITURR/ALDE BECINO DE / SURIOTENA»; Ochoarena (García Gainza, 1989, v,* 555. or.) «DE DIEGO DE MIGUELTORENA / OCHOARENA /AÑO DE 1( )».

\subsubsection{Atalburua}

- Lapurdi

Ainhoa: Gorritia (Colas, 1923, 129. ird.) «CESTE MAISON-APELLEE-GORRITIA-A ESTE / RACHEPTÉE-PAR MARIE DE GORRITI MERE DE FEV IEAN/DOLHAGARAY-DES SOMMES PAR LVY ENVOYES DES/INDES LAQVELE- MAISON-NE-SE POVRRA VANDRE / NY-ENG-AIGER-FAIT EN LAN 1662».

Azkaine: Mvr( )gvia (Xamar, 2016, 44. or.) «MAISON- DE MUR( )GVIA FAIT PAR / MARTIN- GOIECHE 1789».

Kanbo: Elicabidea (Colas, 1923, 136. ird.) «16 IHS 84 / MARTIN DE IAUVRRETCHE / DIT CAPITAIN ET MARIA DE L/ATXALDE- S (SIEUR)- ET -D(ame)- DELICABIDIA».

Sara: Haranbovre (Barandiaran, 2000, 151. or.) «PIERRE HIRIBARREN ET / MARIE DE SANDOVRE SIEVR / ET DAME DE HARANBOVRE/ 1685».

Senpere: Mondvtegvy (Moutché, 2010, 180. or.) «MARTIN D’ALCOLA ET MARIE / D'ARROIOAGVE SEVR ET DAME / DE MONDVTEGVY ET L'AN 1676»; Chenperene-Etcheberria (Colas, 1923, 1259. ird.) «MARTIN DE HABANS M(aitr)E CHIRVRGIEN. ET / IEANETTE DE MONDVTEGVY. SIEVR ET / DAME DE CHENPERENE-ETCHEBERRIA / F(ait). L' AN. 1707».

- Nafarroa Beherea

Armendaritze: Elliczagarai (Colas, 1923, 565. ird.) «ELLICZA8ARAI / PIARES ETA + MARIA 1626».

Banka: Gastigarra eta Itcein (Colas, 1923, 1160. ird.) «+ LAN 1832 ** / BERNARD ETCHEBER/RY ITCEINECO SEMIE GA/STIGARRECO NAGUSI GASTEA»; Oxxaart (Colas, 1923, 1161. ird.) «GEREGHAN SALABERRI / GRACIANA-OCILAM/ EROGAN-SALABERRI / AINNES-ARAMBEL/ OXXAART 1842».

Bidarrai: Cubiburv (Colas, 1923, 1263. ird.) «ANNO DOMINI 1744 / DOMVS ISTA VOCABIT/VR CVBIBVRV ****.

Donibane Garazi: Lomitegvy (Hurmic, 2003, 4. or.) «L'AN 1773 // IEAN PALADAN MARCVERITERAVISE / ONT FAIT. BATIRLA MAISON.D LOMITEGVI»; LeOnenia 
(Hurmic, 2003, 1. or.) «LEONENIA // 1648» (idazkun modernoa); Marensenia (Hurmic 2003, 2. or.) "MARENSENIA» (modernoa).

Jutsi: Bassart (Duvert, 2017, 10. or.) «FAIT. PAR. IOANN/ES. SIEVR. DE. BAS/SART. DE IVXVE / MARGAITA. DE * / ELISONDO: 1782:».

Lekunberri: Teillagorri (Colas, 1923 1150. ird.) «MAI-SON-DE-TE-/ILLA-GORRI * $1822 »$.

Irisarri: Andortei (Moutché, 2010, 181. or.) «IOANNES MIRANDA / ETA IOUANNA HARRI/ET ANDO+RTEICO I/AUN AND*ERIAC 1819»; Irigoinberri (Colas, 1923, 1157. ird.) «E SENNOR DE IRI/8INBERRI */DE AGVERR / FRANCISCO / 1695/IHS».

Ortzaize: Gillantena (Colas, III, 40. ird.) «ESTA. ES / LA. CASA / IAPM/AS. DE/ GVILLANTENA // AGVILA»; Apalasia (Colas, 1923, 1260. ird.) «ESTA ES LA CASA / DE APALASIA/AÑO 1635 / PHARES / APALAS / IVRDANS / d BIDARTE».

Zibitze: Bidart (Colas, 1923, 817. ird.) «ANTON-ETCHE-HANDIP/E -SIEUR + DEBIDA/RT- ANN +O-AFE 1791».

- Zuberoa

Urdiñarbe: Ahetzia (Colas, 1923, 1265. ird.) «AHEZIA / AR( ) / 1783 / Mendez mende jarraikiza / Zaharrek erakutsia / Izena dut Ahetzia / Etche bat naiz idekia».

- Nafarroa Garaia

Anotz (Azkabarte): Beroquia (García Gainza, 1989, V*, 644. or.) «ESTA HIZO JVAN / DE BORDA // ESTA CA+SA DE BERO/QVIA SE HIZO SIENDO DVE/NOS JVAN DE SARASA Y JVANA MARIA DE VILLANVEVA AÑO 1784».

Aranaz: Beltranenea (García Gainza, 1989, V*, 133. or.) «ESTA CASA LLA/MADA BELTRANENEA / YZO AZER HURBANO DE / ZAMORA ESTE AÑO DE 1718».

Doneztebe: Bastallenea (García Gainza, 1989, V**, 590. or.) «A.D.O. / BASTALLENEA / DE / FCI GOYENECHE 1799»; Amasarena Ramonea (García Gainza, 1989, $\mathrm{V}^{* *}$, 590. or.) «AMASA/RENA / RAMO/NEA A 1788».

Eratsun: Juangonea (García Gainza, 1989, V*, 623. or.) «ESTA CASA ES JU/ANGONEA ES / D JUAN DELIZAL/DE IZO PERO D BELAR/RA AÑO 1751 MAESTRO CANTERO».

Etxalar: Castenea (García Gainza, 1989, v*, 569. or.) «CASTENEA REDIFICO / JJ DE PEROCHENA. AÑO 1820».

Ituren: Miguelena (García Gainza, 1989, V**, 46. or.) «ME LLAMO MIGUELENA/N Y SOY DE FRANCISCO YRIARTE / AÑO 1815»; Alberrobarren echea (García Gainza, 1989, V**, 46. or.; Caro Baroja, 1982, IV**, 200. or.) «MAESSE IVAN DE LEGASSA Y MADA/LENA DE ALBERRO VECINOS DE YTU/REN HEDIFICARO HIZIEROM LA CAS/SA LLAMADA ALBERROBARREN / ECHEA EN EL ANNO DE 1612 IHS / IESUS MARIA»; Recaldea (García Gainza, 1989, V**, 46. or.) «ME LLAMO RECALDEA / AÑO 1814»; Juanesenea (García Gainza, 1989, V**;, 46. or.) «JUANESENEA / POR JOSE JOAQUIN / LABAYEN. AÑO 1844».

Labaien: Don Fernandonea (García Gainza, 1989, V**, 178. or.) «SOY DE / DN FERNANDO/NEA».

Larrasoaña: Conderena (García Gainza, 1989, IV*, 376. or.) «CONDERENA / ESTA CASA ES DE PEDRO DE GARAICOECHEA NATURAL / Y VECINO DE ESTA VILLA Y DE PAMPLONA. AÑO DE 1784». 
Legasa: Oteizenea (García Gainza, 1989, V*, 435. or.) «OTEIZENEA AÑO 1900». Lekaroz: Gortaria (García Gainza, 1989, V*, 341. or.) «ESTA CASA SE / LLAMA CORTA/RIA SE QUEMO EL / AÑO 1746».

Lesaka: Yrulecu (García Gainza, 1989, V*** 305. or.) "CASA DE YRU/LECU Y D Jn. J. GOYZUETA / AÑO 1831».

Narbarte: Domingonea (García Gainza, 1989, V*, 439. or.) «DOMINGONEA AÑO 1905».

Urdazubi: Confitervarena (García Gainza, 1989, V**, 685. or.) «VRCEAGA ECHEN / CONFITE RVARENA / 1820».

Urroz (Doneztebe): Mutuverria (García Gainza, 1989, V**, 703. or.) «MUTUVERRIA / REEDIFICADA POR / D JOSE ANTONIO MIGUELENA Y / DOÑA MARIA BAUTISTA ECHANDI / JUNIO DE 1887».

Usi: Azpycoechea (García Gainza, 1989, V**, 168. or.) "AÑO / ESTA CASA LLAMADA / AZPYCOECHEA / SE FABRY/CO SYENDO DUEÑOS / MARTIN JOSE EZCURRA / Y MONICA DE EGOZCUE».

Zia: Loperena (García Gainza, 1989, V** 89. or.) "ME PAREZE QUE ESTOY BUENA / SY ACASSO NO LO SABEN / MI AMO JUAN DE YRIBARREN / YO ME LLAMO LOPERENA / AÑO 1754».

Ziga: Aguerrea. Alcatena. Aldecoa. Arguinaga. Arozarena. Arozteguia. Arraztorena. Arrchea. Arrun/chea. Barazondoa. Berecoechea. Caracoechea. Delizaldea. Dendariena. Echandia. Echeberria. Echeniquea. Echeverria. Gaananea. Gamioa. Goanarena. Goienechea. Ireverria. Irigoien. Iturr(ia). Larraldeandea. Legarrea. Lerabidea. Maiora. Marinea. Mayora. Palacio de Egozcue. Serorena. Soraburua. Suteguia. Yndartea. Yndaverea. Yturraldea (García Gainza, 1989, V*, 341. or.) «PALACIO DE EGOZCUE. SORABURUA. LARRALDEANDEA. ARRUN/CHEA. MARINEA. AROZTEGUIA. YNDAVEREA. GOIENECHEA. ECHE/NIQUEA. IRIGOIEN. BERECOECHEA. SUTEGUIA. LEGARREA. / ECHANDIA. BARAZONDOA. SERORENA. ALDECOA. MAIORA. ARR/CHEA. AROZARENA. ECHEVERRIA. GAMIOA. GOANARENA. / LERABIDEA. GAANANEA. AGUERREA. ALCATENA. IREVERRIA. ARGUINAGA. ITURR(IA). DELIZALDEA. DENDARIENA. / MAYORA. CARACOECHEA./ ECHEBERRIA. YNDARTEA / GAMIOA. YTURRALDEA / AÑO DE 1741 ARRAZ/TOREN/A. ANDR/EAREN»; Etxezuria (García Gainza, 1989, V*, 341. or.) «ETXEZURIA EDIFICADA / POR MARIA FRANCISCA / GARBALENA DE MAÑERU / EL AÑO DE 1851».

Zildotz: Miguelicorena (García Gainza, 1989, V*, 658. or.) «ESTA CASA SE / LLAMA MIGUELICO/RENA Y LA HIZO MIGUEL DE SUES/CUM AÑO 1719».

\subsubsection{Dobela}

- Nafarroa Garaia

Anotz (Ezkabarte): Beltranena (García Gainza, 1989, V*, 643-644. or.) «IHS // ESTA PORTAL/DA LA TRAB/IO IVAN DE CA/MINO POR MAN/DADO DE JVA/NES DE ANOZ Y / MARTIN DE L/ARRAYNZAR / DVENOS DE ES/TA CASA DE / BELTRANE/NA AÑO 1650 / Y FIRMO YO / BELTRAN».

Biotzari: Juliana (Cruchaga y Purroy, 1970, 225. or.) «ESTA OBRA SE Y/ZO EN EL MES DE MA/YO DEL AÑO DE 1748 / JUAN DOMINgU/EZ AMO DE CASA / DE JULIANA Y / ZOLA DE EZqUIETA». 
Eraso: Maticonea (García Gainza, 1989, V**, 7. or.) «ESTA CASA ES MATICON/EA ME IZO ACER MARTIN D URIZA ME IZO TRABA GR / JOS DE ZELAET AÑO 1755».

Gerendiain (Ultzama): Ormechea (García Gainza, 1989, V**, 651. or.) «CASA / ORM/ECHEA / AÑO 1675».

Hiriberri (Aezkoa): Mariato «CASA DE / MARIA-/TO. AÑO / DE / 1842»; ALCAIZARENA «ALCAI/ZARENA».

Ilurdotz: Malezena «ESTA PORTA/LADA IZO/frANCIS/CO DE EPE/LUA ANO/1780/ MALEZ/ENA».

Jaurrieta: Ayarra o (j)andua (Cruchaga y Purroy 1983, 274. or., 195. ird.) «CASA D .../R...F.../AYARRA / O / (J)ANDUA».

Leitza: Totachenea (García Gainza, 1989, $\mathrm{V}^{* *}, 284$. or.) «A ESTA CASA SE LLAMA TOTACHENEA... // AÑO DE 1786».

Urdazubi: Yndianoa baita (García Gainza, 1989, V**, 685. or.) «CASA DE YNDIANOA BAITA AÑO DE 1824».

\subsubsection{Kartela}

- Lapurdi

Ainhoa: Haricelet-Lafaiect (Colas, 1923, 119. ird.) «IHS-MA / MARTIN / DVRUTILE / S(sieur)R D(e) HARICELET-LAFAIE/CT -1641»; Benytene (Duvert, 2017, 19. or.) «CESTE MAIS/ON A ESTEBA / STIEE PAR DO / MINGO DE BER/ROET SIEVR / DE BENYTENE / A FAICT EL AN / 1640».

Kanbo: Vrcvdoy (Colas, 1923, 142. ird.) «PETRI-ET IOA/NNES DE SEMA/RTINS(IEU)RS DE VR/CVDOY- MON- /FAICTE- BASTIR / EN LAN-1618-».

Senpere: Gastambidea (Colas, 1923, 1254. ird.) «LAVRENS DEHI/RIART ET GRAC/ INA DE HIRIGOIEN / SIRE (e)T DAME DE LA / MAISON INFANC/ON DE GASTANBI/DEA-1704».

Ziburu: Gasteluzar (Colas, 1923, 212. ird.) «gASTELVZAR'. D’ ETCHETTO / ET/ MARIE D'HIRIBARREN / 1742»

- Nafarroa Beherea

Aintzila: Ibarretche (Moutché, 2010, 181. or.) «RAMON IRIONDO / MARIA GARRA / "MAITRES* / D IBARRETCHE / "1806"».

Arrosa: Etcheberri (Duvert, 2017, 68. or.) «BERTRAND DELICEI/TS. GRATIANNE IDI/ ART. MAITRES D ETCH/EBERRI DE. BVNVS. FAIT / HARISPE LACARRA»; Orhet (Moutché, 2010, 180. or.) «REFAIT PAR PIERRE / ELISSONDE ET GNE / DUHALDE EPOUX / MAITRES JEUNES / D ORHET EN 1816».

Armendaritze: Mendihy (Moutché, 2010, 181. or.) «FAIT PAR GRACIENNE HARAN/ EUVE ET JEAN LANDERRETCHE / ET ROSITA ARBELETCHE 1909 / MAITRE ET MAITRESSES DE MENDIHY».

Baigorri: Corcavalbehere (Colas, 1923, 331. ird.) «INFA/CON CO/RCAVAL/BEHERE». Bastida: Lafourcade (Colas, 1923, 273. ird.) «1807 LAFOURCADE».

Donibane Garazi: Londresena (Moutché, 2010, 180. or.) «IOANNES DIRIBERRY ET LOVISE DVHALDE / MAITRE ET MAITRESSE DE LA MAISON DE / LONDRESENA 1722».

Eiheralarre: Etcahrt (Moutché, 1923, 179. or.) «IOANNES / DERRECALDE / ET MARGARITA DE / CHURUTCHET MET/RE ET METRESSE D E/TCAHRT». 
Izpura: Çubialde (Colas, 1923, 436. ird.) «IHS HIER/ONYMVS / D IRIART- / 1762 / CUBIALDE / PRESBYTER».

Jutsi: Necueletcheberri (Moutché, 2010, 181. or.) «FAIT. PAR. PIERRE. DE / NECVELETCHEBERRI / SIVR. DE. LA DITE. MAISO/N. JEANNE. MAITRESSE / DE LA. MEME. MAISON. IO/ANNES. OIHEREM. 1784»; Bassart (Duvert, 2017, 10. or.) «FAIT. PAR. JOANNES. SIEVR. DE / BASSART. DE. IUXVE».

Lasa: Meriateguy (Colas, 1923, 324. ird.) «IOANN/ES MA/ITRE D/E LA M/AISON / DE ME/RIATEGUY ET MA/RIA FR/ANCISQUE / D ETCHECHOU/RY MAI/TRESS / EL AN 1770».

Lekunberri: Teillagorria (Colas, 1923, 1264. ird.) «PIERRE 1895 / ETCHELECU / MAISON TEILLAGORRIA / 1792».

Zibitze: Merkabidea (Xamar, 2016, 52. or.) «ECHE. HUNEC. / DUKE. ICENA. M/ ERCABIDE. CIBIS. BERNAT. LORA/NS. ETA. GRAC/ANA. ARANCET / L. AN.1819. EIN.».

- Nafarroa Garaia

Abaurregaina: Elizalde «JUAN JOSEF YLINCHE/TA Y JUAN ANDRES EGUINOA / HICIERON ESTA CASA DE / ELIZALDE AÑO DE 1821».

Arantza: Beltranenea (Caro Baroja, 1982, IV**, 174. or.) «VTOR (vitor)/+ / ESTA CASA LLA/MADA BELTRANENEA / YZO AZER HVRBANO DE / ZAMORA-ESTE AÑO DE 1718».

Arraitza (Zabaltza): Ipasate (García Gainza, 1989, V**, 757. or.) «IPASATE».

Arrieta: Ezkerra (Lopez-Mugartza, 2019, 70. or.) «Se hizo esta casa del Zurdo el año 1831».

Arruitz: Juansarenea (García Gainza, 1989, V**, 216. or.) «ESTA CASA HIZO FRAN/CISCO DE GOLDARAZENA / ES LA CASA DE JUAN SARENE/A HIZO AÑO DE 1769».

Bera: Apezabayta (Caro Baroja, 1982, IV**, 154. or.) «CASA DE APEZABAY/TA REDIFICADA POR / J.M.S. AÑO 1833»; Apeztegvia (Caro Baroja, 1982, IV**, 163. or.) «D APEZTEGVIA+MYGVEL DE ARBVRVA / AÑO+1781»; Arrigaraia (Caro Baroja, 1982, IV** 164. or.) «ARRIGARAIA REDIFICADA / POR JVAN THOMAS DE YRISARRI / Y M TERESA YRIBARREN AÑO 1788»; Elizaldeberriya (Caro Baroja, 1982, IV**, 164. or.) «ELIZALDE+BERRIYA / ARBVRVA+ AÑO 1784»; Gastienea (Caro Baroja, 1982, IV**, 164. or.) «GASTIENEA+REDIFICO / J.J. DE PEROCHENA AÑO 1820»; Maienia (Caro Baroja, 1982, IV**; 163. or.) «MAIENIA + AÑO 1775»; YRISARRI (Caro Baroja, 1982, IV**, 163. or.) «17+79/ YRISARRI»; Vidaburua (Caro Baroja, 1982, IV**, 164. or.) «VIDABURUA+REDIFICO AN/ TONIO ARBURUA AÑO 1823»; Vrtzallenea (Caro Baroja, 1982, IV**; 163. or.) «VRTZALLENEA+REDIFICADA / EN EL AÑO+DE 1783».

Eguaras: Garacoechea (Caro Baroja, 1982, IV**, 373. or.) «ANO- 1747- / ESTA CASA GARACO/ECHEA IZO AZER IVAN / DE ZIA I CATALINA DE ERIZE».

Eltzaburu: Martiñena eta Michelcorena (García Gainza, 1989, V**, 646. or.) «EN MEMORIA DE JOSE YABEN (DE LA CASA DE MICHELCORENA) / Y D MARTIN ERVITI (DE LA CASA MARTIÑENA) / BENEMÉRITOS HIJOS DE ELZABURU A CUYAS EXPENSAS SE SOSTUVO LA ESCUELA PÚBLICA / DE EL AÑO 1795 HASTA EL AÑO 1924». 
Eratsun: Jvangonea (Caro Baroja, 1982, IV**, 271. or.) «ESTA CASA ES JV/ANgONEA ES / DE JVAN DE ELIZAL/De IZO PerO DE Bela / Y AÑO 1751 / MAeStrO CANTerO».

Iribas: Juanane (a) (Colomo Castro) «...RED(IFICO).../JVAN P(EL)IPE DE ASTE.../LA CASA JVANANE(A)... DE ...(GOL)DARAZEN(A)...DE ...».

Leitza: Peryza (Caro Baroja, 1982, IV**, 275. or.) «AÑO DE 1780 / A ESTA CASA SE LLAMA PERYZA / SE LE AÑADIO LA TERCERA PARTE / CON SVS DOS BALCONES POR LOS / DVEÑOS QVE SON JVAN BAPTA DE ZABALETA Y MARIA JOSEFA DE / ECHEBERRYA».

\subsubsection{Lehioburu}

- Nafarroa Garaia

Bera: Yrazoquiverria (García Gainza, 1989, V**; 723. or.) «ANO DE 1731 LA CASA DE YRAZOQUI VERRIA YZO JUAN DE PEROCHENA. AGOSTO 15».

Orkoien: Leonena (García Gainza, 1989, V**, 455. or.) «ESTA CASA SE LLAMA LEONENA / LA HICIERON JVAN FERMIN DE ECHAR/TE Y LORENZA DE ORCOYEN SV / MVJER AÑO MDCCXLIII Y FIRME YO JVAN DE SUESCVN LAVS DEO».

\subsubsection{Beste eraikin batzuk: presa}

- Nafarroa Beherea

Senpere: Camiet (Colas, 1923, 83. ird.) «HAV DA-PRESA-EGINA-MAR:/TIN DE-HIRIART-HELBARV:/N-CAMIET-BALDERNA APEZCEN-VRTHEAN-1705».

\subsubsection{Hilarriak}

\subsubsection{Diskoduna}

- Lapurdi

Arbona: Martiqvet (Zarrabeitia, 2011, 124. or.) «IHS + ESTEVENI DAME DE MARTIQVET / 1620».

Arrangoitze: Cabalcigarai (Colas, 1923, 14. ird.) «CABALC/IGARAI».

Ezpeleta: Domingo pene (Colas, 1923, 160. ird.) «DOMENICH / SOVBELET DO/ MINGO PENE/CO ANDERIA».

Gixune: Menia (Zarrabeitia, 2011, 137. or.) «1822 +++ MENIA».

Itsasu: Harotzarena (Colas, 1923, 168. ird.) «BETIRI (PIERRE) / DE HIRIAR/T S(ieur) R DE HAR/OTZARE/NA».

Kanbo: Curuchet (Colas, 1923, 134. ird.) «SEP(vltv)RE / DE PETRI / DE HARO/ TCHE/NA S(ieu)R / DE CVR/VCHET / 1636».

Lehuntze: Achelecov (Colas, 1923, 23. ird.) «IN (iean?) / C(V)RV/TCHETE / METRE / ACHELECOV / 1734».

Makea: Currut (Colas, 1923, 256. ird.) «CUR/RUT»; Nimaco (Colas, 1923, 258. ird.) «PERRIS (pour Pierre) / D(ominus)S DE NIMACO 1534».

Mugerre: Chouorrenea (Colas, 1923, 25. ird.) «CHOU/OURRE/NEA»; MARICHINIA (Zarrabeitia, 2011, 137. or.) «MArIC/HInIA / 1816»; SERORATEGUY (Colas, 1923, 26. ird.). «SERORA/TEGUY».

Senpere: Alaben (Colas, 1923, 124. ird.) «SEPRE / SEPVLTVR/E DE MART/COT-DE-PERVCHEGV-./SIEVR D / ALABEN / 1669»; Mariatoinea (Colas, 1923, 95. ird.) «PLACA-MARIATOINEA»; MIRICUENEA (Zarrabeitia, 2011, 121. or.) «MIRICUENEA». 
Urruña: Mourguicoa (Colas, 1923, 222. ird.) «MOUR/GUICO-/A»; ETCHECHAHAR (Colas, 1923, 224. ird.) «ETCHE/CHAHAR/1806»; Socuen Bordacua (Zarrabeitia, 2011, 121. or.) «SOCUEN / BORDACUA».

- Nafarroa Beherea

Aiherra: Harguinchumia (Zarrabeitia, 2011, 137. or.) «+HARGUIN/CHUMIA».

Altzumarta: Apostegvy (Colas, 1923, 763. ird.) «HIC IACET MARIA DOMINA DOMVS D APOSTEGVY 1624»; LABIN (Colas, 1923, 762. ird.) «HIC IACET MARIA DOMINA DOMVS DE LABIN 1615».

Amenduze: Seroracova (Colas, 1923, 618. ird.) "MARIE DE ELICABIDE SERORACOVA»; Acciriet (Colas, 1923, 620. ird.) «MA / ICI GIST IOAN SIEVR D ACCIRIET MORVT LE / 5 ME DE / MARS / 1649».

Amorotze: Berhovet eta Hvlondo (Colas, 1923, 625. ird.) «DOMINO E(T) DAVNE DE BERHOVET E(T) HVLONDO 1623»; Beroft (Colas, 1923, 626. ird.) «EEDN SIEVR DE BEROFT 1635».

Arboti: Donna Marie (Colas, 1923, 632. ird.) «CI GIST / JOAN MAIS/TRE DE DO/ NNA MARI/E D ARBO/VET».

Azkarate: Maziariena (Zarrabeitia, 2011, 118. or.) «MAZIA/RIENA».

Banka: Suiarinchahar eta Etchechoto (Colas, 1923, 278. ird.) «1784 / manais / souh/ourou-suiar/inchahar / etco Jauna / marie / orsafr/in aldu/deco etchotoco alaba».

Behauze: Bitarrvi (Colas, 1923, 644. ird.) «YCY CIST IEANA-DE BEHERE-DAME DE BITARRVI-MOVRVT-LE-21-IVIN-1627-».

Behorlegi: Uhalde (Colas, 1923, 451. ird.) «+IHS / MARIA SEN/ORA DE VH/ALDE». Bithiriña: Etchebey (Colas, 1923, 652. ird.) «IHS / ICY- A ETE- ANX/EVELI-GVILLEN / DE LAN-DETCHEBEY- LE 9 + / DECHAMBRE 1700»; OBILVE (Colas, 1923, 670. ird.) «I.N.R.I. / 1629 / IESVS / MARIA / ICY G(ist) ... HARAMBVRV DAME OBILVE MOR/VST LE 26 IV/ILLET»; ( )Ellaigvibel (Colas, 1923, 656. ird.) «ICY GIST/(1)E CORPS DE / (m)ARIA DAM DE/( )ELLAIGVYBEL/(q)VY DECCEDA / (1)E 11 DE FEBRI/ER $1656+»$.

Bizkai: Mendibure (Colas, 1923, 732-733. ird.) «ICI GYST GRATIANE // MAISTRAISE DE MENDIBVRE-/1684»; Mendiburv (Colas, 1923, 730-731. ird.) «ICY GIST IONNES D IRIGOIN- // MAISTRE DE MENDIBVRV-/1684»;O8BACV (OXAPACVI?) (Colas, 1923, 734. ird.) «HIC IACET (cathali)NA DE NEHOROBIA DAME DE O8BACV»; Viscaieche (Duvert, 1985, 23. ird.) «CATALINA DE BELEBET DAME DE VISCAIECHE O3 / 16.14».

Burgue-Erreiti: Aphate (Zarrabeitia, 2011, 135. or.) «MARIE ME D- L- MAISON APHATE DECEDE: Ele 10/SEPTE / DEL 1696»; Petricha (Colas, 1923, 237. ird.) «MARIE D CASENAVE HERITIERE D LA M(aison) D PETRIC-/HA -DECE-DA LE $15^{\circ}$ SEP(TEM)BRE $1702 »$.

Gamoue-Zohazti: Illardo (Colas, 1923, 693-694. ird.) «+ CATHARINE DAME // DE / ILLARDO / 1682».

Gamue: Voriena Borda (Zarrabeitia, 2011, 118. or.) «VO/RIENA VORDA / 1860 »

Garruze: Ginhart (Colas, 1923, 708 ird.) «YCY CIST CATERINE DE CHORIVIT DAME (d)E GINHART M-T (mourut) / LE 29 DE / MARS 1630»; Iriartevi (Colas, 1923, 711. ird.) «CI- GIT- LE- CORPS DE MAISTRE- GVIEeM- D IRIARTE- 
VI- MOVRVT- Ee- 27 DE IV / IEEeT 1629»; Merchot (Colas, 1923, 716. ird.) «MENAVT HERITIER DE MERCHOT MOVRVT / LE 2-DE / IVLLIET / 1634».

Heleta: Garat (Colas, 1923, 587-588. ird.) «HIC IACET GRACIANA FILLA / DE GARA/T QVE / 1633».

Iholdi: Echegoihen (Duvert, 1985, 50. ird.) «1696 / HIL IA/CET IO/ANNA / DE CHIMONDEI D/NA D ECH/EGOIHEN».

Irulegi: Mazia (Zarrabeitia, 2011, 118. or.) «MAZIA».

Landibarre (Behaune): Vhalde (Colas, 1923, 871. ird.) «...D (omi)NA DE / VHAL/ DE HIC(I) / ACET 16( )».

Landibarre (Saint Etienne): (Ar)cubi (Colas, 1923, 884. ird.) «Z. Ri BEIZIAT (ar) CVBIqVO. SEMIA HEBEN DACA OXaili/IAREN BORS / GVERRENIAN / 1626».

Landibarre (Saint Martin): Lapitz (Colas, 1923, 889. ird.) «GRAC/IANA D/AME DE L/APITZ / 1666»; Garate (Colas, 1923, 890. ird.) «GARATECO I(lh)ERRIAN + TRISTAN: DE HEIRABIDE: / DACA: BE/RIAN: 1644».

Lekunberri: Lacabaraseo (Colas, 1923, 449. ird.) «CI GIT MARGARTE SORORA M(aitress)E D(e) LACABARASEO 1636».

Martxueta: Movthilleneco (Colas, 1923, 768. ird.) «IHS/CHVRVCE-HA/V-EGVIN DUT-/MOVTHIL/LENECO/(hil)HER(ri)A»; Giscaie (Colas, 1923, 779. ird.) «T / IHS MARIA / ICI ETE EN/SEVELI LE COR/S DE GRASI/TANE D-/EGIS/CAIE // ARHCUS».

Mehaine: Olloqvi (Colas, 1923, 522. ird.) «PELENAVT / BASAGAIZ / SENOR / DE OLLOQVI / 1601»; O(LLO)QVI (Colas, 1923, 523. ird.) «HIC IACET MARIA DE O( )quI + 1631»; Uhalde (Colas, 1923, 530. ird.) «IOANNE/ S D-NS(dominus) D UH/ALDE- HIC IA/CET- 1668».

Ortzaize: Apalas (Colas, 1923, 337. ird.; Zarrabeitia, 2011, 130. or.) «1651 LA / SENORA / DE APALAS».

Ostankoa: Ecaidu (Duvert, 1985, 5. ird.) «INRI/1656/IESUS/MARIA / + CI GISIT LEG( )DO SIEVR ECAIDV».

Izura-Azme: Mosnias? (Colas, 1923, 825. ird.) «DOMINe De MOSNIAS NAS».

Sarrikota: Elischabere (Duvert, 1981, 5. ird.) «IESVS MARIA IOEPH 1618 // IEAN D ESClAVS MESTRE D ELISCHABERE»; Samacoa (Duvert, 1981, 4. ird.) «IESVS MARIA 1618 // MARGUERITE DAVNE DE SAMACOA»; Samacois (Duvert, 1981, 4. ird.) «IESVS MARIA 1618//ARNAVD DE BECHINDAR (i)S NE DE SAMAC(ois)»; Samacoits (Colas, 640. ird.) «CATHERINE MAISTRESSE- DE SAMA/COITS»; Samacoits (Colas, 1923, 641. ird.) «IEAN DE BICHADARITS MAISTRE- DE SAM/ACOITS».

Urepele: Landarte (Colas, 1923, 277. ird.) «LANDARTEKO HOBIA 1805».

Zohazti: Echart (Colas, 1923, 702. ird.) «(ci) GIST LE CORPS DE DAMA DE ECHART/ INRI / 1639 / IESVS/MARIA».

- Zuberoa

Ainharbe: Bernadeco Petarhan (Colas, 1923, 1007. ird.; Zarrabeitia, 2011, 119. or.) «ERNAVT S(einev)R SEP(ulture) DE LA MAISVN DE BERNADECO / PET-ARHAN»; Habia8ve (Colas, 1923, 1012. ird.) «IC(I) (GIT)? ABARINE D 8OLIBRE DAME D’ HABIA8VE: 1616»; Vhaltx (Colas, 1923, 1017. ird.) «V( ) MEN DONNE D VHALTX / DECEDA LE...». 
Berroeta: Haran (Colas, 1923, 1088-1089. ird.) «CV GIT LE COR/PS DE IEANNE/DETCHEVERRY/DAME DE LA / NOBLE MAISON / DHARAN MO/RTE LE 18 DOCT./1741».

Erango: Oxapacvi (Colas, 1923, 233. ird.) «HEC IACET EXPAN OLEBELERE OXAPACVI C2X8».

Eskiula: Chabalgoiti (Colas, 1923, 1076. ird.) «chaba/lgoiti».

Larrori: Dana Iesaro (Colas, 1923, 1061. ird.) «ICI GIST-AR-DG-M-DANA-IESARODECEDE+ / LE 26 DE / MAR-1647».

Mendibile: Mendebiv (Colas, 1923, 1058. ird.) «har(r)I D MENDEBIV 1655».

Mitikile: Dana (Colas, 1923, 1063-1064. ird.) "(ci) GIT MARIE DE IROLLE DONNEDE / DANA // IHS / MA / LAQVELLE DECEDA ( ) IVILLET-1633+».

Ürrüstoi: Oihenart (Colas, 1923, 1023-1024. ird.) «BERNAT D ASCONEGVI S(IEV) R OIHENART A FACT $\mathrm{x} / / \mathrm{IHS}$ / MA / FAIRE CE CROIS POVR LVI MESME EN L AN 1628»; SVNHARI (Colas, 1923, 1025-1026. ird.) «(gra)CIANNE DECHARIPO DONE DE SVNHARI / IHS MA / 1627 / PAR DE / LASALE».

- Nafarroa Garaia

Etxalar: Apezegia (Apezetxea, 2016, 46-47. ird.) «APEZE/GIA»; ARANCHIPIA (Apezetxea, 2016, 57-58. ird.) «ARAN/CHIPI/A»; Vrrutia (Apezetxea, 2016, 59-60. ird.) «VRRU/TIA»; ARMIIS (Apezetxea, 2016, 18-19. ird.) «ARM//IIS»; Arrehea (Apezetxea, 2016, 14-15. ird.) «ARR//EHEA»; Barberenia (Apezetxea, 2016, 8-9. ird.) «BARBER//ENIA»; Betrisancena (Apezetxea, 2016, 40-41. ird.) «A A 1728 // BerrISA/nCenIA»; Bidazerdia (Apezetxea, 2016, 10-11. ird.) «BIDA/ZEr//DIA»; Borda de Maritorena (Apezetxea, 2016, 154. ird.) «BORDA DE MARITORENA / TRES SEPULTURAS+»; Cacalana (Apezetxea, 2016, 34-35. ird.) "CACALANA A/NO de 1729»; Catalinsansinena (Apezetxea, 2016, 32-33. ird.) «CATAlINSA/nSInenA / Ano dE 1729»; Danvoriena Borda (Apezetxea, 2016, 124-125. ird.) «SE/PULTU/RA DE / DA/N/ VO/RIENA / VORDA / 1860»; Domecuenia (Apezetxea, 2016, 132-133. ird.) «SE/PULTU/RAS DE B/AUTIST/A ARIZTE/GUI / DUENO / DOMEC/UENIA»; Don Paula (Apezetxea, 2016, 36-37. ird.) «don PAULA / Ano de 1729»; Echeberia (Apezetxea, 2016, 150. ird.) «SEPU/LTURAS / DE ECH/EBE//RIA 2»; Elizaldega (Apezetxea, 2016, 137-138. ird.) «ELIZ/ALDE/GA // RA/YA DE/ 1860»; Errandonia (Apezetxea, 2016, 26-27. ird.) «ERRA/ND//ONIA»; Errotagaraya (Apezetxea, 2016, 44-45. ird.) «ZD NO // E( )OTA/CARAYA/ANO»; PERUENA (Apezetxea, 2016, 5. ird.) «Peru/ena»; Ezcurreverea (Apezetxea, 2016, 143. ird.) «EZCV/RREVE/REA:BA 13»; GUANEHEGARAIIA (Apezetxea, 2016, 12-13. ird.) "GUAN/EhEG//ARAIIA»; INARIA (Apezetxea, 2016, 144-145. ird.) «+1859 / inARIA»; Jalanena (Apezetzea, 16, 17. ird.) «JALA//NEN/A»; La Borda de Arechea (Apezetxea, 2016, 140. ird.) "LA BO/RDA DE/ARECHEA / AÑO 1860»; Larrasayes (Apezetxea, 2016, 6. ird.) «LARRA/SAYES»; Maestrunea (Apezetxea, 2016, 155-156. ird.) «MA/ESTR/UEN» «MA/ESTR/ UENE/A»; Marichinia (Apezetxea, 2016, 55-56. ird.) «MArIC/HInIA / 1816»; Marimiguelena (Apezetxea, 2016, 135-136. ird.) «IJO DE // 1729 MAIMIGUE/LENA»; Marisquerena (Apezetxea, 2016, 24-25. ird.) «MArISqVE// rENA»; Marticonea (Apezetxea, 2016, 152. ird.) «SEPUL/TURAS DE MAR/ 
TICO/NEA»; MARTINTONIA (Apezetxea, 2016, 28-29. ird.) «MAR/TINT// ONIA»; Mugerdia (Apezetxea, 2016, 48-49. ird.) "MVG/ERDI/A»; Peruenea (Apezetxea, 2016, 53-54. ird.) «SEPUL/TURAS/DE PE/RUE//NEA 2 AÑO DE 1860»; Olagaraya? (Apezetxea 61-62. ird.) "OLA ( )/ARA ( )/A»; SANJUANENA (Apezetxea, 2016, 30-31. ird.) «SANjXAN/eNA ANO / De 1729»; Slaberia (Apezetxea, 2016, 7. ird.) «SLABE/Ria»; Tolaria (Apezetxea, 2016, 38-39. ird.) "tOlArIA / MAnUeL / ANO de 1729»; Tomasena (Apezetxea, 2016, 139. ird.) «AÑO / 1860/tOM/ASENE/A»; Tomasena (Apezetxea, 2016, 22-23. ird.) «TOM//ASENA»; Tomasena (Apezetxea, 2016, 146. ird.) «toma/ sena / ano / 1860»; Sansinena (Apezetxea, 2016, 149. ird.) «SANSINENEA / 1860 +»; Vparreagerrea (Apezetxea, 2016, 20-21. ird.) «VPAR/REA//GERREA»; Urrutia (Apezetxea, 2016, 128-129. ird.) «URRU/TIA//N 263 i 4»; Ycsebino (Apezetxea, 2016, 42-43. ird.) "yCSeBI/No».

Lintzoain: Martinotena (San Telmo Museoa, 1991, 48. or.) «MAR/TINO/TENA// AÑO DE 1843»; Khasarana (San Telmo Museoa, 1991, 49. or.) "KHASA/ RENA//AÑO 1843».

Luzaide: Doraya (Frankowski, 1920, 125. or.) «A 1605 // DE CASA DORAYA» (berrerabilia); Hunaiyaingo (Frankowski, 1920, 125. or.) «HUNAIYAINGO / HILARRIA / 1672» (berrerabilia); Vichcaya (Frankowski, 1920, 125. or.) «JUANA / SALABERRI / DE CASA VICHCAYA / RIP»; YRIBARNE (Frankowski, 1920, 125. or.) «1721 YRIBARNECO HILARRIA».

Urdazubi: Yturraldea (Colas, 1923, 1144. ird.) «YTUR/AL/DEA».

\subsubsection{Gurutzeak}

- Lapurdi

Kanbo: Alainenia (Zarrabeitia, 2011, 121. or.) «ALAINENIA».

- Nafarroa Beherea

Ahatsa: Elissagaray (Colas, 1923, 1166. ird.) «MO(nsieu)R DE / EL/IS/SAGAR/AY 1785».

Arboti: Echeto (Colas, 1923, 631. ird.) «ICY/EST/LE SEPVLCHRE/dES CORPS HU/ MINS / DE/CHE/TO/1709».

Baigorri: Amoctogvi (Colas, 1923, 326. ird.) «17/32/AMOCT/O/G/VI».

Bidarrai: Pierreseneco (Colas, 1923, 383. ird.) «PIERreseN/eCO DA 1768»; Petrisco (Colas, 1923, 386. ird.) «IHS (I)OANES M/ANO ET MA/RIA DE FER/ANIO / DEL / AMAI/( )ON D/E PETR/IFCO»; Betiriscoena (Colas, 1923, 1226. ird.) «MARIA IANAI / BETIRISCOENA / 1789».

Donaixti: Bihurri (Colas, 1923, 846. ird.) «HIC / IACE/T-IONNA DO/MIN.NA DE B/ IhURR-I/ieSUS/X MA».

Donapaleu: Saint Payine (Colas, 1923, 753. ird.) «IHS / MAIST(r) /E IOAN/NES -D/ ESTILLART-OVVRIE/R DE LA -MONNO9E- DE S / PALAIS-E-SIEVR DE LA / MAISON-DE-STPAYI/NE-D/ERED/A-LE 7/E (septieme) MAY / IESVS / MARIA».

Ibarrola: Echepare (Colas, 1923, 791. ird.) «IHS / NOBLE / BERNART DE / LA SALA DE ECHEPARE».

Iholdi: Oyhanarteco (Colas, 1923, 553. ird.) «HE/ME-/N DA MARIA/OYHANART-/ EC-O A-NDER-IAREN // OY-/HA-/NARTECO/ILHERRIA». 
Mehaine: Ouilicategui (Colas, 1923, 512. ird.) «MARIANNE GARAT/ OUILICATEGUI / ANDERIA / SORTMIA / URRIAREN / 31AM 1761AM».

- Zuberoa

Ainharbe: Habiagve (Colas, 1923, 1004. ird.) «IHS / MARIA / CI gIS / FE AT / PER ARNAAT DOhIARS / ET CATALINE SA FA/ME / S(ieu)R ET DAME DE HA/BIAgVE».

- Nafarroa Garaia

Arizkun: Pordoñenea (Pérez de Villarreal, 1986, 34. ird.) «PORDOÑENEA»; BYDEGAÑEA (Pérez de Villarreal, 1986, 35. ird.) «SE/PUL/TURA / DE BYDE/GAÑEA $1930 »$.

7.2.7.3. Jarlekua edo sepultura

- Lapurdi

Ahetze: Harretche (Colas, 1923, 33. ird.) «HILLERRI: HAV HARRE-TCHECOA: DA. 1659 ».

Ainhoa: Gascoinarenia (Colas, 1923, 126. ird.) «SEPULTURA- LARRONDO- MIGUEL-/LAPEIRA/MARIA-/MARTINA/DERIZE-/GASCOI-/NARENIA/1804».

Azkaine: Harispea (Colas, 1923, 197. ird.) «+BERTRAN- D VRRITZAGVE- ESTDECEDE: LE- VNNIESME- DE- NOVEMBRE-1649 / EST-EN/TERRE / AV PNT / MONV/MENT / DE HAR/ISPEA *»; Ascain Errota (Colas, 1923, 195. ird.) «SEPVLTV/RE DE AS/CAIN ER/ROTAA»; Cethaberen eta Ascain Errota (Colas, 1923, 193. Ird.) «CETHAB/ERENECO / THONB/ATIC-HV/NARAIN/OCOAC-A/ SCAIN-ER/ROTACO/AK- DIRA»; Haranibar (Colas, 1923, 200. ird.) «+++ IZOZAGVERRE-MARTISSANS- DE HARA(n)IBAR- A- ESTE-DECEDEZ 9 / MARS 1592»; Indiano Iaunarena (Colas, 1923, 201. ird.) «+HAV-DA-THOMBAMIGVEL-D-ARRAIOAGA-AZCAINGO INDIANO-IAUNARENA- HILLA / OCTOB/ REREN / 22+ 1651»; Larochoreneqvo (Colas, 1923, 199. ird.) «+MIGVEL DETECHEVERZ LAROCHORENEqVO SEPVLTVRA DE HAV EGUIN/A 1692»; $M i$ geleneco (Colas, 1923, 194. ird.) «MIGELENECO / THOMBA».

Bidarte: Garaicoetchea D Ardagaray (Colas, 1923, 207. ird.) «MONV/MENT/ DE LA MAIS-/ON-DE / GARAICOET/CHEA/D ARDA/GA-RAY/1740»; Bvtvreneco (Colas, 1923, 204. ird.) «HAV DA BVTVRENECO IARLEQVBA»; Lafargva (Colas, 1923, 205. ird.) «ESTA: SEPVL/TVRA-DE - AD/AME-D-LAFARGVA-DELAN-1512».

Ezpeleta: Aguerre (Colas, 1923, 148. ird.) «JOANES BEL/TZAGUI ETA / MARIA OLHA/ GARAI SENAR / EMAZTE AGU/ERRECO JAUN/ANDEREN THU/MBA 1784»; Bidartenia (Colas, 1923, 148. ird.) «IHS MA SEP(ultv)RE DE FEV IOAN/NES DE BIDART M(aitr)E / MARTINETIER- ET / MARIE DIHARASSARRY- SA VEFUE S(IEU) R / ET DAME DE BIDART/ENIA-ET-PO(V)R LEURS / SVCCESSEVRS- PAR / ELLE FAICTE- FAIRE LE 8 E AVRIL 1645 / PASSANS PRIES DIEV / PO(V)R LES FIDELLES TRESPASSES»; Gastambide (Colas, 1923, 147. ird.) «IHS MA SEP(vltv) RE DE PIERRE DE LISSERR-AGVE CHARPENTIER M(AITR)E DE LA MAISON DE GASTAMBIDE- / A LAN- DE- G-/RACE 1718 / PRIES- DIEV / POUR- LES- AMES».

Haltsu: Etcheberria (Colas, 1923, 57. ird.) «SEP(ULTU)RE DE M(aitre)/BERNARD/ HARRIET/CONSEILLER / ET MEDECIN /DV ROY / SR DE LA / MAISON / DETCHE/ 
BERRIA/1771»; Migeletchegai (Colas, 1923, 55. ird.) «MARTIN-DIS/TIARTCATA/LINA-DELICA/LDE-MIGELETC/HEGAICO-TUM/BA-FAIT 1767».

Itsasu: Larrondo (Colas, 1923, 172. ird.) «IHS MA SEP(VLTV)RE- POVR- MARTINDE- LARRONDO: ET. FRANCEISE- DE: S MARTIN- CONIONTS: SIEVR ET DAME / DE LA MAISON / NOBLE ET / INFAÇONE / DE- LARROND/O-DITXATX/OV. 1729».

Kanbo: Bassusena eta Larreburua (Colas, 1923 137. ird.) «IHS MA SEPVLTVRE DE- LA- MAISON DE BASSVSENA ET CELLE DE- LARREBVRVA-DE CAMBO QUIA- ETE / FAIT A / LANNEE / 1724».

Larresoro: Hirigoyena (Colas, 1923, 66. ird.) «IHS MA SEP(ultu)RE- DE POVRM(AÎTR)E- IEAN DAGVERRE NO(TAI)RE-ROYAL ET MARIE- DARQVIE-CONOINTS M(aitre)E ET MAISTRASSE / DE HIRIGO/YENA- DV P(rése)N/T- LIEVDE - L/ARRASSO/RE 1709»; Lariscoa (Colas, 1923, 64. ird.) "IHS MA SEP(ULTU)RE DE MO(?):PO(u)R M(aîtr)E CHARLES DE TEILLERIE PCESTRE (prètre) DE LA MAISON- DE LARISCOA-DV- P(rése)N/T- LIEV- DE/LARRESSO/ RE $1710 »$.

Sara: Arriaga (Barandiaran, 2000, 181. or.) «HARRIA/GACO IA/RLEKHU/A»; Arrosagarai (Barandiaran, 2000, 181. or.) "ARROSAGA/RAICO- IAR/LEKHUA / 1721»; Arrosagarai (Colas, 1923, 188. ird.) «ARROSSAGA/RAICO-IAR/LEKUA/1791»; Axular (Colas, 1923, 187. ird.) «MONVMENT- / DE- MESSIEVRS- / DAXULAR- / ONCLE- ET- / NEPVEV- / DIGNES- CVRES / DE- CE- LIEV- / DESCEDERENT/EN- LAN-/1644- ET- 1653»; Baratcharte (Barandiaran, 2000, 181. or.) «BARACHARTECO I/AR-LECCVA ETA / EMANA- HARRIA / 1707»; Cvelbehere (Barandiaran, 2000, 181. or.) «CVEL/BEHE/RECO / IARLE/CKHVA / 1707»; Cubieta (Barandiaran, 2000, 181. or.) «CVBIETACO / IARLEKUA»; Harriaga (Colas, 1923, 189. ird.) «HARRIA/GACO IA/RLEKHUA»; HAROZARENA (Barandiaran, 2000, 181. or.) «IHALARRE / HAROZARE/NECO IARLE/ CHVA 1723»; Lehenburu (Barandiaran, 2000, 181. or.) «LEHEN/BURUC/O IARL/EKHUA»; Mendiondo (Barandiaran, 2000, 135. or.) «IHS / MENDIOND/ OCO SEME/C HAR/IZMEN/DI APEZAC»; Moscorrondo (Barandiaran, 2000, 181. or.) «MOSCOR/RONDOCO / THOMBA / DA HAU»; Teileria (Barandiaran, 2000, 181. or.) «TEILERI/ACO IA/RLEKHV/A».

Senpere: Çugarret (Colas, 1923, 87. ird.) «+MARTIN-DEMOLERES-SIEVR-DE-ÇUGARRET-DECELELE-18-DA-DOCTOBRE»; Lasau (Colas, 1923, 91. ird.) «+LASAUCO SEPVLTVRA»; Etchechuria (Colas, 1923, 103. ird.) «LA-/SEPV/LTURE/-DE-/ ETCHE/CHUR/IA»; Iranaçabalarenea (Colas, 1923, 82. ird.) «IHS-MARIA- ICI DECEDE DOM(i)NGO-D EREBE SR(sieur) DE IRANAÇABALARENEA-MARI D IANA (de Jeanne) DHAMBILA LE DIX-NEHUEME DE JUILLET +1651»; Isabeleneco (Colas, 1923, 93. ird.) «IOANES DESCLAU-ETA MARGARITA-ISABELENECOALABAREN-»; Moniuscorenecoa (Colas, 1923, 95. ird.) «MONIUS/CORENE/ COA-»; Mariatorena (Colas, 1923, 81. ird.) «-DAMOTZ-V(rrutia)DECEDA LE29 D(O)CTOBRE 1566 +CY GIST-CATERINA DOLABARATS DAME DE MARIATORENA-DECEDA-28 MAY 1661. M(aitr)E-I-DE HABANS-NOT(ai)RE ROYAL-8-DE LAD(ite)- MA(is)ON- DECEDA-LE-26-DE-MAY-1672».

Urkodoi (Azparren): Bonalde (Colas, 1923, 252. ird.) «ICI LA SEPVLTVRE DE LA MAISON DE BONALDE QVE LE SEIGNEUR RECOIVE CEV/X QVI -Y SO/NT ET SERONT EN/TERRES / DANS SA / GLOIRE A/MEN FAIT / LAN DE GR/ACE 1744». 
Ustaritze: Aguerre (Colas, 1923, 104. ird.) «IESUS MA/RIA-IOSE/PE-BAL/IA-DIBA/RAGVE/RRECO/SEPVLT/VRA»; NAGILA (Colas, 1923, ird. 105) «IHS / NAGILA». Zuraide: Errecarte (Colas, 1923, 192. ird.) «SEPVLTVRA / ERRECARTE/COA. 1727/ DADOM18 / DESE8VRA/RENA (Miguel de Segurarena)».

- Nafarroa Beherea

Irisarri: Larralde (Colas, 1923, 377. ird.) «PLACE ATTRILLE A PIERRE / LARRETEGUI. I- IZABEI CAR/ACOIT.S MAITREE MAITRE/SSE DECEDE DE LARRALDE IRISA/ARRI. $1717+++»$.

Jutsi: Larramendy (Colas, 1923, 794. ird.) «CY GIT-ANGEL/IQVE-DARBER/ATXDAME-DE / LARRAMEND/Y-DECEDEE-L/E 27-OCTOBR/E: 1750-».

Landibarre (Saint Etienne): Harambvrv (Colas, 1923, 882. ird.) «HIC (iac)ET MARIA / DE SIAINE DOMINA / HARMBVR( ) / (1)E 9 APRIL- / ( ) / 1663»; HARAN$B V R V$ (Colas, 1923, 880. ird.) «HIC IACET CORPV/S NOBILIS IOAN/NIS DOMINI d HA/RANBVRV OVi OB/IIT DIE 13 AEBRV/ARII ANNO DOMINI MEMEN/TO MORI / 1734»; Soccaro (Colas, 1923, 873. ird.) «NOBLE- MA/RIA- DAME- DES SALLES DE / SOCCARO-ET / S+ ETIENNE / A ESTE- ENTE/RREE- ICI LE 3 / FEVRIER 1711».

- Zuberoa

Ainharbe: Ber(n)adeco Petharan (Colas, 1923, 1007. ird.) «ERNAVT S(ieu)R SER(seigneur?) DE LA MAISVN DE BER(n)ADECO PETHARAN».

Lexantzü: Domec (Colas, 1923, 970. ird.) «METRE JEAN DE LASALE CHANOINE DE SAINTE ENGRACE ET PRÉBENDIER DE LA MAISON DE DOMEC».

- Nafarroa Garaia

Amaiur: Arozare(na) (Totorikagoena, 2013, 1. ird.) «SEPVLTV / AROZARE»; Arozarena (Totorikagoena, 2013, 27. ird.) «ESTAS/SEPVLTV/RAS SON DE / AROZARE/NA ANO 1718»; Echebercea (Totorikagoena, 2013, 18. ird.) «SEPVL/ TVRA DE / ECHEBER/CEA-1717».

Arizkun: Anchorena (Totorikagoena, 2013, 21. ird.) «S.P.A. (sepultura) / DE / ANCHO/RENA»; Joanhetar(en) a (Totorikagoena, 2013, 17. ird.) «JOANHE/TAR( ) A»; Mariber(z)enea (Totorikagoena, 2013, 2. ird.) «MARIBE( ) / ZENEA»; Palacio de Vrsva (Caro Baroja, 1982, IV**, 246. or.) «DEL PALACIO DE. VRSVA»; Sastrearena (Caro Baroja, 1982, IV**, 261. or.) «ESTAS / SEPVL/TVRAS / SON DE / ASTRE/ARENA / 2»; Ynda (Caro Baroja, 1982, IV**, 261. or.) «ESTA SE(pvltv) /RA ES DE / LA CASA / DE YNDA / 1»; Yndatea (Totorikagoena, 2013, 4. ird.) «YNDA/TEA»; Yreberria (Totorikagoena, 2013, 5. ird.) «S.P.A. (SEPULTURA)/ES DE YR/EBERRIA.»; Zabalarena (Totorikagoena, 2013, 3. ird.) «ZABA/LARENA».

Elortz: Erl(a)rena (Caro Baroja, 1982, IV**** 68. or.) «EST( ) E/PVLTV/RA ES / ( ) $\mathrm{ERL}($ )/( )ENA / ANO / D( ) / (1)741 + +».

Erratzu: Borda (Totorikagoena, 2013, 15. ird.) «ESTA-SE/PULTURA / ES DE LA / CASA-DE / bOR-dA»; Echeniqverena (Totorikagoena, 2013, 35. ird.) «ESAS DOS / SEPVLTV/RAS SON DE / ECHENI/QVERENA».

Etxalar: Isastia (Apezetxea, 2016, 159. ird.) «2 SEPUL/TURA / DE / ISAS/TIA / RIP». 
Gazolatz: Larracea (García Gainza, 1989, V*, 509. or.) «ESTA SEPULTURA ES DE / IOHAN DE ASIAIN HIJO / DE LA CASA LARRACEA / DE IHOANA DE GAZOLATZ / SU MUGER I DE SUS HE/REDEROS EL QUOAL MORIO / A VII DE IULLLIO MCVVIII / ELLA A XV DENERO MCVXVI».

Iheltz (Lizoain): Miguelena (García Gainza, 1989, V*** 83. or.) «ESTA SEPULTURA ES DE LA CASA DE MIGUELENA CUIO DUEÑO ES MARDE ARMENDARIZ AÑO $1742 »$.

Zubieta: Irigoien (Caro Baroja, 1982, IV**, 209. or.) «ESTA SEPA / ES DE LA CASA / DE IRIGOIEN / AÑO 1694».

Zugarramurdi: Catalenea (Peña Santiago, 1999, 248. or.) «ESTA SEPV/LTVRA ES DE / LA CASA DE / CATALENE/A( )EA ANO / DE 1784».

7.2.7.4. Mausoleoa

- Nafarroa Garaia

Burlata: Benitorena (Colomo Castro) «LA EXC(elentísi)MA-/DIPUTACION- / DENAVARRA / AL INSIGNE MAES-/TRO-COMPOSITOR-Y- MUSICÓLOGO-D- / MIGVEL / HILARION / ESLAVA / ELIZONDO / HIJO-ESCLARECIDO- DE-ESTE-LVGAR- DE- / BURLADA / A Casa Benitorena 21 octubre 1807 / W Madrid 23 Julio 1878».

7.2.7.5. Tabularra buru kurbaduna (XIX-XX)

- Nafarroa Garaia

Abaurregaina: Casa Remondegui (Colomo Castro) «+ SEPULTU/RA DE CA/SA REM/ ONDEGI».

Azpilkueta: Iribarrenea Borda (Pérez de Villarreal, 1986, 39. ird.) «+BORDA / IRIBARRENEA»; Lapitzea (Pérez de Villarreal, 1986, 40. ird.) "CA-SA / LAPITZEA»; Posada (Pérez de Villarreal, 1986, 36. ird.) «posada R.I.P».

Etxalar: Berruta (Apezetxea, 2016, 158. ird.) «SE/PULTU/RA DE / CASERIO / BERRU/ TA AÑO / DE 1888».

Garralda: Bizcai (Colomo Castro) «SEPUL/TURA / DE BIZCAI».

7.2.7.6. Tabularra

- Lapurdi

Ainhoa: Esponda (Colas, 1923, 127. ird.) «IHS / ( )PONDACO/SEPVLTVRA/MARTIN DE/GOIHENETCHE/ETA-MARIA/DESEGVRA/EGUINA 1685»; Chaparreria (Totorikagoena, 2013, 20. ird.) «( )MIG( ) / DE PEIRE / S(iev) R DE CHA/PARRERI/A 1643»; Murua (Colas, 1923, 125. ird.) «MURUA»; Quiquerenborda (Colas, 1923, 120. ird.) «QUIQUERENBORDA».

Ezpeleta: Apestegvi (Colas, 1923, 163. ird.) «( )EP(VLTV)RE DE / ( )IERE DO/LLAGARAI / MARTINE / DOLLAGA/RAI-SIVR / ET- (dame) D APES/TEGVI-1719»; Aphestegvy (Totorikagoena, 2013, 15. ird.) «SEP(vltv)RE / GARATI/ANA DAM/E DE APHES/TEGVY / 1668»; Etchegaraya (Colas, 1923, 157. ird.) «SEP(ultu)RE / DE LA MAISON / DETCHE/GARAYA / 1686»; Gvelariarena (Totorikagoena, 2013, 16. ird.) «BETIRI / DE S(ieu)R DE / GVELAR/IARENA / 1633».

Haltsu: Celhay (Colas, 1923, 59. ird.) «SEP(vltv)RE DE I/OANNA. D/E. HIRIAR.T / DAME DE. C/ELHAY / 1676». 
Itsasu: Itvrchoco (Colas, 1923, 171. ird.) «SEP/VLTVRE DE / E SABADEINE / DE BIDEGA/IN DAME+ / DE ITVRCHO/CO 1675»; Landaux (Totorikagoena, 2013, 23. ird.) «SE(ULTU) PRE DE / MARTIN / DE BASTE/RECHE SE (sieur) DE LANDA/ UX 1669».

Kanbo: Ithurealdia (Totorikagoena, 2013, 19. ird.) «+sep(vltv)RE DE / DOMINGO / DE CELHAT / E TIVLANT/O DE ETCHE/GOIEN SE/UR ET DA/ME DE ITHU/REALDIA / 1692»; Ithurrat (Colas, 1923, 132. ird.) «REPE (requiescat in pace) / SEP DE I/OVLIAN/TO DAM/E DAME / DITHUR/RAT / 1659»; Phagaldegaraia (Colas, 1923, 133. ird.) «SEPVLTURE / DE IA(cob)ES DE / MARTEINE/T DOMINH DE O/ RDOIZCOITI SI/EVR ETA DAME DE PHAGALDEGARAIA».

Larresoro: Escanda (Colas, 1923, 74. ird.) «SEP( )LTVRE / DE DOMINGO / DE TO( ) CVERRI / ET GRACIANE / TEILLARIE / CONNIOINS/( )R ET ME DE ( )A MAISON / ESCANDA 1786»; Hareche (Colas, 1923, 73. ird.) «BERNAT / SIEVR DE / HARECHE / FEVRIER 1638»; Morocvrenia eta Saintperenia (Colas, 1923, 78. ird.) «IHS MA SEP(vltu)RE DE POVR SIEUR- PIERRE- DE SAINT PE- M(aîtr) E CHIRVGIEN- ET GRACIANE DE SORHAINDE- CO/NIOINTS- SIEVR / ET DAME DE LA / MAISON- DE M/OROCVRENIA / AVTREMENTE S(ai)/NTPERENIA 1714».

Urkodoi: Fagalde (Colas, 1923, 1241. ird.) «SEP(ULT)RE DE / DOMINC/H- DAME / D FAGA/LDE / 1653».

- Ternua

Placentia (O’Reilly House Museum): Ussanoneneco (Egaña, 2018, 183. or.) «GANNIS / DE SALE/CE (m? )ARIA / USSANO / NENECO / SEMEA».

\subsection{Etxe izenen zerrenda herrialdeka antolaturik}

\subsubsection{Lapurdi}

Ahetze: Harretchecoa.

Ainhoa: Benytene, Chaparreria, Esponda, Gascoinarenia, Gorritia, Haricelet-Lafaiect, Murua, Quiquerenborda.

Arbona: Martiquet.

Arrangoitze: Cabalcigarai.

Azkaine: Ascain Errota, Cethabereneco, Haranibar, Harispea Indiano Iaunarena, Larochoreneqvo, Migeleneco, Mvr()Gvia.

Bidarte: Garaicoetchea D Ardagaray, Bvtvreneco, Lafargva.

Ezpeleta: Aguerreco, Apestegvi, Aphestegvy, Bidartenia, Domingo Peneco, Etchegaraya, Gastambide, Gvelariarena.

Gixune: Menia.

Haltsu: Celhay, Etcheberria, Migeletchegaico, Ithurrat, Larreburua, Phagaldegaraia, Vrcudoy.

Itsasu: Harotzarena, Itvrchoco, Landaux, Larrondo.

Kanbo: Alainenia, Bassusena, Curuchet, Elicabidea, Ithurealdia.

Larresoro: Escanda, Hareche, Hirigoyena, Lariscoa. Morocurenia, Saintperenia.

Lehuntze: Achelecov.

Makea: Currut, Nimaco.

Mugerre: Chouorrenea, Marichinia, Serorateguy.

$50 \quad$ Cuadernos de Etnología y Etnografía de Navarra (CEEN), 94, 2020, 9-62

ISSN: 0590-1871 ISSN-e: 2530-5840 ISSN-L: 0590-1871 
Sara: Arriaga, Arrosagarai, Arrosagaraico, Axular, Baratcharte Cvelbehere, Cubieta, Haranbovre, Harriagaco, Harozarena, Lehenburu, Mendiondo, Moscorrondo, Teileria.

Senpere: Alaben, Camiet, Chenperene-Etcheberria, Çugarret, Etchechuria, Gastambidea, Iranaçabalarenea, Isabeleneco, Lasauco, Mariatoinea, Mariatorena, Miricuenea, Mondvtegvy, Moniuscorenecoa.

Urkodoi (Azparren): Bonalde, Fagalde.

Urruña: Etchechahar, Mourguicoa, Socuen Bordacua.

Ziburu: Gasteluzar.

7.3.2. Nafarroa Beherea

Ahatsa: Elissagaray.

Aiherra: Harguinchumia.

Aintzila: Ibarretche.

Altzumarta: Apostegvy, Labin.

Amenduze: Acciriet, Seroracova.

Amorotze: Berhovet, Beroft, Hvlondo.

Arboti: Donna Marie, Echeto.

Armendaritze: Elliczagarai, Mendiby.

Arrosa: Etcheberri, Orhet.

Azkarate: Maziariena.

Baigorri: Amoctogvi, Corcavalbehere.

Banka: Etchechotoco, Gastigarreco, Itceineco, Oxxaart, Suiarinchahar.

Bastida: Lafourcade.

Behauze: Bitarrvi.

Behorlegi: Uhalde.

Bidarrai: Betiriscoena, Cubibvrv, Petrisco, Pierreseneco.

Bithiriña: ()Ellaigvibel, Etchebey, Obilve.

Bizkai: Mendibure, Mendiburv, Osbacv (Oxapacvi?), Viscaieche.

Burgue-Erreiti: Aphate, Petricha.

Donaixti: Bihvrri.

Donapaleu: Saint Payine.

Donibane Garazi: Leonenia, Lomitegvy, Londresena, Marensenia.

Eiheralarre: Etcahrt.

Erango: Oxapacvi.

Gamoue-Zohazti: Illardo.

Gamue: Voriena Borda.

Garruze: Ginhart, Iriartevi, Merchot.

Heleta: Garat.

Ibarrola: Echepare, Palacio De Vhalde.

Iholdi: Echegoihen, Oyhanarteco.

Irisarri: Andorteico, Irigoinberri, Larralde.

Irulegi: Mazia.

Izpura: Çubialde.

Izura-Azme: Mosnias?.

Jutsi: Bassart, Larramendy, Necueletcheberri. 
Landibarre (Behaune): Vhalde.

Landibarre (Saint Etienne): (Ar)Cubiqvo Haramburv, Haranbvrv, Inchoussarri, Soccaro.

Landibarre (Saint Martin): Lapitz, Garateco.

Lasa: Meriateguy.

Lekunberri: Lacabaraseo, Teillagorri, Teillagorria.

Martxueta: Giscaie, Movthilleneco.

Mehaine: Olloqvi, Ouilicateguico, Uhalde.

Ortzaize: Apalas, Apalasia, Gillantena.

Ostankoa: Ecaidu.

Ozaze: Copen.

Sarrikota: Elischabere, Samacoa, Samacois, Samacoits, Samacoits.

Urepele: Landarteko.

Ustaritze: Aguerreco, Nagila.

Zibitze: Bidart, Merkabidea.

Zohazti: Echart.

Zuraide: Errecarte.

\subsubsection{Zuberoa}

Ainharbe: Ber(N)Adeco Petharan, Bernadeco Petarhan, Habiagve, Vhaltx.

Berroeta: Haran.

Eskiula: Chabalgoiti.

Larrori: Dana Iesaro.

Lexantzü: Domec.

Mendibile: Mendebiv.

Mitikile: Dana.

Urdiñarbe: Abetzia.

Ürrüstoi: Oihenart, Svnhari.

\subsubsection{Nafarroa Garaia}

Abaurregaina: Casa Remondegui, Elizalde.

Amaiur: Arozarena, Echebercea.

Anotz (Ezkabarte): Beltranena, Beroquia.

Arizkun: Anchorena, Bydegañea, Joanhetar(En)A, Mariber(Z)Enea, Palacio De Vrsva, Pordoñenea, Sastrearena, Ynda, Yndatea, Yreberria, Zabalarena.

Arantza: Beltranenea.

Arraitza (Zabaltza): Ipasate.

Arrieta: Ezkerra.

Arruitz: Juansarenea

Azpilkueta: Iribarrenea Borda, Lapitzea.

Bera: Apezabayta, Apeztegvia, Arrigaraia, Elizaldeberriya Gastienea, Maienia, Vrtzallenea, Vidaburua, Yrazoquiverria, Yrisarri.

Biotzari: Juliana.

Burlata: Benitorena.

Donamaria: Ochoarena, Suriotena.

Doneztebe: Amasarena Ramonea, Bastallenea.

52 Cuadernos de Etnología y Etnografía de Navarra (CEEN), 94, 2020, 9-62

ISSN: 0590-1871 ISSN-e: 2530-5840 ISSN-L: 0590-1871 
Eguaras: Garacoechea.

Elortz: $\operatorname{Erl}(A)$ Rena.

Eltzaburu: Martiñena, Michelcorena.

Eraso: Maticonea.

Eratsun: Juangonea, Jvangonea.

Erratzu: Borda, Echeniqverena.

Etxalar: Apezegia, Aranchipia, Armiis, Arrehea, Barberenia, Berruta, Betrisancena, Bidazerdia, Borda De Maritorena, Cacalana, Castenea, Catalinsansinena, Danvoriena Borda, Domecuenia, Don Paula, Echeberia, Elizaldega, Errandonia, Errotagaraya, Ezcurreverea, Guanehegaraiia, Inaria, Isastia, Jalanena, La Borda De Arechea, Larrasayes, Maestrunea, Marichinia, Marimiguelena, Marisquerena, Marticonea, Martintonia, Mugerdia, Olagaraya?, Peruena, Peruenea, Sanjuanena, Slaberia, Tolaria, Tomasena, Sansinena, Vparreagerrea, Urrutia, Ycsebino.

Garralda: Bizcai.

Gazolatz: Larracea.

Gerendiain (Ultzama): Ormechea.

Hiriberri (Aezkoa): Alcaizarena, Mariato.

Iheltz (Lizoain-Arriasgoiti): Miguelena.

Ilurdotz: Malezena.

Iribas: Juanane $(A)$.

Ituren: Alberrobarrenechea, Alberrobarren Echea, Juanesenea, Miguelena, Recaldea. Jaurrieta: Ayarra O (J)Andua.

Labaien: Don Fernandonea.

Larrasoaña: Conderena.

Legasa: Oteizenea.

Leitza: Peryza, Totachenea.

Lekaroz: Gortaria.

Lesaka: Yrulecu.

Lintzoain: Khasarana, Martinotena.

Luzaide: Doraya, Hunaiyaingo, Vichcaya, Yribarneco.

Narbarte: Domingonea.

Orkoien: Leonena.

Urdazubi: Confitervarena, Yndianoa Baita, Yturraldea.

Urroz (Doneztebe): Mutuverria.

Usi: Azpycoechea.

Zia: Loperena.

Ziga: Aguerrea, Alcaten, Aldecoa, Arguinaga, Arozarena, Arozteguia, Arraztorena, Arrchea, Arrun/Chea, Barazondoa, Berecoechea, Caracoechea, Delizaldea, Dendariena, Echandia, Echeberria, Echeniquea, Echeverria, Etxezuria, Gaananea, Gamioa, Goanarena, Goienechea, Ireverria, Irigoien, Iturr(Ia), Larraldeandea, Legarrea, Lerabidea, Maiora, Marinea, Mayora, Palacio De Egozcue, Serorena, Soraburua, Suteguia, Yndartea, Yndaverea, Yturraldea.

Zildotz: Miguelicorena.

Zubieta: Irigoien.

Zugarramurdi: Catalenea. 


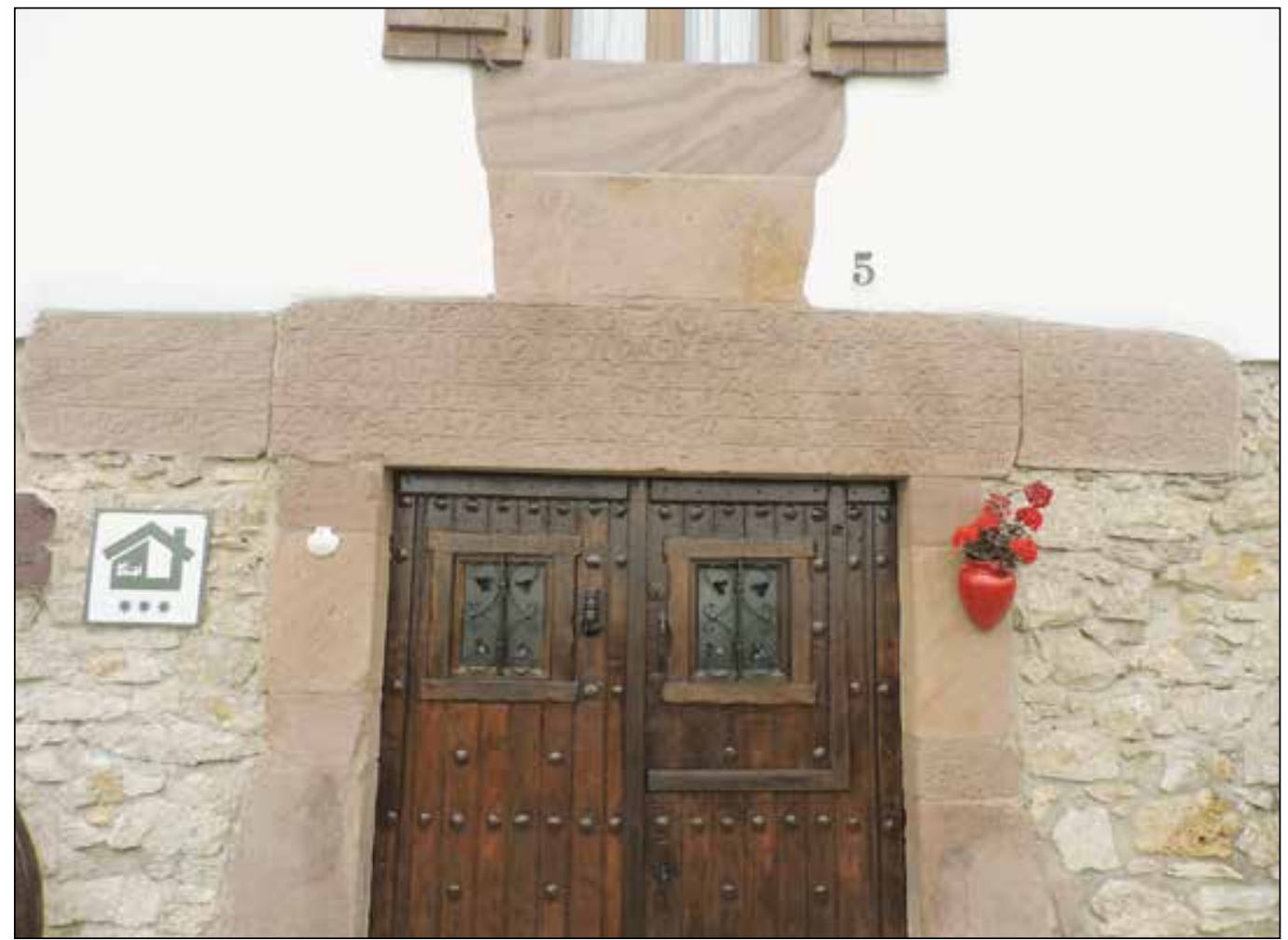

7. irudia. Zigako Ostatuaren atalburua, 1741.

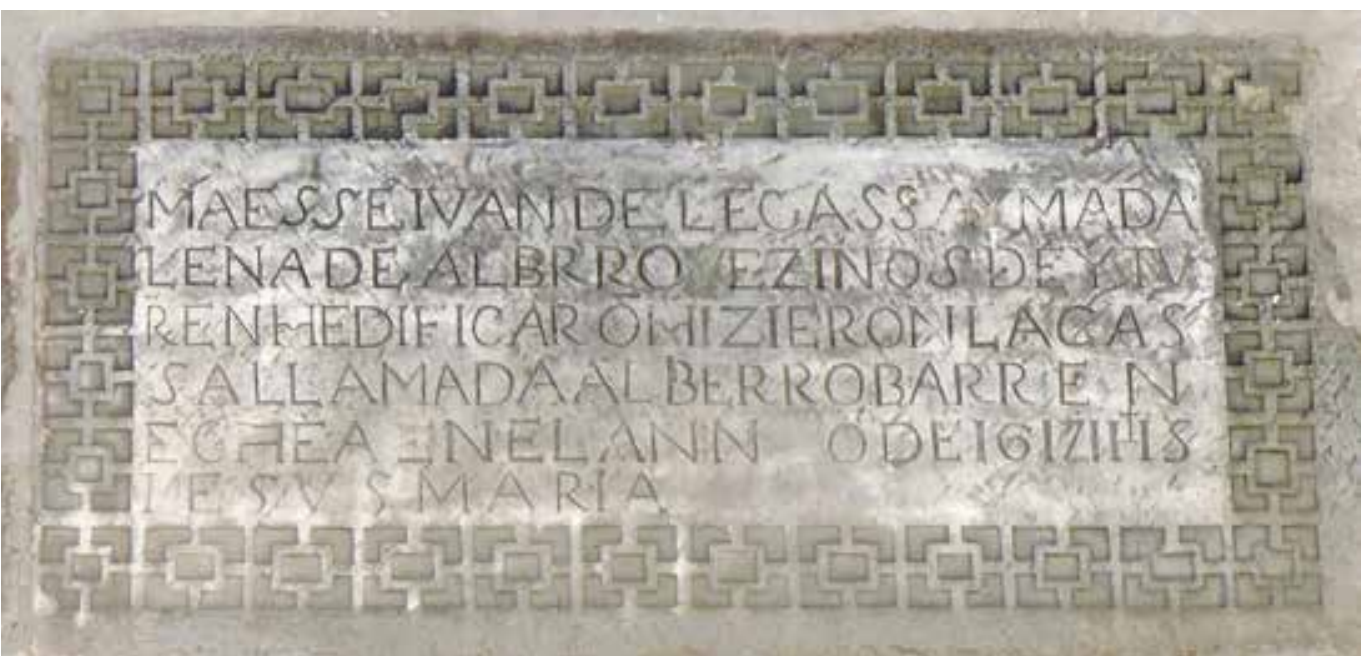

8. irudia. Iturengo Alberrobarrenechea, 1612. 


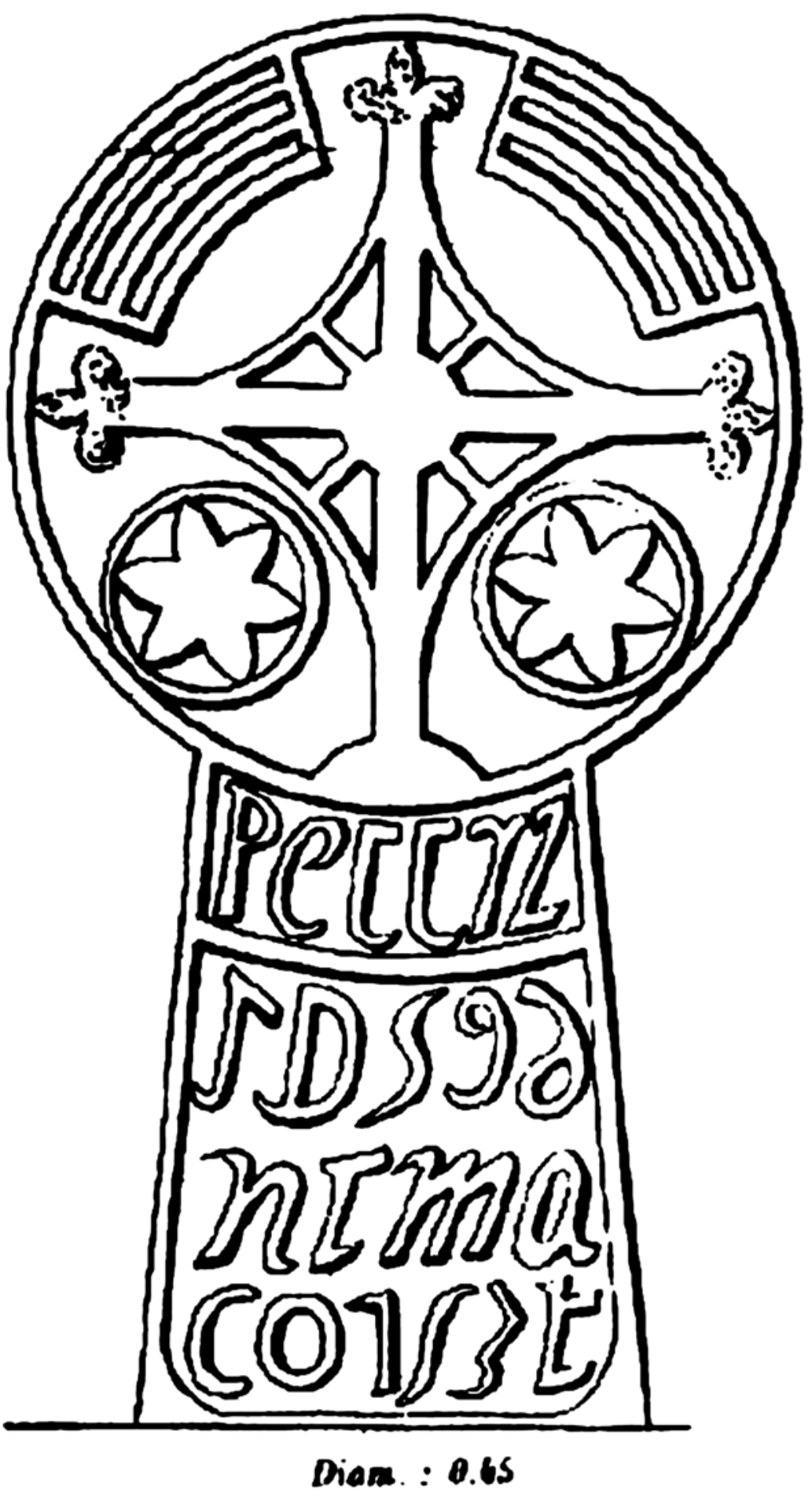

9. irudia. Nimaco etxea 1537, Makean (Colas, 1923, 258. ird.). 


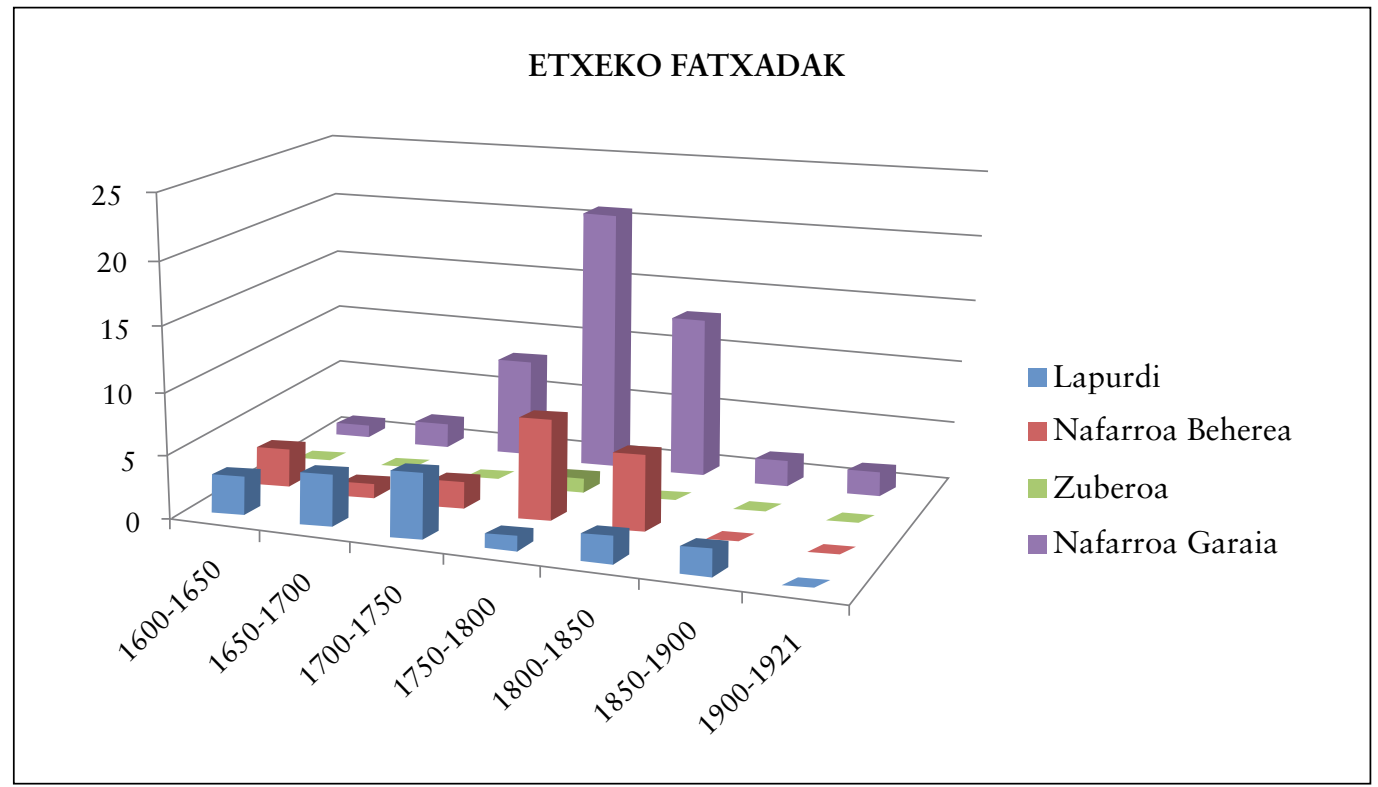

3. grafikoa. Etxe izen zizelkatuen presentzia etxeko fatxadetan.

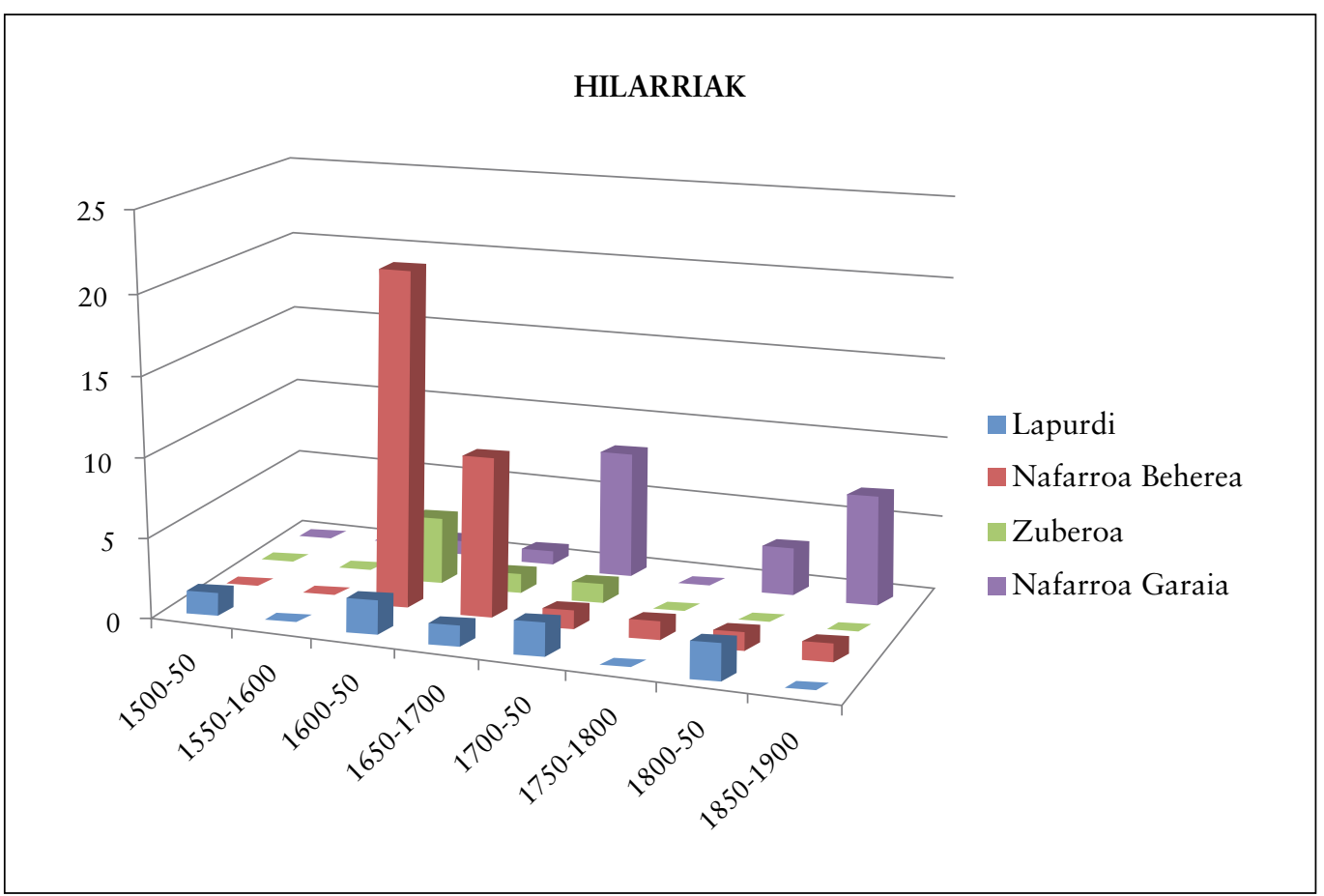

4. grafikoa. Etxe izenen presentzia hilarrietan (diskodunak zein gurutzeak). 


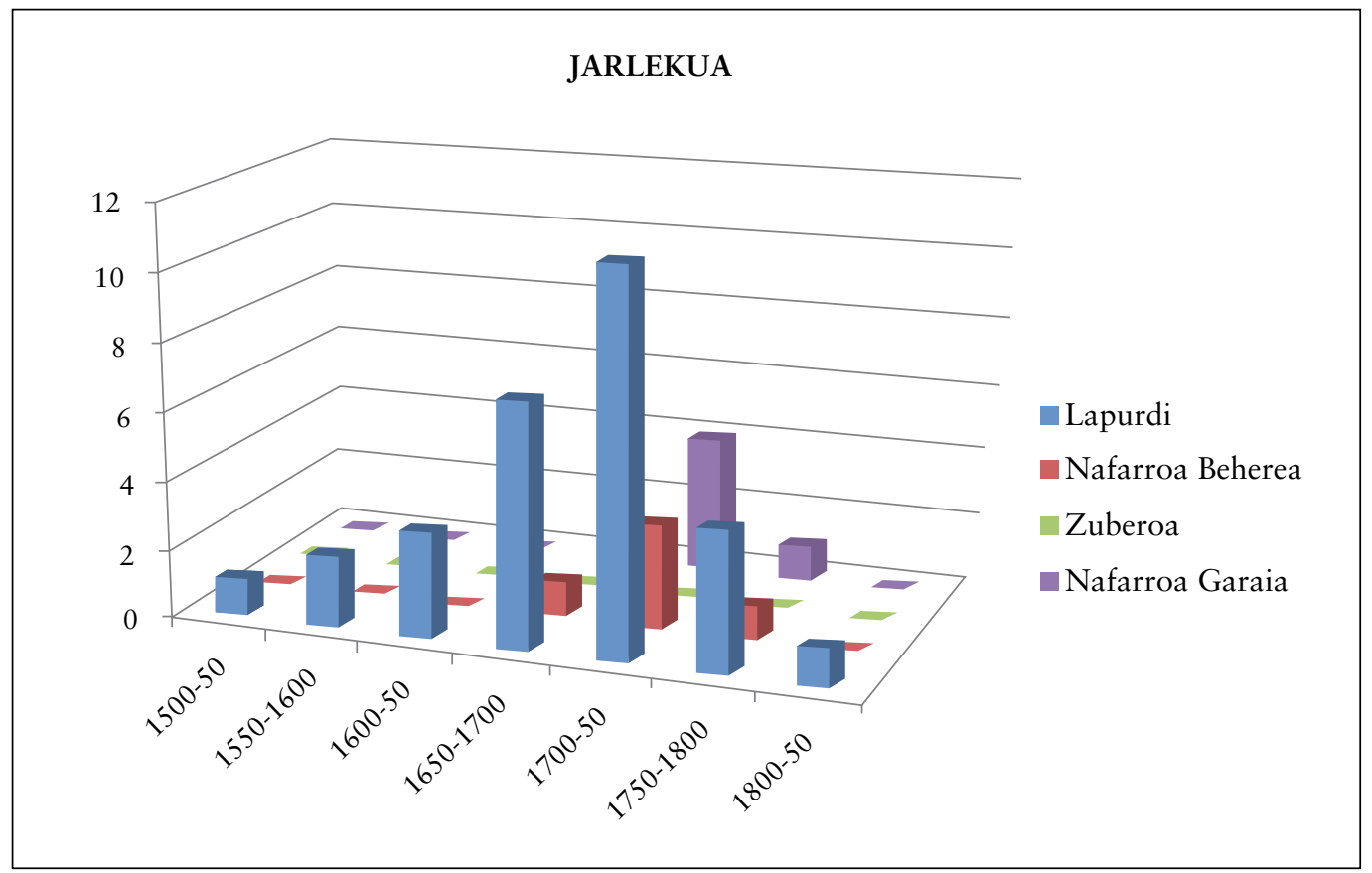

5. grafikoa. Etxe izenen presentzia jarlekuetan.

\section{ERREFERENTZIAK}

Adot Lerga, A. (2014). El Consejo y Chancilleria Real de Navarra (Baja Navarra) y el euskera (1523-1624). En J. aMadariaga Orbea \& A. Adot, El euskera en las altas instituciones de gobierno a través de la Historia. Euskara gobernuko goi erakundeetan Historian zehar. Iruña: Pamiela.

Aguirre Sorondo, A. (2004). Señalización de tumbas y estelas discoidales. En Actas del VII Congreso Internacional de Estelas Funerarias, Santander, 24-26 de octubre de 2002, (III, 861-879. or.) Fundación Marcelino Botín.

Aguirre Sorondo, A. (2013). Capilla de Nuestra Señora de Sokorri, Boletín Informativo de Estelas Discoideas, 28, 7-10.

Annuaire officiel des abones au telephone.(1988). Pyrennees-Atlantiques.

Antonelli, Q. (2006). W.A. B. L. Epigrafía popolare alpina (Quaderni del Parco, 6). Tonadico: Ente Parco Paneveggio San Martino.

Aldaba Domínguez, J. (2014). Genealogía de las casas de Izcue/Izkue, Antzina, 17, 78-117. Apezetxea Zubiri, P. (2016). Etxalarko hilarriak. Joandakoen oroigarriak, Ttipi-Ttapa. Apezetxea Zubiri, P. \& Salaberri Zaritiegi, P. (2009). Etxalarko etxeen izenak. Etxalar: Etxalarko udala.

Arantzako Euskara Batzordea. (2016). Arantzako telefono gida. https://sedeelectronica. arantza.eus/wp-content/uploads/2019/01/TELEFONO-GIDA-2016-compressed.pdf helbidetik eskuratua.

Arbizu Gabirondo, N. (1996). Estudio epigráfico de Iturmendi. Cuadernos de Etnologia y Etnografía de Navarra, 68, 253-266. 
Asín Semberoiz, F. J. (1995). Navascués en el siglo XX: (apuntes para un historia local). Pamplona: autor.

Barandiaran, J. M. (1926). Pueblo de Aurizperri (Espinal). Los establecimientos humanos y las condiciones naturales. Anuario de Eusko Folklore. (Berrarg.: Obras Completas. III. liburukia, Bilbao, 1973, 255-272. or.).

Barandiaran, J. M. (1980). Euskaldunak: La etnia vasca (3). Bilbo: Etor.

Barandiaran, J. M. (2000). Bosquejo etnográfico de Sara. Ataun: Jose Miguel de Barandiarán Fundazioa.

Barandiaran, J. M. \& Manterola, A. (2011). Casa y familia. Derio: Labayru Fundazioa.

Belasko, M. (2016a). Toponimia de Sigués. Sigüés: Ayuntamiento de Sigüés.

Belasko, M (2016b). Oiconimia y mapa de Sigüés. Sigüés: Ayuntamiento de Sigüés.

Belasko, M. (2017). Los nombres de las casas en Navarra se mantienen más en la zona vascófona. helbidetik eskuratua. https://www.unav.edu/web/catedra-de-lengua-cultura-vasca/noticias/detalle-noticia/2017/05/26/los-nombres-de-las-casas-en-navarra-se-mantienen-mas-en-la-zona-vascofona/-/ asset_publisher/pXsp2NHohyjO/content/2017-05-26-noticia-fyl-nombres-casas-navarra/10174

Belasko, M. \& Colomo, K. (koord.). (2014). Casas de Valdizarbe y Valdemañeru: nombres e historia. Izarbeibarra eta Mañeruibarra: etxe izenak. PamplonaIruñea: Asociación Loxa \& Gobierno de Navarra.

Bidart, P. (1997). El estilo neo-vasco como objeto de estudio antropológico. In $A u$ ñamendi Eusko Entziklopedia. http://aunamendi.euskoikaskuntza.eus/eu/ arquitectura-neo-vasca/ar-1138/ helbidetik eskuratua.

Braga, I. et al. (2014). Ultzama ibarreko ondasun historiko, kulturala eta naturala babesteko araubidea eta katalogoa. Ultzamako Udala. http://siun.navarra. es/Instrumento.aspx?tab=doc\&id=15646 helbidetik eskuratua.

Buces Cabello, J. (2011). Orbaizetako etxeak; la historia de Orbaizeta a través de sus casas. Orbaizetako Udala \& Aranzadi Sociedad de Ciencias.

Caro Baroja, J. (1949). Los vascos. Donostia: Sociedad de Amigos del País. Berrarg. 2000 , Istmo.

Caro Baroja, J. (1972). Etnografía histórica de Navarra (3 liburu). Iruña: Caja de Ahorros de Navarra.

Caro Baroja, J. (1974). De la vida rural vasca (Estudios Vascos, IV). Donostia: Txertoa. Caro Baroja, J. (1982). La casa en Navarra (4 lib.). Iruña: Caja de Ahorros de Navarra.

Carrasco Pérez, J. (1973). La población de Navarra en el siglo XIV. Pamplona: Universidad de Navarra. https://doi.org/10.1086/ahr/80.2.388

Castellote Herrero, E. \& Fernández López, M. C. (2017). Corpus de escrituras expuestas y su interés para la historia del español: exvotos pintados de la provincia de Guadalajara. Scriptum digital: revista de corpus diacrònics i edició digital en llengües iberoromàniques, 6, 127-154.

Colas, L. (1923). La tombe basque, recuil d'inscriptions funéraires et domestiques $d u$ Pays Basque français. Bayonne: Folzer.

Colomo, K. (2014). Etxe izenak. Izarbe eta Mañeru ibarretako ondasun ez materiala. https://www.academia.edu/25415481/Garesko_etxe_izenak helbidetik eskuratua. 
Colomo, K. (2020a). Mañeruibarko euskara etxe izenen eta izengoitien bidez. https:// www.academia.edu/43183429/Ma\%C3\%B1eruibarko_euskara_etxe_izenen_eta_izengoitien_bidez helbidetik eskuratua.

Colomo, K. (2020b). Zer kontatzen dute Aezkoako etxeek? Epigrafia eta dekorazio tradizionala Aezkoako etxeetako atalburuetan (XVI-XIX mendeak). In Actas HilarriCon, Jornada sobre estelas discoideas (Abaurrea Alta / Abaurregaina, 22 al 24 de junio del 2018) (54-112. or.). Abaurregaina: Museo de Estelas de Abaurrea Alta-Abaurregainako Hilarriak.

Cruchaga y Purroy, J. (1970). Un estudio etnográfico de Romanzado y Urraul Bajo. Cuadernos de Etnología y Etnografía de Navarra, 5, 143-265.

Dibon, P. (2011). Bardozeko etxe-izen berriak, GHF.

Doike Eskuara Taldea. (2005). Baztango etxeen telefono gida. http://www.erabili.eus/ zer_berri/berriak/dokumentuak/2005/BaztangoTelefonoGida.pdf helbidetik eskuratua.

Duvert, M. (1981). Etude d'un groupe de stèles discoïdales du XVIIème siècle en Amikuze (Basse-Navarre). Cuadernos de Etnología y Etnografía de Navarra, 37, 183-212.

Duvert, M. (1985). Contribution à l'étude des stèles discoïdales basques dans la Navarre d'Ultra-Puertos. Cuadernos de Etnología y Etnografía de Navarra, 46, 145-200.

Duvert, M. (2006). Monuments funéraires (stèles tabulaires) en Pays basque nord: lieux et modes de création. In Actas do VIII Congreso Internacional de Estelas Funerárias. Museu Nacional de Arqueologia 16, 17, 18 de Maio de 2005 (O Arqueólogo Portugués, suplemento 3) (157-178. or.). Lisboa: Museu Nacional de Arqueologia.

Duvert, M. \& Etchandy, K. (2017). Euskal atalburuak. Les linteaux basques (Ondarea, 14). Baiona: Elkar.

Echegaray Corta, B. (1925). Significación jurídica de algunos ritos funerarios del País Vasco. Revista Internacional de Estudios Vascos, 16(1), 94-118.

Egaña Goya, M. (2018). A Permanent Place in Newfoundland: Seventeenth-Century Basque Tombstones in Placentia. Newfoundland and Labrador Studies, $33,1$.

Eleizalde, L. (1923). Lista alfabéticas de voces toponomásticas vascas, Revista Internacional de los Estudios Vascos, 24,2, 283-303.

Elosegi, X. (2005). Sara, etxeak eta deiturak lau mendez (XVI-XIX), 31, Lankidetzan bilduma.

Esparza, E. J. (1964). De toponimia navarra, Principe de Viana, 94-95, 67-126.

Esparza, E. J. (1965). De toponimia navarra, Principe de Viana, 98-99, 161-227.

Etxegarai Korta, B. (1926). Euskal Erriko etxên izenak, Euskera, 7 (3-4), 84-123.

Frankowski, E. (1920). Estelas discoideas de la península ibérica. Madrid: Museo Nacional de Ciencias Naturales.

García Gainza, M. C. (1989). Catálogo monumental de Navarra. Pamplona: Gobierno de Navarra.

Garciandía, J. A. (2013). Casas de Leitza en 1796, Antzina, 15, 77-103.

Hernandorena, V. (1978). Goizueta'ko etxe eta baserri'en izenak: 1616 urtetik - 1925'ño, Cuadernos de Etnología y Etnografia de Navarra, 10, 75-90. 
Hurmic, L. (2003). Maisons de Saint-Jean-Pied-de-Port: Linteaux et pierres sculptées des façades. Les Amis de la Vieille Navarre.

Ibáñez, N. T. (2017). Etxakunzes de Abaurregaina. Turismo Abaurrea, 2017/05/27. https://www.turismoabaurrea.com/2017/05/etxakunzes-de-abaurregaina. html helbidetik eskuratua.

Ibáñez San Millán, N. T. (2020). Estelas discoidales del valle de Aezkoa. In Actas HilarriCon, Jornada sobre estelas discoideas (Abaurrea Alta / Abaurregaina, 22 al 24 de junio del 2018) (113-188. or.). Abaurregaina: Museo de Estelas de Abaurrea Alta-Abaurregainako Hilarriak.

Ibarra Murillo, O. (2002). Erroibarko eta Esteribarko oikonimoak. Fontes Linguae Vasconum: Studia et documenta, 91, 493-516.

Ibarra Murillo, O. (2003). Erroibarko eta Esteribarko oikonimoak II. Fontes linguae vasconum: Studia et documenta, 92, 129-164.

Icíar, J. (2002). Arte sutilísima por la cual se enseña a escribir perferctamente. Hecho experimentado y ahora de Nuevo añadido por Juan de Icíar Vizcaino (facsimile-edizioa). [Valladolid]: Junta de Castilla y León \& Ayuntamiento de Valladolid.

Imotz eta Basaburuko Udaletako Euskara Zerbitzua. (1997). Basaburua Imotz. Telefono gida-1997. Imotz eta Basaburuko Udalak.

Iñigo Ariztegi, A. (1996). Toponomástica histórica del valle de Santesteban de Lerín. Pamplona: Gobierno de Navarra.

Iñigo Ariztegi, A. (2000). Nombres de oficios en la oiconomia navarra, Fontes Linguae Vasconum: Studia et documenta, 83, 139-149.

Iñigo Ariztegi, A. (2005). Nombres propios de persona en la oiconimia navarra. In J. L. Rodríguez Sádaba, La Onomástica en Navarra y su relación con la de España: actas de las primeras Jornadas de Onomástica (Pamplona, 2003) (201-218. or). Iruña: UPNA.

Iñigo Arzitegi, A. (2008). Izengoitiak Nafarroako oikonimia historikoan. In Jean Haritschelhari omenaldia (Iker, 21) (281-307. or). Bilbo: Euskaltzaindia.

Iñigo, A. \& Rekalde, P. (2018). Euskal oikonimia Baztan-Bidasoa eremuko lekukotasun historikoen argitan. In A. Zabalza Seguín, De Engracia a Garazi. El misterio de los nombres en Navarra / Engraxitik Garazira. Izenen misterioa Nafarroan. Iruña: Aranzadi.

Irigaray Gil, J. (2019). Recuperación del uso de la estela discoidal en Auritz-Burguete, Cuadernos de Etnología y Etnografía de Navarra, 93, 255-275. https://doi.org/10.35462/ceen.93.7

Itulain Irurita, J. (2002). Los nombres de las casas en el valle de Izagaondoa (16002001), Cuadernos de Etnología y Etnografía de Navarra, 77, 49-126.

Itulain Irurita, J. (2005). Oiconimia del valle de Unciti, Cuadernos de Etnología y Etnografía de Navarra, 80, 85-178.

Itulain Irurita, J. (2019). Las casas de Izagaondoa-Izagaondoako etxeak. [Iruña]: Asociación Grupo Valle de Izagaondoa.

Jimeno Jurío, J. M. (1986). Toponimia de la Cuenca de Pamplona. Cendea de Cizur. Bilbao: Euskaltzaindia.

Jimeno Jurío, J. M. (1987). Toponimia de la Cuenca de Pamplona. Cendea de Galar. Bilbao: Euskaltzaindia. 
Jimeno Jurío, J. M. (1989). Toponimia de la Cuenca de Pamplona. Cendea de Olza. Bilbao: Euskaltzaindia.

Jimeno Jurío, J. M. (1990). Toponimia de la Cuenca de Pamplona. Cendea de Iza. Bilbao: Euskaltzaindia.

Jimeno Jurío, J. M. (1991). Estudio toponímico de Burlada, Burlata: Burlatako Udala.

Lancre, P. (2004). Tratado de brujería vasca. Tafalla: Txalaparta.

Lauburu. (2004). Les stèles discoidales et l'art funéraire, hil harriak. Baiona: Lauburu/ Elkarlanean.

Leizaola, F. (1985). Toponimia del valle de Atez. In Aingeru Irigarayri omenaldia. Donostia: Eusko Ikaskuntza.

Lopez-Mugartza Iriarte, J. K. (2008). Erronkaribarko oikonimia, mitoak eta elezaharra. In X. Artiagoitia \& J. A. Lakarra, Gramatica jaietan. Patxi Goenagaren omenez (523-543). Bilbo: UPV/EHU.

Lopez Mugartza J. K (koord.) (2018a). Erronkaribarko etxeak. Las casas del Valle de Roncal, Pamplona: Servicio de Euskera del Valle de Roncal.

Lopez-Mugartza Iriarte, J. K. Iribarren Larrea, M. T. \& Larrea Irigoien; C. (2019). Artzibarlo etxeak. Las casas del Valle de Arce. Artzibarko Udala.

Lopez Mugartza J. K. \& Zabaltza Garate, I. (koord.). (2018). Aezkoako etxeen izenak, Pamplona-Iruñea: Aezkoako batzarre Nagusia-Junta General de Aezkoa.

López Selles, A., Saralegui, C. \& Cruchaga y Purroy, J. (1983). Piedras familiares y piedras de tumbas de Navarra. Cuadernos de Etnología y Etnografía de Navarra, 41-42, 223-357.

Madariaga Orbea, J. (2004). Espacio doméstico y espacio sepultural en Euskal Herria, pesiglos XVI al XVIII. In J. M. Imizcoz, Casa, familia y sociedad (429487. or.). Bilbo: UPV/EHU.

Maiora Mendia, F. (2013). Valdorba. Nombres de casas. Artaxoa.

Maiora Mendia, F. (2014). Valdizarbe. Nombres de casas. Artaxoa.

Monteano, P. J. (2017). El iceberg navarro. Euskera y castellano en la Navarra del siglo $X V I$. Iruña: Pamiela.

Moutché, G. (2010). Que disent les maisons basques? Biarritz: Atlantica.

O'Shea, H. (1887). La maison basque. Pau: Léon Ribaut. (Berrarg. 2009, Pyremonde).

Orpustan, J.-B. (2000). Les noms des maisons médiévales en Labourd, Basse-Navarre et Soule. Saint-Etienne-de-Baigorry. Izpegi.

Otero, X. et al. (2007). Jose Rota, Aezkoa. Arraiotz: Txoria errekan.

Peña Santiago, L. (1999). Arte popular vasco. Donostia: Txertoa.

Pérez de Villarreal, V. (1986). Estelas discoideas del valle de Baztán. Cuadernos de Etnología y Etnografía de Navarra, 48, 309-364.

Perurena Loiarte, P., Salaberri Zaratiegi, P. \& Zubiri Lujanbio, J. J. (2011). Goizuetako etxeen izenak. Pamplona-Iruñea: Pamiela.

Petrucci, A. (2013a). La escritura ideología y representación, Buenos Aires: Ampersand.

Petrucci, A. (2013b). Escrituras últimas. Ideología de la muerte y estrategias de lo escrito en el mundo occidental. Buenos Aires: Ampersand.

Sagüés Goñi, X. (2012). Genealogía de las casas de Beorburu, Antzina, 13, 65-75.

Sagüés Goñi, X. \& Martínez, M. (2013). Genealogía de las casas de Lizaso, Antzina, $16,73-87$. 
Sagüés Goñi, X. (2015). Casas de Gorronz-Olano, Antzina, 20, 106-117.

Sagüés Goñi, X. (2016a). Casas de Eltzaburu, Antzina, 21, 88-102.

Sagüés Goñi, X. (2016b). Genealogía de las casas de Auza, Antzina, 22, 88-108.

Sagüés Goñi, X. (2017). Zenotz, Antzina, 24, 100-108.

Sagüés Goñi, X. (2018b). Iraizotz, Antzina, 25, 94-136.

Sagüés Goñi, X. (2018a). Casas Eltso, Antzina, 26, 96-112.

Sagüés Goñi, X. (2019). Urritzola-Galain, Antzina, 27, 83-105.

Sagüés Goñi, X. (2020). Casas de Larraintzar, Antzina, 29, 90-130.

Salaberri Zaritiegi, P. (1995). Nafarroako zenbait izengoitiren inguruan, Fontes Linguae Vasconum: Studia et documenta, 67, 451-466.

Salaberri Zaritiegi, P. (2006). Nafarroako euskal oikonimoz, Anuario del Seminario de filología vasca Julio Urquijo, 40, 1-2, 871-874.

Salaberri Zaritiegi, P. \& Zubiri Lujanbio, J. J. (2009). Euskal deituren jatorria eta etxe izengoitiak. Anuario del Seminario de Filología Vasca Julio de Urquijo, 43, $1-2$.

San Telmo Museoa. (1991). Hilarrien katalogoa. Catálogo de estelas. Donostia: Kultur Udal Patronatua.

Satrustegi, J. M. (1965-1966). Las casas de Valcarlos, Anuario de Eusko Folklore, 21, $13-34$.

Totorikagoena, A. (2013). Euskal grafia erabilgarria 144 irudiekin, Eskuz.

Ursua Irigoyen, I. (2001). Guesálaz, pueblo a pueblo. Estella: Graficas Iratxe.

Urtasun Villanueva, B. (1971) Toponimia de Oroz-Betelu, Fontes Lingua Vasconum: Studia et documenta, 9, 333-347.

Xamar, J. C. Etxegoien. (2016): Etxea. Ondarea, historia, mintzoa. Iruña: Pamiela.

Zabalza Seguín, A. (2010). La herencia duradera: los apellidos en la Navarra moderna. In G. Salinero \& I. Testón Núñez, Un juego de engaños. Movilidad, nombres y apellidos en los siglos XV a XVIII. Madrid: Casa de Velázquez.

Zarrabeitia Miñaur, P. (2011). Estelas discoidales de Euskal Herria. Iruña: Pamiela.

Zuazo, K. (2005). Euskara batua. Ezina ekinez egina. Elkar.

\section{Legegintza}

- 571/1963 Dekretua, martxoaren 14koa, armarriak, ikurrak, harri heraldikoak, justizia-erroiluak, mugape-gurutzeak eta interes historiko-artistikoko antzeko piezak babesteari buruzkoa. (BOE, 1963/03/30).

- 14/2005 Foru Legea, azaroaren 22koa, Nafarroako kultur ondareari buruzkoa.

\section{Nafarroako Errege Artxibo Nagusia}

Deierri: 1678ko apeoa RE_ESTADISTICA, leg. 14, n. ${ }^{\circ}$ 33; 1726ko apeoa RE_ESTADISTICA, leg. 15, n. $^{\circ} 30$.

Gesalatz: 1668ko apeoa RE_ESTADISTICA, leg. 14, n. ${ }^{\circ} 24 ; 1726 \mathrm{ko}$ apeoa RE_ESTADISTICA, leg. 15, n. $^{\circ} 22$.

Erromantzatua: $1677 \mathrm{ko}$ apeoa RE_ESTADISTICA, leg. 23, n. ${ }^{\circ} 22 ; 1727 \mathrm{ko}$ apeoa RE_ ESTADISTICA, leg. 24, n. 29. 